\author{
Universidade de São Paulo \\ Escola de Engenharia de São Carlos \\ Departamento de Engenharia Elétrica
}

THALES EUGENIO PORTES DE ALMEIDA

Sistema de sensoriamento de orientação para um veículo aquático de superfície utilizando sensores de baixo custo 

THALES EUGENIO PORTES DE ALMEIDA

\section{Sistema de sensoriamento de orientação para um veículo aquático de superfície utilizando sensores de baixo custo}

Dissertação de Mestrado apresentada a Escola de Engenharia de São Carlos como parte dos requisitos para obtenção do Título de Mestre em Ciências, Programa de Engenharia Elétrica.

Área de Concentração: Sistemas Dinâmicos.

Orientador: Prof. Dr. José Roberto Boffino de Almeida Monteiro

São Carlos

2014 
AUTORIZO A REPRODUČ̃̃ TOTAL OU PARCIAL DESTE TRABALHO, POR QUALQUER MEIO ÇONVENCIONAL OU ELETRÔNICO, PARA FINS DE ESTUDO E PESQUISA, DESDE QUE CITADA A FONTE.

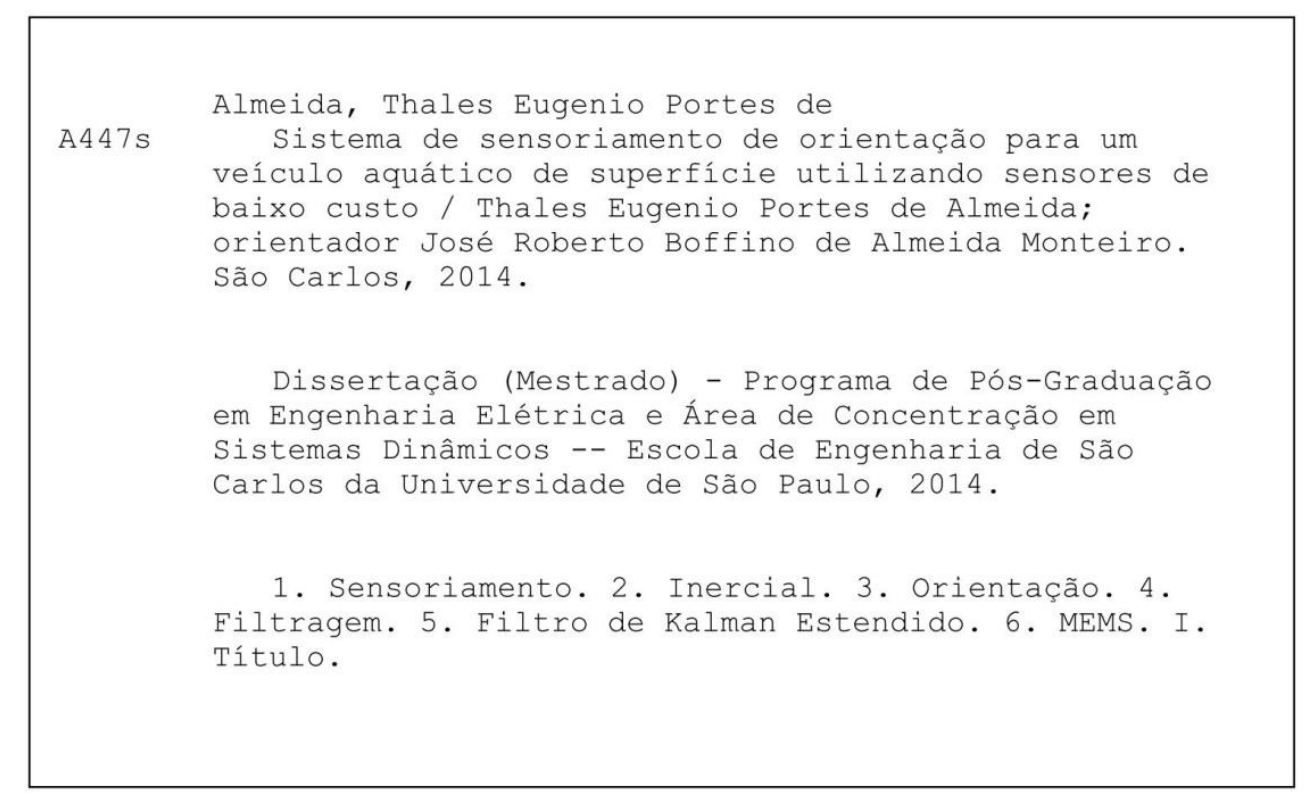




\section{FOLHA DE JULGAMENTO}

Candidato: Engenheiro THALES EUGENIO PORTES DE ALMEIDA.

Título da dissertação: "Sistema de sensoriamento de orientação para um veículo aquático de superfície utilizando sensores de baixo custo".

Data da defesa: $14 / 02 / 2014$

\section{Comissão Julgadora:}

Resultado:

Prof. Dr. José Roberto Boffino de Almeida Monteiro (Orientador) A PROVADO (Escola de Engenharia de São Carlos/EESC)

Prof. Associado Glauco Augusto de Paula Caurin (Escola de Engenharia de São Carlos/EESC)

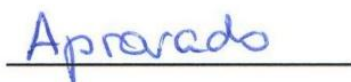

Prof. Dr. Eduardo do Valle Simões

APROVADO

(Instituto de Matemática e Computação/ICMC)

Coordenador do Programa de Pós-Graduação em Engenharia Elétrica e Presidente da Comissão de Pós-Graduação:

Prof. Titular Denis Vinicius Coury 

Dedico este trabalho aos meus pais, Alecio e Rosa, aos meus irmãos, Thomas e Thulio e à minha namorada, Neriane, peças fundamentais na minha formação, por todo o suporte, educação e amor. 



\section{Agradecimentos}

Agradeço primeiramente a Deus, pelo dom da vida, por mostrar o caminho a seguir.

Aos meus pais, Alecio (in memoriam) e Rosa, por fazerem o possível e o impossível por seus filhos, pela educação, exemplo, toda a dedicação, amor e carinho.

Aos meus irmãos, Thomas e Thulio, sempre presentes, por todos os bons momentos que passamos e pela amizade incansável.

À minha namorada, Neriane, pelo amor e carinho, por fazer parte da minha vida e por toda sua dedicação que me fez seguir em frente.

Aos meus amigos, Geyverson, William, Marcelo, Tatiane, Moussa, Jhonatan, Artur, Oureste, Guilherme, Rafael, Omar e Samuel e aos professores Manoel, Diógenes e Rodrigo por todo o suporte durante esta fase em minha formação, pela amizade e pelos diversos momentos de descontração dentro e fora do laboratório.

Ao Professor José Roberto, pela orientação e inúmeras contribuições para a realização deste trabalho, pela dedicação, competência e amizade.

À CAPES pelo apoio financeiro durante o período de mestrado. 

"Os que se encantam com a prática sem a ciência são como os timoneiros que entram no navio sem timão nem bússola, nunca tendo certeza do seu destino."

Leonardo da Vinci 



\section{Resumo}

Almeida, T. E. P. (2014). Sistema de sensoriamento de orientação para um veículo aquático de superfície utilizando sensores de baixo custo (Mestrado) - Escola de Engenharia de São Carlos, Universidade de São Paulo, São Carlos, 2014.

O presente trabalho trata do desenvolvimento de um sistema de sensoriamento de orientação utilizando sensores inerciais de baixo custo, de tecnologia MicroElectroMechanical Systems, MEMS, que apresentam altas taxas de ruído. Assim, é realizada a filtragem e fusão dos dados dos sensores para obtenção de uma estimativa confiável, com a aplicação do filtro de Kalman estendido. O sistema é utilizado para a navegação e controle em um veículo aquático de superfície autônomo. No desenvolvimento do trabalho são investigados os princípios da navegação inercial, da representação da orientação e os sistemas de coordenadas envolvidos, apresentando o método por ângulos de Euler, quatérnios e DCM e o procedimento de atualização conforme a variação da orientação. O sistema desenvolvido foi testado em bancada e em um barco com formato de trimarã construído no Laboratório de Controle e Eletrônica de Potência, na Escola de Engenharia de São Carlos, mostrando os resultados dos testes realizados navegando em uma represa, obtendo resultados satisfatórios para essa aplicação. É mostrado também o comportamento dinâmico dos veículos aquáticos de superfície através do estudo da dinâmica de corpos rígidos.

Palavras-chave: Sensoriamento, Inercial, Orientação, Filtragem, Filtro de Kalman Estendido, MEMS. 



\section{Abstract}

T. (2014). Orientation sensing system for an surface aquatic vehicle applying low cost sensors. (Master Degree) - Escola de Engenharia de São Carlos, Universidade de São Paulo, São Carlos, 2014.

This work describes the development of an orientation sensing system composed of low cost inertial sensors with MicroElectroMechanical Systems (MEMS) technology, which presents high noise levels. Thus, filtering and sensor's measurements fusion is done in order to achieve a reliable estimation, trough an extended Kalman filter. The system is used for navigation and control of an autonomous aquatic surface vehicle. In this work, the principles of inertial navigation, orientation representation as well as the coordinate frames involved are investigated, presenting the methods trough Euler angles, quaternions and DCM, and the update proceeding according to the orientation changes. The developed system was tested in the lab and on a trimaran shaped vessel navigating on a dam, wich was developed in the Control and Power Electronics Laboratory at the São Carlos School of Engineering, achieving satisfactory results for this application. It is also shown the dynamic behavior of the surface aquatic vehicles, using rigid-body dynamics.

Key-Word: Sensing, Inertial, Orientation, Filtering, extended Kalman filter, MEMS. 



\section{Lista de Figuras}

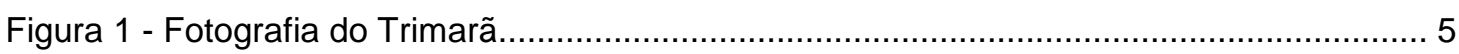

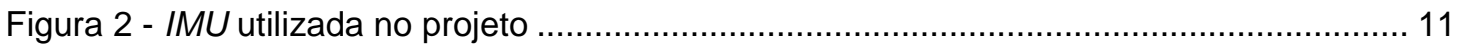

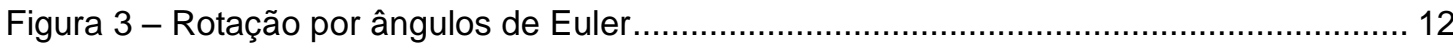

Figura 4 - Ângulos de rotação na notação aeroespacial..................................................... 13

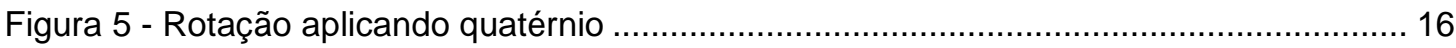

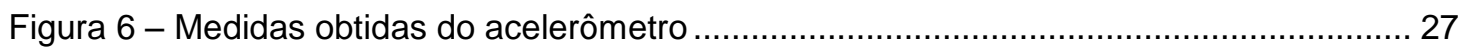

Figura 7 - Medidas obtidas do magnetômetro ............................................................... 28

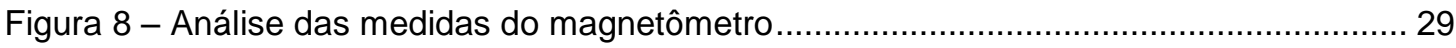

Figura 9 - Variação da amplitude na leitura do magnetômetro com mudança na temperatura ambiente. 30

Figura 10 - Ângulos de Euler no primeiro procedimento de teste offline aplicando o FKE..... 32

Figura 11 - Ângulos de Euler no primeiro procedimento de teste offline, apenas com a

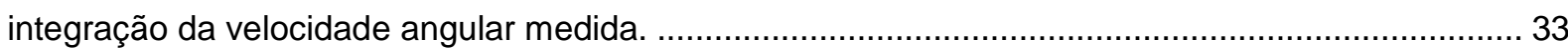

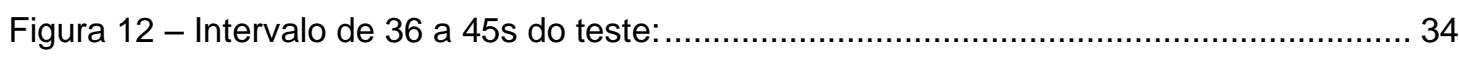

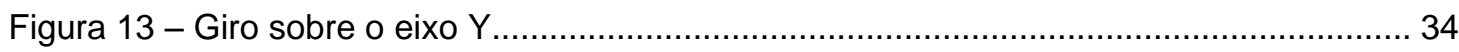

Figura 14 - Ângulos de Euler no segundo procedimento de teste offline aplicando o FKE .... 35

Figura 15 - Ângulos de Euler no segundo procedimento de teste offline, apenas com a

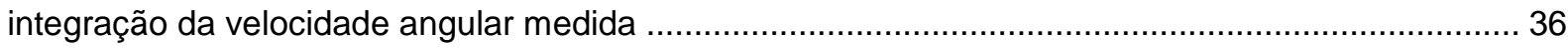

Figura 16 - Intervalo entre 19 e $37 \mathrm{~s}$ do segundo procedimento de teste ................................ 36

Figura 17 - intervalo entre 60 e 90s do segundo procedimento de teste ............................... 37

Figura 18 - intervalo entre 123 e 135s do segundo procedimento de teste .......................... 37

Figura 19 - Medidas de campo magnético e valores esperados............................................ 38

Figura 20 - Medidas de campo magnético e valores esperados.......................................... 38

Figura 21 - Píer do Centro de Recursos Hídricos e Ecologia Aplicada (CRHEA-USP) .......... 39

Figura 22 - Fotografia do trimarã e da lancha utilizada para rebocá-lo .................................. 40

Figura 23 - Estimativas de orientação obtidas pelo sistema embarcado aplicando o FKE no primeiro experimento

Figura 24 - Curva gerada com a integração apenas das medidas de velocidade angular no primeiro experimento

Figura 25 - Intervalo final do primeiro experimento ........................................................... 41

Figura 26 - Estimativas de orientação obtidas pelo sistema embarcado aplicando o FKE no segundo experimento

Figura 27 - Curva gerada com a integração apenas das medidas de velocidade angular no segundo experimento 42

Figura 28 - Intervalo final do segundo experimento 43 
Figura 29 - Medidas obtidas pelo acelerômetro 44

Figura 30 - Medidas obtidas pelo giroscópio ………….................................................. 44

Figura 31 - Medidas obtidas pelo magnetômetro ………............................................. 45

Figura 32 - Sistema de coordenadas e variáveis ................................................................. 53

Figura 33 - Visão superior do veículo, com variáveis do equacionamento .............................. 56 


\section{Sumário}

CAPÍTULO 1 ...........................................................................................................1

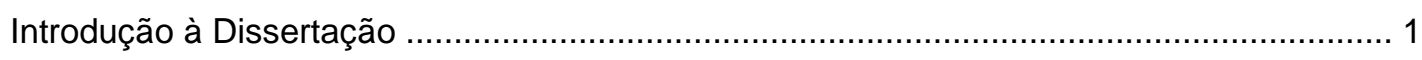

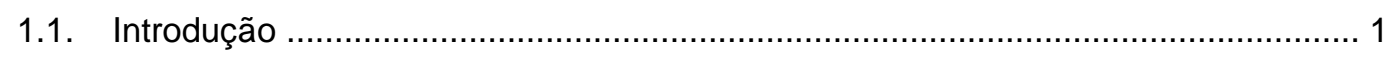

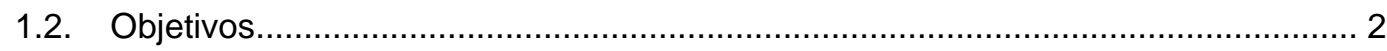

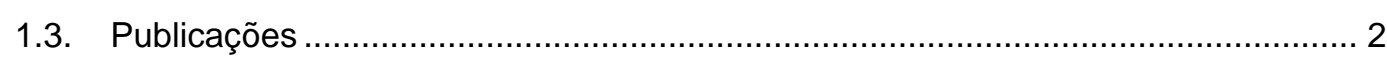

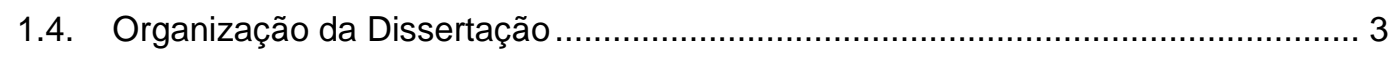

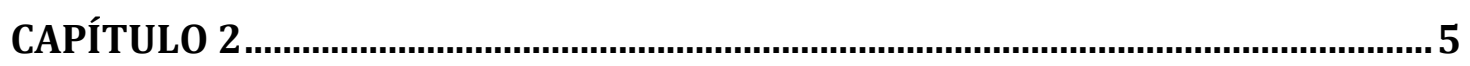

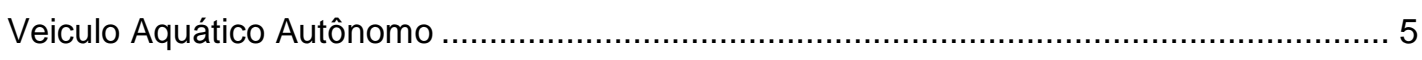

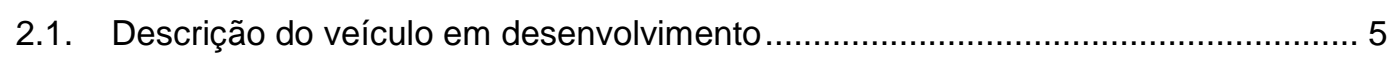

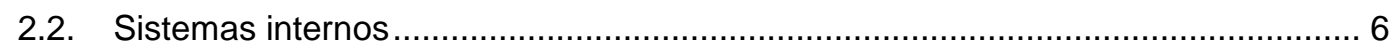

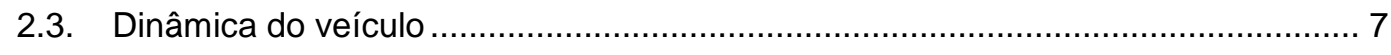

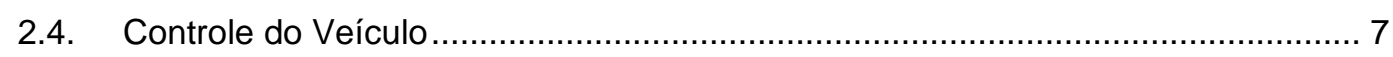

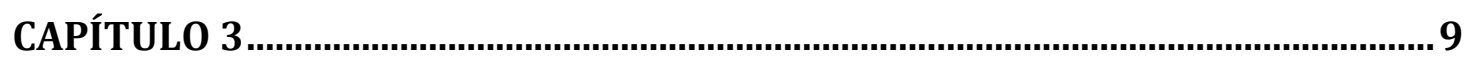

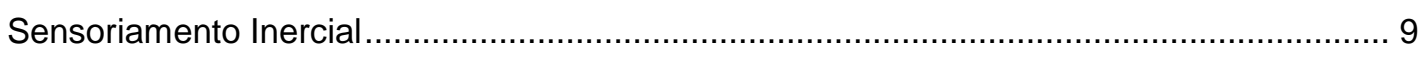

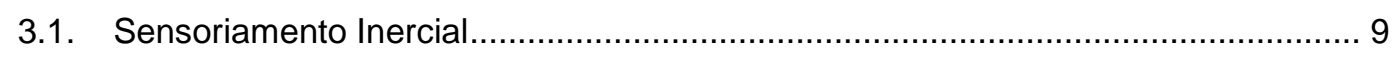

3.2. Unidade de medida inercial de baixo custo ......................................................... 10

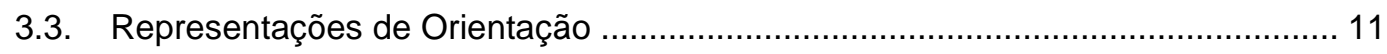

3.3.1. Ângulos de Euler ...................................................................................... 12

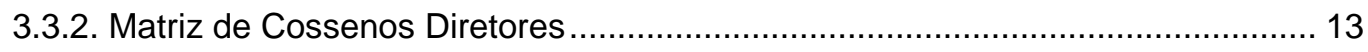

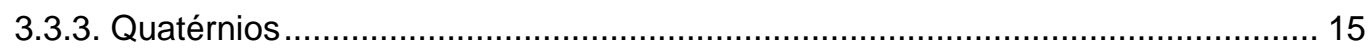

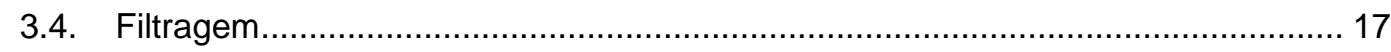

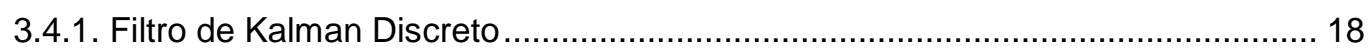

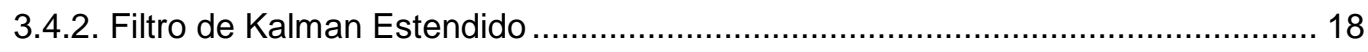

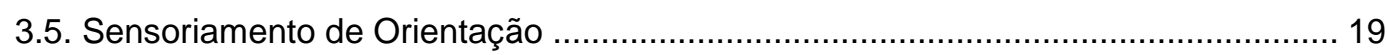

3.5.1. Método de Obtenção da Medida................................................................... 20

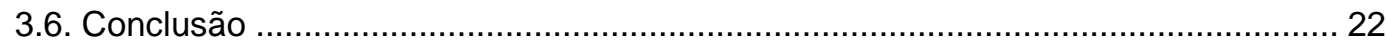


CAPÍTULO 4

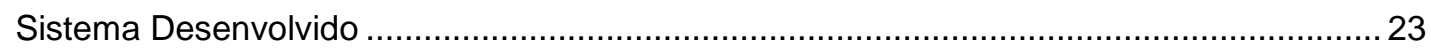

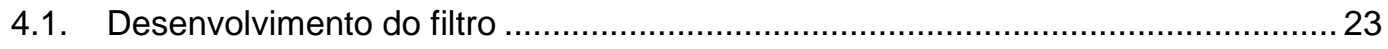

4.2. Considerações quanto à calibração dos sensores..............................................26

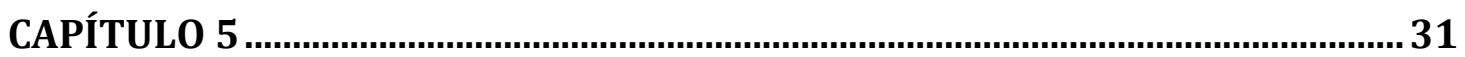

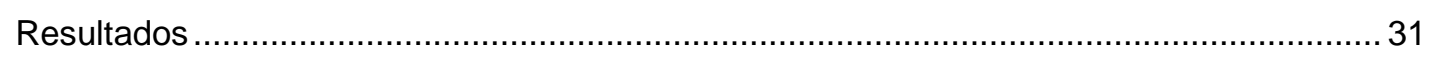

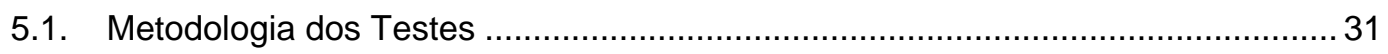

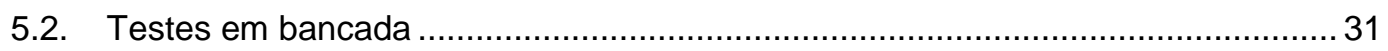

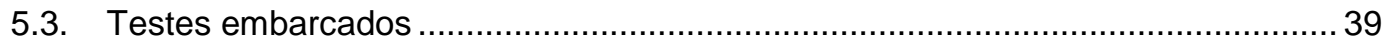

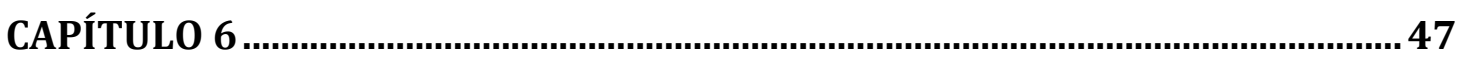

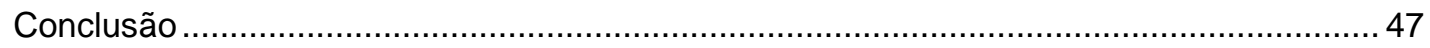

REFERÊNCIAS BIBLIOGRÁFICAS .................................................................49

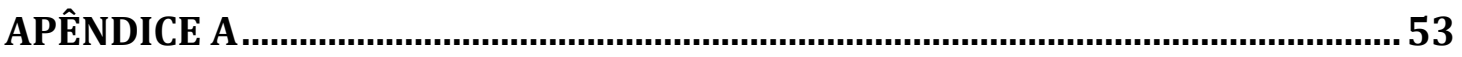

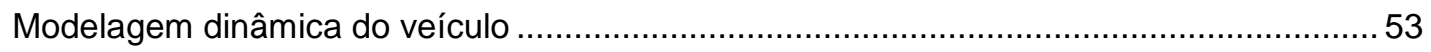

A.1 Dinâmica de corpos rígidos........................................................................... 53

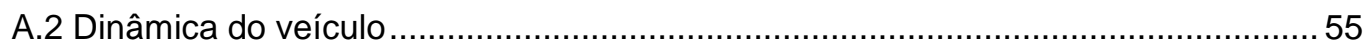




\section{Capítulo 1}

\section{Introdução à Dissertação}

\subsection{Introdução}

Os veículos autônomos são veículos capazes de operar, executar missões e tarefas de forma completamente autônoma e independente, sem a intervenção humana, e sem a necessidade da presença de um ser humano no veículo (Ferreira, Hugo et al., 2007).

A utilização de veículos aquáticos autônomos possibilita a execução de tarefas arriscadas em ambientes aquáticos, sem que a vida de um ser humano seja colocada em risco. Dentre as aplicações pode-se listar operações de segurança e monitoramento (Dias et al., 2009), exploração dos oceanos (Rufino, 2009), pesquisa ambiental e hidrográfica, incluindo rastreamento de poluentes (Su et al., 2006), aquisição de dados marinhos ou ainda para a comunicação com veículos submersos (Alves et al., 2006).

Para operar, um veículo aquático autônomo depende de vários subsistemas, entre eles os sistemas de navegação e controle de trajetória, sensoriamento para navegação, motorização, armazenamento de energia, além dos demais sistemas exigidos pela missão a ser executada (Ferreira, $\mathrm{H}$ et al., 2007).

O Sensoriamento para a navegação envolve a obtenção dos parâmetros necessários para o funcionamento do controle de trajetória, como posição e orientação, de forma a fornecer uma referência confiável sobre a qual são aplicadas as regras de controle. Assim estes sensores são essenciais para o cumprimento das trajetórias demandadas pela missão executada.

No intuito de estimular a pesquisa no segmento dos veículos autônomos, foi desenvolvido um veiculo aquático autônomo de superfície no departamento de engenharia elétrica, SEL - EESC, na 
Universidade de São Paulo. O veículo desenvolvido tem a forma de trimarã (Peng and Han, 2009) e conta com um sistema de propulsão por dois motores elétricos.

Em relação à navegação, o veículo deve ser capaz de traçar uma trajetória entre a posição atual e a posição desejada. Para isso, é necessário que o sistema de controle seja capaz de operar os motores segundo a dinâmica do veículo, contando com um sistema de sensores inerciais capazes de fornecer a orientação estimada do veículo para as correções necessárias devido à perturbações durante o trajeto.

No intuito de desenvolver um sistema de sensoriamento de orientação utilizando sensores de baixo custo disponíveis no mercado, devem ser estudados quais sensores são necessários, a forma de integrar os dados oriundos desses sensores para obter a referência de orientação, compreender como é feita a representação espacial do veículo, os métodos de representação e atualização conforme o veículo se movimenta.

Tratando-se de sensores de baixo custo, estes apresentam imprecisão nas medidas, sendo necessário desenvolver um sistema de filtragem capaz de obter bons resultados através da fusão dos dados de diversos sensores. Os métodos mais comuns envolvem a utilização de filtro de Kalman ou de filtros complementares (Du, Liu and Du, 2010).

\subsection{Objetivos}

O objetivo do trabalho é desenvolver um sistema de sensoriamento capaz de estimar a orientação de forma confiável, utilizando sensores de baixo custo, para operar embarcado no veículo que está sendo desenvolvido, sendo este um dos sistemas essenciais para a navegação.

Desta forma, é necessário desenvolver o estudo sobre os sistemas de navegação inercial e sistemas de sensoriamento inercial, incluindo a análise e descrição dos sensores envolvidos e dos métodos de filtragem e fusão dos sinais dos sensores, necessários para se obter um resultado preciso.

\subsection{Publicações}

Os artigos desenvolvidos pelo candidato a Mestre em Ciências, relacionados diretamente com esse trabalho são listados abaixo:

- Paula, G. T. ; Almeida, T. E. P. ; MONTEiRo, J. R. B. A. ; SAntanA, M. P. ; ROMERO, G. B. ; FARACCO, J. C. . Development of an Autonomous Aquatic Vehicle Employed on Special Activities. In: International Conference on Electrical Systems for Aircraft, Railway and Ship Propulsion, 2012, Bologna. Proceedings of International Conference on Electrical Systems for Aircraft, Railway and Ship Propulsion, 2012. 
- MONTEIRO, J. R. B. A. ; SUETAKE, M. ; PAULA, G. T. ; ALMEIDA, T. E. P. ; SANTANA, M. P. ; ROMERO, G. B. ; FARACCO, J. C. ; MONACO, F. J. ; PINTO, R. S. . Wind Velocity Neural Estimator for Small Autonomous Surface Vehicle. In: II Brazilian Conference on Critical Embedded Systems, 2012, Campinas. Proceedings of II Brazilian Conference on Critical Embedded Systems, 2012.

\subsection{Organização da Dissertação}

No capítulo 2 é apresentado o veículo em desenvolvimento e suas características. Neste veículo serão realizados os testes do sistema de sensoriamento desenvolvido.

No capítulo 3 são apresentados os fundamentos do sensoriamento inercial e mostrados os métodos de representação espacial de um corpo e sua atualização conforme o corpo se movimenta. São apresentados os sensores inerciais e suas características. É mostrada a teoria de filtragem com filtro de Kalman e filtro de Kalman estendido, utilizados neste projeto para a obtenção de uma estimativa confiável a partir dos sensores ruidosos e de baixa qualidade.

No capítulo 4 é apresentado o sistema proposto para a obtenção da orientação do veículo e também algumas considerações sobre a calibração dos sensores, essencial para 0 bom funcionamento do estimador.

No capitulo 5 são apresentados os resultados obtidos no desenvolvimento do projeto, sendo apresentados os resultados para os testes preliminares em bancada e os testes na aplicação embarcada.

Conclui-se o trabalho no capitulo 6, sendo apresentadas também as sugestões para continuação do trabalho. 



\section{Capítulo 2}

\section{Veiculo Aquático Autônomo}

\subsection{Descrição do veículo em desenvolvimento}

O veículo desenvolvido no laboratório tem o formato de um trimarã. Uma fotografia do veículo é mostrada na Figura 1.

Figura 1 - Fotografia do Trimarã

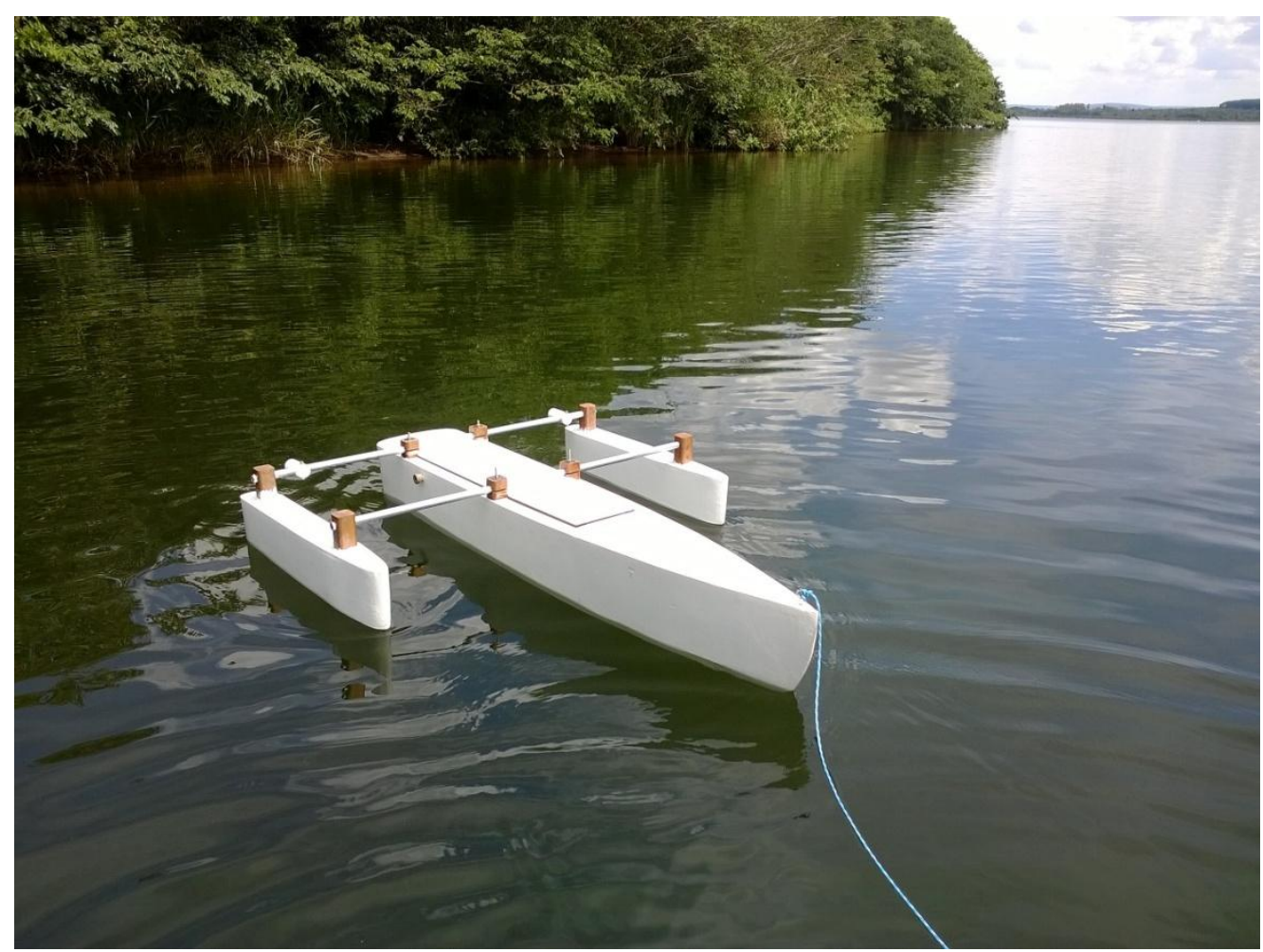


O Conceito de Trimarã consiste em uma embarcação composta por três estruturas, sendo um corpo principal no centro do veículo e dois corpos laterais, chamados amas, estruturas que ajudam na estabilidade do veículo.

A escolha do conceito de trimarã para o desenvolvimento do veículo se deu devido à estabilidade deste tipo de veículo, além da grande área útil que pode ser aproveitada, e com baixo deslocamento de água, gerando pouca interferência e ondas mesmo em altas velocidades (Peng, Zhou and Han, 2007).

A embarcação conta com um computador central, de arquitetura ARM, responsável pela execução das tarefas atreladas ao veículo para a execução das missões; e um sistema de interface com microcontrolador ARM Cortex-M3, voltado ao acionamento dos motores e comunicação com os sensores e demais tarefas menos complexas.

A propulsão do veículo se dá por meio de dois motores similares, um de cada lado, de forma que o veículo possa fazer curvas apenas pela diferença de velocidade dos motores, sem a necessidade de um leme.

O veículo conta ainda com um conjunto de sensores inerciais, capazes de fornecer as medidas necessárias para o sistema de sensoriamento de orientação, e um receptor de sinal de sistema de posicionamento global, GPS, de forma que as missões possam ser executadas com precisão de posicionamento satisfatório.

\subsection{Sistemas internos}

O trimarã conta com um computador central de baixo consumo, encarregado das tarefas de gerenciamento do veículo, comunicação com ambiente externo, controle de missão e demais demandas computacionais para o veículo. Este computador possui processador ARM11 de $700 \mathrm{MHz}$, com 512 MB de memória RAM, executando um sistema operacional embarcado GNU/Linux.

Uma placa secundária, com microcontrolador do tipo ARM Cortex-M3, atua em conjunto com o computador central, sendo encarregada das tarefas de controle de máquinas para propulsão, gerenciamento de energia e interface com periféricos e sensores.

O Sistema como um todo é alimentado por uma bateria do tipo chumbo-ácido automotiva. Diversos conversores $\mathrm{DC} / \mathrm{DC}$ adéquam o nível de tensão fornecido pela bateria para as necessidades de cada componente.

Os motores são alimentados por baterias de lítio-íon, que são carregadas a partir da bateria principal, evitando assim altas correntes de descarga na bateria de chumbo, que poderiam comprometer sua vida útil e afetar a execução das missões do veículo (Linden and Reddy, 2002). 
O veículo conta com sensores inerciais numa unidade de medida inercial composta por acelerômetro, giroscópio e magnetômetro, cada um com três eixos ortogonais de medida, que são utilizados para o desenvolvimento do sensoriamento de orientação; receptor GPS para auxiliar no controle de trajetória e posicionamento. Há também um sensor de proximidade subaquático, sonar, para detecção de obstáculos.

No veículo poderão ainda ser incorporados os mais diversos sistemas necessários para execução de missões, como sensores de qualidade de água ou de monitoramento ambiental, anemômetros e anemoscópios, estando disponíveis diversas interfaces, como USB, serial, I2C e SPI para comunicação com o computador, facilitando na diversidade de aplicações da plataforma.

\subsection{Dinâmica do veículo}

A fim de compreender o comportamento do veículo, considerando o posicionamento dos motores e a ausência de leme, além das possíveis interferências externas, desenvolve-se a modelagem do comportamento dinâmico do veículo.

Para tal, é necessária uma introdução à mecânica dos corpos rígidos, aplicada ao estudo de um corpo com as liberdades e restrições de movimento apresentadas por um veículo aquático. A partir desse estudo, desenvolve-se um sistema que leve em conta as propriedades do veículo em estudo, com suas particularidades e também com as simplificações que possam ser aplicadas.

O desenvolvimento da análise do comportamento dinâmico do veículo é apresentado no Apêndice A.

\subsection{Controle do Veículo}

O veículo, contando com o sistema de propulsão e curva via dois motores, sem leme, deve ter um sistema de controle adequado a essa configuração e que seja capaz de atuar no veículo dentro das necessidades da trajetória para cumprir as missões a que seja designado.

Existem diversas técnicas para o desenvolvimento de controladores que atendam às necessidades do projeto, entre eles o controle PID (Rufino, 2009), que leva em consideração o modelo dinâmico do veículo e o controle por lógica fuzzy (LEE and KWON, 2004); sendo que podem ser estudados em um ambiente simulado antes da aplicação em campo.

O controlador PID atua comparando o valor atual da variável de controle e o valor de referência, o erro $e(t)$ entre esses dois valores é calculado e usado para a atuação do controlador. Este possui três constantes de controle, $K_{P}, K_{l}$ e $K_{D}$ que são o ganho proporcional, ganho integrativo e ganho derivativo respectivamente, e o funcionamento obedece à regra da equação (1).

$$
\tau_{P I D}=K_{P} e(t)+K_{D} \frac{d}{d t} e(t)+K_{I} \int_{0}^{t} e(\tau) d \tau+e(0)
$$


O ganho proporcional reduz o tempo de subida e o erro em regime permanente, o ganho integrativo elimina o erro em regime permanente e o ganho derivativo aprimora a estabilidade do sistema. Os ganhos são calculados com base no tempo de resposta esperado e o modelo desenvolvido do comportamento dinâmico do corpo, a fim de otimizar o comportamento. 


\section{Capítulo 3}

\section{Sensoriamento Inercial}

\subsection{Sensoriamento Inercial}

Para a navegação de um sistema autônomo é necessário que seja definido o sistema de coordenadas global sobre o qual serão computadas a posição do veículo, a posição do alvo e a trajetória, também sobre este sistema são definidas a velocidade e a orientação. Utilizando os pontos cardeais para definir um sistemas de coordenadas ortogonal, a orientação é computada de forma a descrever o eixo principal e a rotação do corpo como ângulos em relação aos eixos do sistema (Rufino, 2009).

Qualquer sistema em movimento permite que sua posição seja obtida, partindo de um ponto inicial conhecido, apenas pela análise dos movimentos do próprio corpo, sem auxilio de elementos externos no ambiente, utilizando-se sensores inerciais, num processo conhecido como Dead Reckoning (Goyal et al., 2011).

Tal processo consiste da integração temporal do movimento, através de medidas das acelerações e velocidades lineares e angulares sofridas pelo corpo, de forma que conhecida a posição e orientação exata do corpo em um dado momento, é possível obter a posição em qualquer instante.

São necessários sensores altamente precisos, de modo a minimizar o acúmulo de erros ao longo do tempo, geralmente são empregados sistemas a laser e fibra ótica para a medida de variações angulares e sistemas piezelétricos para a medida de acelerações lineares (Tan and Park, 2005). 
Outra medida importante para a obtenção da orientação é a do campo magnético da terra. $\mathrm{O}$ vetor norte magnético fornece uma referência que embora tenha variações conhecidas e mapeadas no globo terrestre, pode ser considerada constante dentro de uma área limitada.

O sistema composto pelos sensores inerciais é chamado de Unidade de Medida Inercial, IMU, do inglês Inertial Measurement Unit. Aplicando-se os devidos condicionamentos de sinal e cálculos sobre os sinais de medida da IMU, de forma a se estimar a orientação, o sistema pode ser chamado de Sistema de Referência de Orientação, ou AHRS, do inglês Attitude Heading Reference System.

O uso de sensores inerciais é essencial em aplicações de transporte como aviões, nas quais a vida de seres humanos depende do conhecimento exato das condições de voo. Porém, o custo de sensores inerciais altamente precisos, como os utilizados em aviões comerciais ou militares, é extremamente elevado, o que inviabiliza seu uso em sistemas de baixo custo.

Uma alternativa ao uso dos custosos sistemas de sensoriamento de alta precisão é o uso de sensores microeletromecânicos de baixo custo, conhecidos como MEMS, do inglês MicroElecrtoMechanical Systems, que são sensores produzidos com processos de microeletrônica de circuitos integrados.

Esse tipo de sensores apresentam custos baixos, mas ao mesmo tempo possuem taxas de erros que inviabilizariam seu uso em aplicações sensíveis como em aviões comerciais e militares. Ainda assim, são capazes de fornecer dados confiáveis para aplicações menos críticas. (Denti, Galatolo and Schettini, 2010)

Dessa forma, recorre-se à utilização de técnicas de filtragem para se obter melhores resultados a partir dos dados obtidos pelos sensores, sendo a abordagem mais comum a utilização de filtro de Kalman (Li, Landry and Lavoie, 2008), ou suas variações Extended Kalman Filter (Jang and Liccardo, 2007) e Unscented Kalman Filter (Marina, 2011), e utilizando diferentes métodos de representação da orientação do veículo além da abordagem dos ângulos de Euler (Hadri and Benallegue, 2009), como o Quaternion (Yongliang et al., 2008) ou a representação pela matriz de cossenos diretores da rotação, DCM, do inglês Direction Cosine Matrix (Cifuentes and Braidot, 2012).

As IMUs são vastamente utilizadas em veículos, principalmente aéreos, mas também em terrestres e náuticos, porém não se limita apenas a eles. O sensoriamento inercial também tem sido bastante utilizado na área médica de reabilitação, analisando o movimento de uma pessoa (Madgwick, Harrison and Vaidyanathan, 2011) ou de partes do corpo humano (Sabatini, 2011).

\subsection{Unidade de medida inercial de baixo custo}

É utilizada no projeto uma IMU de baixo custo, composta por três sensores de tecnologia MEMS, sendo um acelerômetro ADXL345, um giroscópio ITG3205 e um magnetômetro HMC5883; todos com três eixos ortogonais de medida. Dispostos em uma única placa de circuito impresso de forma que os eixos dos três sensores coincidem, mostrada na Figura 2. 


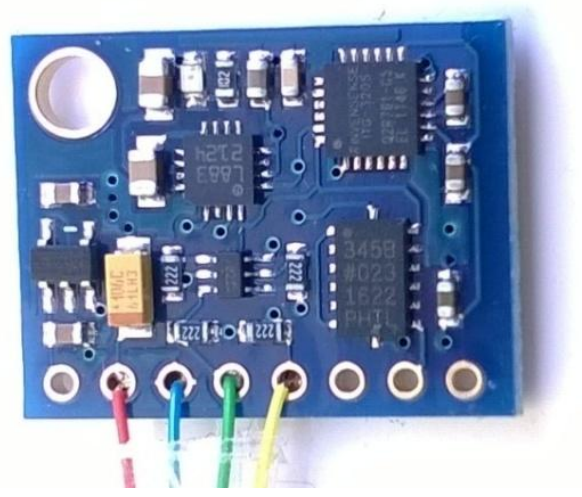

O maior empecilho na aplicação das IMUs de baixo custo reside na baixa qualidade das medidas, onde são apresentados ruídos ou erros intrínsecos à tecnologia dos sensores, sensíveis à variação da temperatura, além de apresentarem erros de quantização, erros devido ao desalinhamento dos sensores ou mesmo à não-ortogonalidade dos trios de sensores dentro de cada componente. (Denti, Galatolo and Schettini, 2010)

Os principais parâmetros de desempenho dos sensores utilizados para o projeto estão mostrados na Tabela 1.

Tabela 1 - Parâmetros dos componentes da IMU

\begin{tabular}{|c|c|c|c|}
\hline & Giroscópio & Acelerômetro & Magnetômetro \\
\hline Amplitude de operação & $\pm 2000(\%)$ & $\pm 10 \mathrm{~g}$ & \pm 8 Gauss \\
\hline Resolução & $0,0695(\% / s)$ & 3,9 mili $\mathrm{g}$ & 0,73mili Gauss \\
\hline Margem de erro & $\pm 6 \%$ & $\pm 1,0 \%$ & $\pm 5 \%$ \\
\hline Desvio devido à temperatura & $\pm 10 \%\left(0^{\circ}\right.$ a $\left.55^{\circ} \mathrm{C}\right)$ & $\pm 1,2 \mathrm{mili} \mathrm{g} /{ }^{\circ} \mathrm{C}{ }^{1}$ & 2 \\
\hline Ruído & $0,7^{\circ} / \mathrm{s}-\mathrm{rms}$ & $1,1 \mathrm{LSBrms}$ & 2mili Gauss \\
\hline Não-linearidade & $0,2 \%$ & $\pm 0,5 \%$ & $\pm 0,1 \%$ \\
\hline Máxima Taxa de Amostragem Fixa & $8 \mathrm{kHz}$ & $3,2 \mathrm{kHz}$ & $75 \mathrm{~Hz}$ \\
\hline
\end{tabular}

${ }^{1} \mathrm{~g}=9,81 \mathrm{~m} / \mathrm{s}^{2}$, a aceleração da gravidade. ${ }^{2}$ Dado não fornecido, porém 0 fabricante apresenta 0 método para correção da medida devido à variação de temperatura.

\subsection{Representações de Orientação}

É possível representar a Orientação de um Objeto utilizando varias técnicas, sendo a mais comum a representação por ângulos de Euler, na qual três ângulos definem a inclinação e rotação do objeto em relação ao sistema de coordenadas do ambiente.

Porém, essa técnica apresenta singularidade quando a inclinação é máxima. Para evitar a singularidade existem algumas formas alternativas para se representar a orientação, entre elas o uso de Quatérnios ou a Matriz de Cossenos Diretores DCM, do inglês Direction Cosines Matrix. 


\subsection{1. Ângulos de Euler}

Uma das formas mais simples e diretas de se representar a orientação de um objeto no espaço tridimensional é por meio dos ângulos de Euler. Definidos dois sistemas de coordenadas de três dimensões no espaço, sendo um sistema local fixado ao objeto e um global fixado ao ambiente, a orientação do sistema móvel pode ser definida em relação ao sistema fixo como uma sequência de três rotações.

Na Figura 3 o processo é mostrado de modo simplificado, onde são aplicadas as três rotações, com ângulos $\alpha, \beta$ e $Y$, levando do sistema de coordenadas $X_{0} Y_{0} Z_{o}$ para o sistema $X Y Z$, aplicando a sequência aeroespacial das rotações, 'zyx', com a primeira rotação em relação a $Z$, a segunda em relação a $Y$ e a terceira em relação a $X$ (Craig, 2005).

\section{Figura 3 - Rotação por ângulos de Euler}

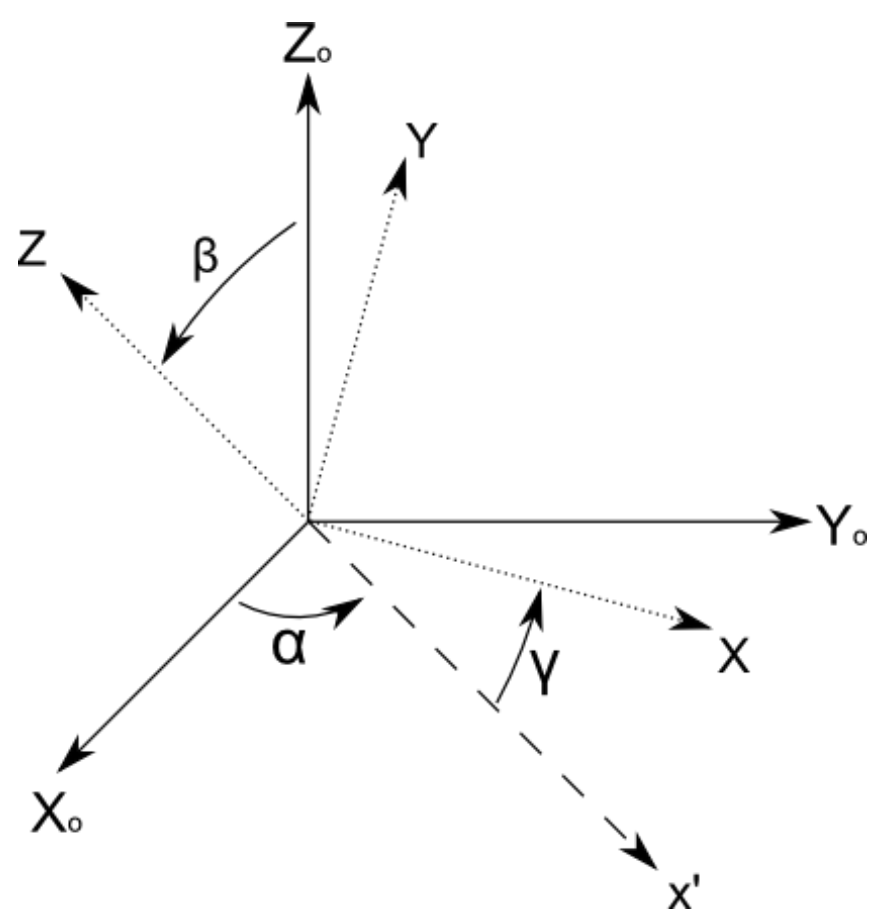

Quando aplicado em aeronáutica, ou navegação em geral, é utilizado um conceito ligeiramente modificado dos ângulos de Euler, de forma a simplificar os cálculos relacionados à navegação.

Usando como exemplo um avião para a simplificar a observação, o sistema de coordenadas local é definido de forma que a origem coincida com o centro de massa, o eixo $X$ apontando para a frente do avião, eixo $Y$ para a asa direita e o eixo $Z$ para baixo, o sistema fixo como xyz. São definidos então três ângulos de rotação, $\phi$ a rotação em relação a $X ; \theta$ ângulo entre $X$ e a sua projeção no plano xy; $\psi$ o ângulo entre a projeção de $X$ no plano xy e o plano xz, conforme ilustrado na Figura 4.

Os ângulos são conhecidos popularmente pelo seu uso nos aviões, $\phi$ como rolagem, $\theta$ como arfagem e $\psi$ como guinada. 
Figura 4 - Ângulos de rotação na notação aeroespacial

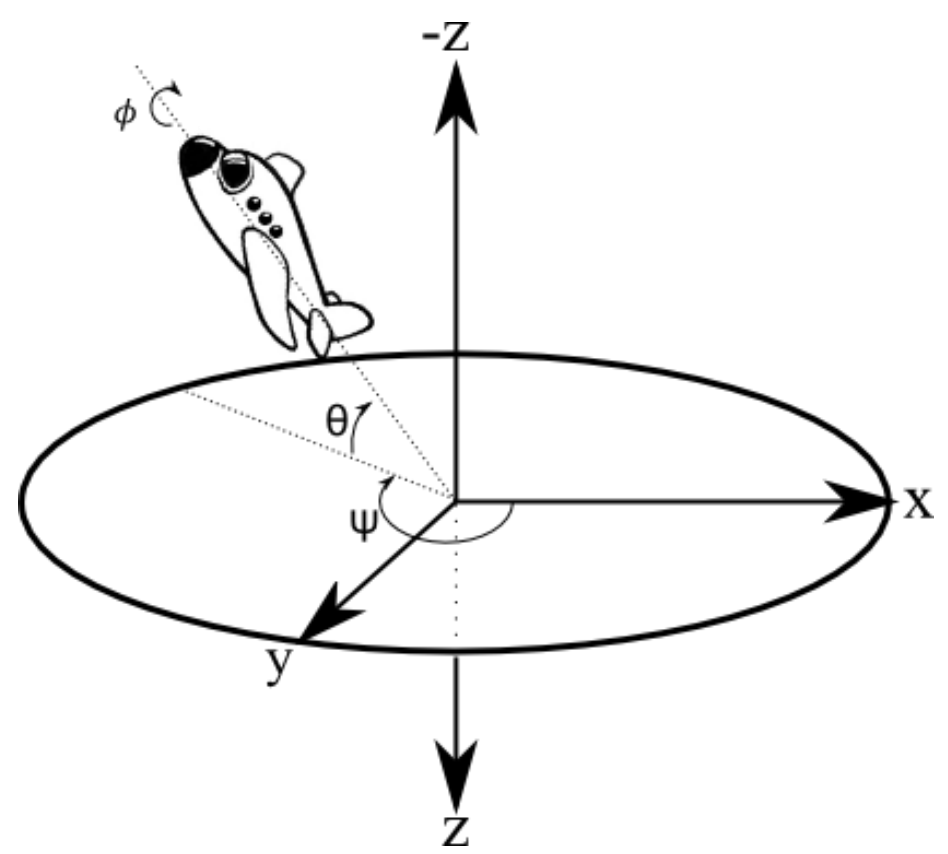

Assim, conhecendo a variação angular nos três eixos do veículo, como são obtidas pelos sensores no próprio veículo, $\omega_{x}, \omega_{y}$ e $\omega_{z}$, é possível atualizar os ângulos $\phi, \theta$ e $\psi$ através da relação (2).

$$
\left[\begin{array}{c}
\dot{\phi} \\
\dot{\theta} \\
\dot{\psi}
\end{array}\right]=\left[\begin{array}{ccc}
1 & \sin \phi \tan \theta & \cos \phi \tan \theta \\
0 & \cos \theta & -\sin \theta \\
0 & \sin \phi \sec \theta & \cos \phi \sec \theta
\end{array}\right]\left[\begin{array}{c}
\omega_{x} \\
\omega_{y} \\
\omega_{z}
\end{array}\right]
$$

Esta forma de representação é bastante simples e prática, mas possui singularidade para $\theta=\pi / 2$, o que pode levar a problemas em algumas aplicações. Este problema também é conhecido como Gimbal Lock.

\subsubsection{Matriz de Cossenos Diretores}

O Método $D C M$ consiste em atualizar diretamente a matriz de rotação entre o sistema de coordenadas móvel e o sistema fixo.

Definindo como $R_{\alpha}^{z}$ uma rotação de ângulo a em relação ao eixo z, o novo sistema de coordenadas, rotacionado em relação ao antigo, pode ser obtido por (3).

$$
\begin{gathered}
x_{\text {novo }}=x_{\text {velho }} \cos \alpha+\mathrm{y}_{\text {velho }} \sin \alpha \\
y_{\text {novo }}=y_{\text {velho }} \cos \alpha-\mathrm{x}_{\text {velho }} \sin \alpha \\
z_{\text {novo }}=z_{\text {velho }}
\end{gathered}
$$

$$
\text { Assim, } R_{\alpha}^{z}=\left[\begin{array}{ccc}
\cos \alpha & \sin \alpha & 0 \\
-\sin \alpha & \cos \alpha & 0 \\
0 & 0 & 1
\end{array}\right]
$$


Da mesma forma, com uma rotação $\beta$ em torno do eixo y, o novo sistema de coordenadas pode ser obtido pelas equações (4).

$$
\begin{gathered}
x_{\text {novo }}=x_{\text {velho }} \cos \beta-z_{\text {velho }} \sin \beta \\
y_{\text {novo }}=y_{\text {velho }} \\
z_{\text {novo }}=x_{\text {velho }} \sin \beta+z_{\text {velho }} \cos \beta
\end{gathered}
$$

$$
\text { Assim } R_{\beta}^{y}=\left[\begin{array}{ccc}
\cos \beta & 0 & -\sin \beta \\
0 & 1 & 0 \\
\sin \beta & 0 & \cos \beta
\end{array}\right]
$$

Aplicando em sequência uma rotação $\alpha$ em torno ao eixo $z$ e uma rotação $\beta$ em torno ao novo y, o novo sistema pode ser obtido como a multiplicação de cada rotação, de forma que a rotação total $R$, é obtida por $R=R_{\beta}^{y} R_{\alpha}^{z} I$

$$
R=R_{\beta}^{y} R_{\alpha}^{z} I=\left[\begin{array}{ccc}
\cos \beta & 0 & -\sin \beta \\
0 & 1 & 0 \\
\sin \beta & 0 & \cos \beta
\end{array}\right]\left[\begin{array}{ccc}
\cos \alpha & \sin \alpha & 0 \\
-\sin \alpha & \cos \alpha & 0 \\
0 & 0 & 1
\end{array}\right] I=\left[\begin{array}{ccc}
\cos \alpha \cos \beta & \sin \alpha \cos \beta & -\sin \beta \\
-\sin \alpha & \cos \alpha & 0 \\
\cos \alpha \sin \beta & \sin \alpha \cos \beta & \cos \beta
\end{array}\right] I
$$

Assim, para as três rotações usadas para descrever a orientação de um objeto em um novo sistema de coordenadas em relação ao sistema de coordenadas antigo, com os ângulos $\psi$ em torno ao eixo $z, \theta$ em torno ao novo eixo y e $\phi$ em torno ao eixo $x$ após as duas rotações anteriores, a matriz de rotação é definida como $M(\psi, \theta, \phi)$, sendo esta a sequência de rotações usadas para representações aeroespaciais.

$$
M(\psi, \theta, \phi)=\left[\begin{array}{ccc}
\cos \theta \cos \phi & \cos \theta \sin \phi & -\sin \theta \\
\sin \psi \sin \theta \cos \phi-\cos \psi \sin \phi & \sin \psi \sin \theta \sin \phi+\cos \psi \cos \phi & \sin \psi \cos \theta \\
\cos \psi \sin \theta \cos \phi+\sin \psi \cos \phi & \cos \psi \sin \theta \sin \phi-\sin \psi \cos \phi & \cos \psi \cos \theta
\end{array}\right]
$$

Assim, um vetor $x$ qualquer no espaço pode ser representado nos dois sistemas de coordenadas, com respeito aos eixos em cada uma delas; no sistema fixo $x=x_{1} X+x_{2} Y+x_{3} Z$ ou em

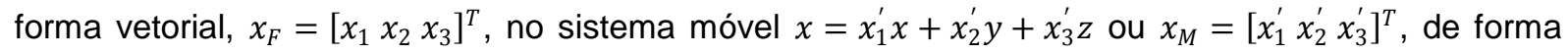
que o vetor pode ser transformado entre os sistemas de coordenadas utilizando a matriz de rotação descrita, $x_{M}=M(\psi, \theta, \phi) x_{F}$.

Por conveniência, a matriz de rotação $M(\psi, \theta, \phi)$ será denotada por ${ }_{F}^{M} C$, sendo esta a representação usual das $D C M$, assim $x_{M}={ }_{F}^{M} C x_{F}$.

É evidente que as colunas da DCM representam os eixos do sistema de coordenadas fixo em relação aos eixos do sistema móvel, enquanto as linhas da matriz representam os eixos do sistema móvel em relação ao sistema fixo. A matriz 3x3 é ortonormal (Phuong et al., 2009).

Da mesma forma que com os ângulos de Euler, a matriz é atualizada utilizando os dados de velocidade angular do corpo nos três eixos, $\omega_{x}, \omega_{y}$ e $\omega_{z}$, através da integração de (7) (Nebot and Durrant-Whyte, 1999). 


$$
{ }_{F}^{M} \dot{C}=\left[\begin{array}{ccc}
0 & -\omega_{z} & \omega_{y} \\
\omega_{z} & 0 & -\omega_{x} \\
-\omega_{y} & \omega_{x} & 0
\end{array}\right]{ }_{F}^{M} C
$$

Sendo que para aplicações em tempo real a integração pode ser feita através da aproximação (8), onde $(I+\Delta \theta)$ é a $D C M$ que relaciona o sistema no tempo $k$ com o sistema rotacionado no tempo $k+1$, sendo válido apenas para pequenas variações nos ângulos, com tempo de amostragem mínimo.

$$
{ }_{F}^{M} C(k+1)={ }_{F}^{M} C(I+\Delta \theta) \operatorname{com} \Delta \theta=\left[\begin{array}{ccc}
0 & -\Delta \psi & \Delta \theta \\
\Delta \psi & 0 & -\Delta \phi \\
-\Delta \theta & \Delta \phi & 0
\end{array}\right], I=\left[\begin{array}{lll}
1 & 0 & 0 \\
0 & 1 & 0 \\
0 & 0 & 1
\end{array}\right]
$$

Os ângulos de Euler podem ser obtidos da DCM por meio das equações (9) (Cifuentes and Braidot, 2012).

$$
\begin{aligned}
& \theta=-\sin ^{-1}{ }_{F}^{M} C_{1,3} \\
& \phi=\tan ^{-1}\left(\frac{{ }_{F}^{M} C_{2,3}}{{ }_{F} C_{3,3}}\right) \\
& \psi=\tan ^{-1}\left(\frac{{ }_{F}^{M} C_{1,2}}{{ }_{F} C_{1,1}}\right)
\end{aligned}
$$

\subsubsection{Quatérnios}

Outro método muito usual para representar a orientação de um corpo no espaço tridimensional é através de quatérnios unitários, que é uma generalização dos números complexos em quatro dimensões, representado por quatro números reais, $q_{0} q_{1} q_{2}$ e $q_{3}$, com norma unitária, de forma que:

$$
q=q_{0}+\mathbf{q}=q_{0}+q_{1} \mathbf{i}+q_{2} \mathbf{j}+q_{3} \mathbf{k}
$$

Assim, qo é a parte escalar e q é a parte vetorial do quatérnio q (Kupiers, 1999).

O quatérnio pode então ser compreendido como um escalar $q_{0}$ associado a um vetor $\mathbf{q}$ tal que $\mathbf{q}=q_{\mathbf{i}} \mathbf{i}+q_{2} \mathbf{j}+q_{3} \mathbf{k}$, sendo que $\mathbf{i}$, $\mathbf{j}$ e $\mathbf{k}$ satisfazem $\mathbf{i}^{2}=\mathbf{j}^{2}=\mathbf{k}^{2}=\mathbf{i j k}=-1$, assim pode ser compreendido que $\mathbf{i}, \mathbf{j}, \mathbf{k}$ representam uma base ortonormal em $\mathbb{R}^{3}$.

A orientação de um sistema de coordenadas móvel $\mathrm{M}$, em relação a um sistema fixo $\mathrm{F}$ pode ser obtida através de uma rotação de ângulo $\theta$ em torno a um vetor ${ }^{F} \hat{\boldsymbol{r}}$ em $\mathrm{F}$, conforme mostrado na Figura 5 (Madgwick, 2010). 
Figura 5 - Rotação aplicando quatérnio

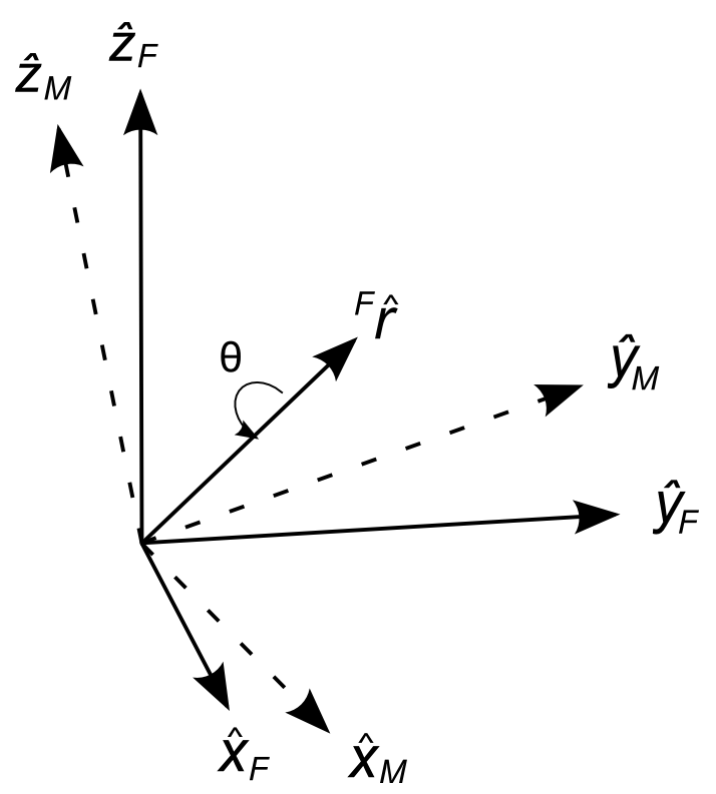

Essa orientação pode ser descrita por um quatérnio ${ }_{M}^{F} \widehat{\boldsymbol{q}}$ como mostrado em (11), na qual $\mathrm{r}_{\mathrm{x}}, \mathrm{r}_{\mathrm{y}}$ e $r_{z}$ são os componentes do vetor ${ }^{F} \hat{\boldsymbol{r}}$ nos eixos do sistema $F$.

$$
{ }_{M}^{F} \widehat{\boldsymbol{q}}=\left[\begin{array}{llll}
q_{0} & q_{1} q_{2} q_{3}
\end{array}\right]=\left[\begin{array}{llll}
\cos \frac{\theta}{2} & -r_{x} \sin \frac{\theta}{2} & -r_{y} \sin \frac{\theta}{2} & -r_{z} \sin \frac{\theta}{2}
\end{array}\right]
$$

O quatérnio conjugado ${ }_{M}^{F} \widehat{\boldsymbol{q}}^{*}$ faz o processo inverso, descrevendo o sistema $\mathrm{F}$ em relação a $M$, sendo definido por equação (12).

$$
{ }_{M}^{F} \widehat{\boldsymbol{q}}^{*}={ }_{F}^{M} \widehat{\boldsymbol{q}}=\left[\begin{array}{llll}
q_{0} & -q_{1} & -q_{2} & -q_{3}
\end{array}\right]
$$

O produto de dois quatérnios da forma ${ }_{M}^{F} \widehat{\boldsymbol{q}}$ representa a composição das orientações,

denotado por $\otimes$, assim ${ }_{C}^{A} \widehat{\boldsymbol{q}}={ }_{C}^{B} \widehat{\boldsymbol{q}} \otimes{ }_{B}^{A} \widehat{\boldsymbol{q}}$. O Produto $\otimes$ é determinado pela regra de Hamilton e é não comutativo.

$$
a \otimes b=\left[\begin{array}{llll}
a_{1} & a_{2} & a_{3} & a_{4}
\end{array}\right] \otimes\left[\begin{array}{llll}
b_{1} & b_{2} & b_{3} & b_{4}
\end{array}\right]=\left[\begin{array}{l}
a_{1} b_{1}-a_{2} b_{2}-a_{3} b_{3}-a_{4} b_{4} \\
a_{1} b_{2}+a_{2} b_{1}+a_{3} b_{4}-a_{4} b_{3} \\
a_{1} b_{3}-a_{2} b_{4}+a_{3} b_{1}+a_{4} b_{2} \\
a_{1} b_{4}+a_{2} b_{3}-a_{3} b_{2}+a_{4} b_{1}
\end{array}\right]^{T}
$$

Um vetor tridimensional ${ }^{F} v^{\prime}$, no sistema de coordenadas $F$, pode ser obtido no sistema de coordenadas $\mathrm{M}$ usando a relação ${ }^{M} v={ }_{M}^{F} \widehat{\boldsymbol{q}} \otimes{ }^{F} v \otimes{ }_{M}^{F} \widehat{\boldsymbol{q}}^{*}$, sendo adicionado um elemento de valor 0 como primeiro elemento do vetor para efetuar as operações com 4 elementos; ${ }^{F} v=\left[\begin{array}{c}0 \\ F\end{array} v^{\prime}\right]$.

Assim essa rotação pode ser descrita por uma matriz de rotação, como demonstrado em (14). (Inoue, 2011)

$$
{ }^{M} v={ }_{M}^{F} \widehat{\boldsymbol{q}} \otimes{ }^{F} v \otimes{ }_{M} \widehat{\boldsymbol{q}}^{*}=\left[\begin{array}{lll}
2\left(q_{0}^{2}+q_{1}^{2}\right)-1 & 2\left(q_{1} q_{2}+q_{0} q_{3}\right) & 2\left(q_{1} q_{3}-q_{0} q_{2}\right) \\
2\left(q_{1} q_{2}-q_{0} q_{3}\right) & 2\left(q_{0}^{2}+q_{2}^{2}\right)-1 & 2\left(q_{2} q_{3}+q_{0} q_{1}\right) \\
2\left(q_{1} q_{3}+q_{0} q_{2}\right) & 2\left(q_{2} q_{3}-q_{0} q_{1}\right) & 2\left(q_{0}^{2}+q_{3}^{2}\right)-1
\end{array}\right]{ }^{F} \boldsymbol{v}^{\prime}
$$


A atualização do quatérnio conforme o movimento do objeto pode ser feita por meio das medidas das velocidades angulares nos três eixos, assim como nos métodos $D C M$ e Euler, por meio do vetor ${ }^{s} \omega=\left[\begin{array}{llll}0 & \omega_{x} & \omega_{y} & \omega_{z}\end{array}\right]$ com $\omega_{x}, \omega_{y}$ e $\omega_{z}$ as velocidades angulares e então aplicando a integração de (15).

$$
{ }_{F}^{M} \dot{q}=\frac{1}{2}{ }_{F}^{M} \hat{q} \otimes S_{\omega}
$$

Para o caso discreto no tempo t, é aplicado procedimento de (16), com ${ }^{s} \omega_{t}$ o vetor de velocidade angular no instante $\mathrm{t}, \Delta t$ o período de amostragem e ${ }_{F}^{M} \hat{q}_{e s t, t-1}$ o quatérnio obtido anteriormente.

$$
\begin{aligned}
& { }_{F}^{M} \dot{q}_{\omega, t}=\frac{1}{2}{ }_{F}^{M} \hat{q}_{e s t, t-1} \otimes s \omega_{t} \\
& { }_{F}^{M} q_{\omega, t}={ }_{F}^{M} \hat{q}_{e s t, t-1}+{ }_{F}^{M} \dot{q}_{\omega, t} \Delta t
\end{aligned}
$$

Os ângulos de Euler podem ser obtidos por meio de (17).

$$
\begin{gathered}
\theta=-\sin ^{-1}\left(2 q_{1} q_{3}-2 q_{0} q_{2}\right) \\
\phi=\tan ^{-1}\left(\frac{2 q_{2} q_{3}+2 q_{0} q_{1}}{2 q_{0}^{2}+2 q_{3}^{2}-1}\right) \\
\psi=\tan ^{-1}\left(\frac{2 q_{1} q_{2}+2 q_{0} q_{3}}{2 q_{0}^{2}+2 q_{1}^{2}-1}\right)
\end{gathered}
$$

\subsection{Filtragem}

O Filtro de Kalman, desenvolvido em 1960 por R. E. Kalman, trata de uma solução recursiva para filtragem linear de dados discretos, utilizando equações matemáticas para estimar o estado de um processo de modo a minimizar do erro quadrático médio. (Welch and Bishop, 2006)

Trata-se de um algoritmo recursivo ótimo de processamento de dados, que incorpora todas as informações disponíveis, processando todas as entradas independentemente da precisão das medidas a fim de estimar as variáveis desejadas, usando o conhecimento da dinâmica do processo e das medidas, da descrição estatística dos ruídos, erros de medidas e incertezas dos modelos dinâmicos e também de qualquer informação sobre as condições iniciais. (Maybeck, 1979)

O resultado do filtro provém de ciclos consecutivos de predição e atualização sendo que os passos são baseados em funções de densidade de probabilidade gaussianas. Porém se a dinâmica dos estados do sistema ou do observador não for linear, as funções de densidade de probabilidade que estimam o mínimo quadrado deixam de ser gaussianas e o filtro não-linear ótimo exigiria demasiado esforço computacional. 
Uma abordagem não ótima para resolver o problema usando a simplicidade do filtro linear é apresentada pelo filtro de Kalman estendido, FKE, que aplica o filtro de Kalman utilizando uma linearização da dinâmica original do sistema ao redor do estado previsto. (Ribeiro, 2004)

\subsubsection{Filtro de Kalman Discreto}

O filtro de Kalman discreto é utilizado para estimar o estado $x \in \mathbb{R}^{n}$ que obedece a equação linear estocástica (18).

$$
x_{k}=A x_{k-1}+B u_{k-1}+w_{k-1}
$$

Com uma medição $z \in \mathbb{R}^{\mathrm{m}}$ obedecendo (19)

$$
z_{k}=H x_{k}+v_{k}
$$

$w_{k}$ representa a perturbação no processo e $v_{k}$ os ruídos na medida, sendo ambos considerados ruídos brancos, independentes e com distribuição normal.

$$
\begin{aligned}
& p(w) \sim N(0, Q) \\
& p(v) \sim N(0, R)
\end{aligned}
$$

Com $Q$ a matriz de covariância do ruído do processo e $R$ a matriz de covariância do ruído da medida. A matriz $A$ relaciona o estado no tempo anterior com o estado atual, o vetor $B$ relaciona a entrada de controle $u$ com o estado atual e a matriz $H$ relaciona o estado atual com a medida $z$.

O algoritmo segue da aplicação de (21)

$$
\begin{gathered}
\hat{x}_{k}^{-}=A \hat{x}_{k-1}+B u_{k-1} \\
P_{k}^{-}=A P_{k-1} A^{T}+Q \\
K_{k}=P_{k}^{-} H^{T}\left(H P_{k}^{-} H^{T}+R\right)^{-1} \\
\hat{x}_{k}=\hat{x}_{k}^{-}+K_{k}\left(z_{k}-H \hat{x}_{k}^{-}\right) \\
P_{k}=\left(I-K_{k} H\right) P_{k}^{-}
\end{gathered}
$$

Nestas equações $\hat{x}_{k}^{-}$é a estimativa a priori com $P_{k}^{-}$a matriz de covariância a priori, então estes são recalculados com base no ganho de Kalman, $K_{k}$, levando em consideração o quanto essas estimativas divergem do modelo de observação, obtendo $\hat{x}_{k}$ e $P_{k}$ (Grewal and Andrews, 2001).

\subsubsection{Filtro de Kalman Estendido}

No caso do filtro de Kalman estendido o processo obedece a uma equação estocástica não linear (22). 


$$
x_{k}=f\left(x_{k-1}, u_{k-1}, w_{k-1}\right)
$$

Com uma medição $z \in \mathbb{R}^{m}$ obedecendo a equação (23).

$$
z_{k}=h\left(x_{k}, v_{k}\right)
$$

Novamente $w_{k}$ representa a perturbação no processo e $v_{k}$ os ruídos na medida, tidos como ruídos brancos, independentes e com distribuição normal e media zero. Assim, no desenvolvimento o equacionamento eles podem ser assumidos como nulos.

$$
\begin{gathered}
\tilde{x}_{k}=f\left(\hat{x}_{k-1}, u_{k-1}, 0\right) \\
\tilde{z}_{k}=h\left(\tilde{x}_{k}, 0\right)
\end{gathered}
$$

Então é adotada a linearização de (25).

$$
\begin{gathered}
x_{k} \approx \tilde{x}_{k}+A\left(x_{k-1}-\hat{x}_{k-1}\right)+W w_{k-1} \\
z_{k} \approx \tilde{z}_{k}+H\left(x_{k}-\tilde{x}_{k}\right)+V v_{k}
\end{gathered}
$$

Com $A$ a jacobiana de derivadas parciais de $f$ em relação a $x, W$ a jacobiana de derivadas parciais de $f$ em relação a $w, H$ a jacobiana de derivadas parciais de $h$ em relação a $x$ e $V$ a jacobiana de derivadas parciais de $h$ em relação a $v$.

O algoritmo segue da aplicação de (26).

$$
\begin{gathered}
\hat{x}_{k}^{-}=f\left(\hat{x}_{k-1}, u_{k-1}, 0\right) \\
P_{k}^{-}=A_{k} P_{k-1} A_{k}^{T}+W_{k} Q_{k-1} W_{k}^{T} \\
K_{k}=P_{k}^{-} H_{k}^{T}\left(H_{k} P_{k}^{-} H_{k}^{T}+V_{k} R_{k} V_{k}^{T}\right)^{-1} \\
\hat{x}_{k}=\hat{x}_{k}^{-}+K_{k}\left(z_{k}-h\left(\hat{x}_{k}^{-}, 0\right)\right) \\
P_{k}=\left(I-K_{k} H_{k}\right) P_{k}^{-}
\end{gathered}
$$

\subsection{Sensoriamento de Orientação}

O sensoriamento de orientação consiste em definir através dos sensores embarcados, para qual direção no espaço o corpo está apontando. No caso de navegação, é comumente definido o sistema de coordenadas NED, North East Down, fixo ao ambiente com o eixo x apontando para o norte, y para o leste e $z$ para baixo, em relação ao qual são calculados os ângulos de rotação que levam ao sistema de coordenadas dinâmico, fixado ao corpo.

Em se tratando de sensores de baixo desempenho, como os MEMS utilizados no projeto, apenas a integração das medidas de velocidade angular, como apresentado na seção 3.3, levaria 
rapidamente ao acúmulo de erros e consequentemente à estimativa errônea de orientação, assim se faz necessário aplicar técnicas para aprimorar a precisão da medida final.

\subsubsection{Método de Obtenção da Medida}

A obtenção de uma medida de orientação aprimorada pode se dar por meio da fusão dos dados obtidos pelos sensores de aceleração, velocidade angular e campo magnético da terra, utilizando técnicas de filtragem, com diferentes formas de representação espacial.

Uma técnica amplamente utilizada consiste da obtenção do vetor gravidade através dos acelerômetros, seguido da ponderação entre a variação angular dada pelo vetor gravidade e as medidas dos giroscópios, chamado de filtro complementar, obtendo assim os ângulos $\phi$ e $\theta$; então esses ângulos, juntamente com as medidas obtidas pelos magnetômetros, são utilizados para calcular o ângulo $\Psi$ (Caruso, 2000). Esta técnica porém apresenta singularidade para a inclinação máxima em $\phi$ ou $\theta$.

Para evitar o problema da singularidade, recorre-se ao uso das representações de orientação via quatérnios ou diretamente pela DCM, envolvendo assim a modelagem do sistema de sensoriamento para a descrição da planta do sistema e então aplicar técnicas de filtragem mais avançadas, com a fusão dos dados dos sensores.

Existem diversos métodos de fusão dos dados obtidos pelos sensores através de filtragem, com filtro de Kalman (Phuong et al., 2009), filtro de Kalman estendido (Goyal et al., 2011)(Yongliang et al., 2008), unscented Kalman Filter (Marina et al., 2011), ou outros métodos incluindo gradient descent algorithm (Madgwick, Harrison and Vaidyanathan, 2011) e sliding mode observer (Hadri and Benallegue, 2009).

Em (Sabatini, 2006) é desenvolvido um sistema de determinação de orientação baseado em sensores inerciais e magnético, aplicando filtro de Kalman estendido e a representação por quatérnios. $O$ vetor de estado do filtro é composto pelos elementos do quatérnio acrescentado dos desvios estimados do acelerômetro e magnetômetro. As medidas dos giroscópios $(\vec{\omega})$ fazem parte da matriz de atualização do sistema.

São usados como observador as medidas obtidas pelo acelerômetro $(\vec{a})$ e pelo magnetômetro $(\vec{m})$, sendo que estas medidas passam por um teste de validação para evitar erros grosseiros.

Os modelos dos sensores, adotados para a construção do sistema são mostrados por (27).

$$
\left\{\begin{array}{c}
\vec{\omega}={ }^{g} K \vec{\omega}_{\text {true }}+{ }^{g} \vec{b}+{ }^{g} \vec{v} \\
\vec{a}={ }^{g} K\left[C_{n}^{b}(q)\left(\vec{g}+\vec{a}_{\text {body }}\right)\right]+{ }^{a} \vec{b}+{ }^{a} \vec{v} \\
\vec{m}={ }^{m} K C_{n}^{b}(q) \vec{h}+{ }^{m} \vec{b}+{ }^{m} \vec{v}
\end{array}\right.
$$


Com ${ }^{g} K,{ }^{g} K$ e ${ }^{m} K$ fatores de escala das matrizes, idealmente iguais à matriz identidade $I$; ${ }^{g} \vec{b},{ }^{a} \vec{b}$ e ${ }^{m} \vec{b}$ os vetores de desvio, idealmente nulos; ${ }^{g} \vec{v},{ }^{a} \vec{v}$ e ${ }^{m} \vec{v}$ os ruídos, assumidos como ruído branco gaussiano, não correlacionados, com media zero e matrizes de covariância $\sum_{g}=\sigma_{g}^{2} I$, $\sum_{a}=\sigma_{a}^{2} I$ e $\sum_{m}=\sigma_{m}^{2} I . \vec{\omega}_{\text {true }}$ são as velocidades angulares reais, $\vec{g}$ o vetor gravidade, $\vec{a}_{b o d y}$ as demais acelerações sofridas pelo corpo, $\vec{h}$ o vetor do campo magnético real e $C_{n}^{b}$ a matriz de rotação, DCM, entre o sistema móvel e o fixo.

Os quatérnios usados em navegação são unitários, e a natureza ruidosa das medidas pode levar à perda desta característica, assim o quatérnio atualizado deve passar por um processo de normalização.

Em (Edwan et al., 2011) é desenvolvido um sistema de determinação de orientação com sensores inerciais de baixo custo, utilizando o filtro de Kalman estendido, com a representação por DCM. Nesse equacionamento, são utilizados nove parâmetros para representar os três parâmetros independentes, os ângulos de rotação, de forma que há redundância de informação entre os elementos da DCM, assim podem ser reduzidos os elementos a serem computados para seis, a fim de minimizar o esforço computacional.

O vetor de estados é composto dos seis elementos da DCM, aumentado de três elementos de desvio do giroscópio. As medidas do giroscópio fazem parte da matriz de atualização do sistema. O observador utilizado leva em conta as medidas do acelerômetro e do magnetômetro. Os modelos dos sensores usados para a construção do sistema são mostrados em (28).

$$
\begin{gathered}
\tilde{\sigma}=\omega_{i b}^{b} \Delta t+b_{g} \Delta t+w_{g} \sqrt{\Delta t} \\
a^{b}=C_{n}^{b} g^{n}+v_{a} \\
h_{m}^{b}=C_{n}^{b} h_{m}^{n}+v_{m}
\end{gathered}
$$

Nos quais $\tilde{\sigma}$ representa o vetor de velocidade angular, $\omega_{i b}^{b}$ a medida de velocidade angular obtida pelo giroscópio, $b_{g}$ o desvio da medida do giroscópio, $w_{g}$ o ruído branco gaussiano da medida do giroscópio, $a^{b}$ a aceleração medida no corpo, $g^{n}$ o vetor gravidade, $h_{m}^{b}$ o campo magnético medido no corpo, $h_{m}^{n}$ o campo magnético real da terra, $v_{a}$ e $v_{m}$ ruídos brancos gaussianos das medidas do acelerômetro e do magnetômetro. $C_{n}^{b}$ é a DCM que relaciona o sistema de coordenadas do corpo com o sistema fixo. Com $\Delta t$ o intervalo de tempo entre as medidas.

Para este caso, o modelo de aceleração não leva em conta as acelerações sofridas pelo corpo além da gravidade durante o movimento e o autor sugere que a magnitude das medidas deve ser comparada com a magnitude da gravidade, e sendo muito discrepante deve ser aumentada a variância desta medida a ser usada no filtro, assim o autor diz que a variância é tida como dinâmica.

O mesmo se aplica à medida do campo magnético, caso o valor medido seja muito discrepante do valor real, a variância desta medida é aumentada. 
Como a DCM é uma matriz ortogonal e a natureza ruidosa das medidas pode levar à perda desta característica, a matriz atualizada com os novos valores obtidos do filtro deve passar por um processo de ortogonalização.

Em (Phuong et al., 2009) é feito um estudo comparativo da aplicação dos modelos por ângulo de Euler, DCM e quatérnios, descrevendo de forma extensa o método com DCM e sucintamente os outros dois. Os resultados mostram que o método DCM é um pouco mais lento computacionalmente, mas chega a apresentar metade do erro que o método por ângulos de Euler diretamente, além de não apresentar singularidades. Comparando DCM com quatérnios, o esforço computacional é semelhante, com o erro apresentado pelo método DCM ligeiramente menor.

No caso da DCM são aplicados dois filtros consecutivos: no primeiro a DCM é atualizada em termos do giroscópio e acelerômetro e então; no segundo filtro, a DCM é atualizada em termos do giroscópio e do magnetômetro. Novamente a DCM deve passar por um processo de ortogonalização após as atualizações do processo de filtragem.

Em (Sabatini, 2006) é mostrado que através do filtro de Kalman, o valor RMS do erro na

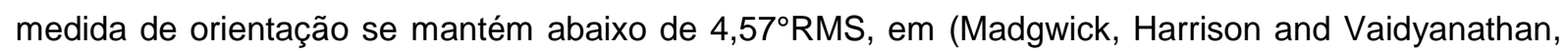
2011) o erro de orientação calculado através do filtro de Kalman, no sistema proprietário fornecido com a IMU, foi de $1,344^{\circ} \mathrm{RMS}$. Em (Phuong et al., 2009) é mostrado que o erro absoluto se mantém abaixo de $0,5^{\circ}$ em uma amostra de 10 segundos.

\subsection{Conclusão}

A bibliografia analisada envolvendo o desenvolvimento de um sistema de sensoriamento de orientação mostra que é possível elaborar, a partir de sensores de baixo custo, um sistema suficientemente preciso para a aplicação em um veículo autônomo; as técnicas de filtragem aplicando o filtro de Kalman, juntamente com a devida representação espacial do corpo, permitem a obtenção de uma estimativa de orientação com pouco ruído, permitindo sua aplicação para navegação. 


\section{Capítulo 4}

\section{Sistema Desenvolvido}

O sistema para filtragem foi desenvolvido aplicando a representação da orientação via quatérnios e o filtro estendido de Kalman, fazendo a integração das medidas de todos os sensores em um único passo, a escolha dos quatérnios sobre o método DCM se deu pela redução nas dimensões dos vetores e matrizes que serão computados pelo computador embarcada, visando minimizar o esforço computacional, sem o comprometimento da qualidade da estimativa.

O filtro foi desenvolvido inicialmente com o software MATLAB® pela facilidade de implementação e a possibilidade de analises gráficas dos resultados. Posteriormente o filtro foi programado em linguagem C, com auxilio da biblioteca GNU GSL para os cálculos envolvendo geometria analítica e matrizes, para ser executado diretamente no computador embarcado no veículo.

\subsection{Desenvolvimento do filtro}

O sistema desenvolvido é baseado no filtro proposto por Sabatini (2012). O processo de filtragem faz a atualização do quatérnio que representa a orientação do veículo, assim a cada passo as medidas de todos os sensores são utilizadas, fazendo a atualização em um único passo, e não com a aplicação de etapas sucessivas, como em (Caruso, 2000) e (Phuong et al., 2009).

O filtro é construído baseado no modelo dos sensores mostrado em (29). São considerados dois sistemas de coordenadas, sendo um fixo ao ambiente, $F$, e um ao veículo, $M$, utilizando quatérnios para descrever a relação entre eles.

$$
\left\{\begin{array}{c}
\overrightarrow{\boldsymbol{\omega}}=\vec{\omega}_{\text {real }}+{ }^{g} \vec{v} \\
\overrightarrow{\boldsymbol{a}}=C_{F}^{M}(q) \vec{g}+{ }^{a} \vec{v} \\
\overrightarrow{\boldsymbol{m}}=C_{F}^{M}(q) \vec{h}+{ }^{m} \vec{v}
\end{array}\right.
$$


Sendo:

- $\overrightarrow{\boldsymbol{\omega}}, \overrightarrow{\boldsymbol{a}}$ e $\overrightarrow{\boldsymbol{m}}$ as medidas do giroscópio, acelerômetro e magnetômetro, respectivamente;

- ${ }^{g} \vec{v},{ }^{a} \vec{v}$ e ${ }^{m} \vec{v}$ os ruídos das medidas, assumidos como ruído gaussiano branco, não correlacionados, com media zero e matrizes de covariância $\sum_{g}=\sigma_{g}^{2} I, \sum_{a}=\sigma_{a}^{2} I$ e $\sum_{m}=\sigma_{m}^{2} I$.

- $\vec{\omega}_{\text {real }}$ as velocidades angulares reais

- $\vec{g}$ o vetor gravidade

- $\vec{h}$ o vetor do campo magnético real

- $C_{F}^{M}$ a matriz de rotação, DCM, entre o sistema móvel e o fixo.

No modelo para a aceleração, considerando-se que para o veículo no qual será aplicado o sistema desenvolvido a velocidade é baixa e, pelo deslocamento se dar na superfície da água, não existirão acelerações bruscas, foram desconsideraras as demais acelerações além da gravidade sofridas pelo veículo.

O procedimento de filtragem é dado pelas etapas de predição e atualização, sendo que a etapa preditora faz uso das medidas de velocidade angular para obter o estado predito, enquanto que a atualização faz uso das medidas de aceleração e campo magnético, obtendo assim a estimativa filtrada.

Desta forma, para a etapa preditora é analisado o efeito do movimento angular do veículo sobre o quatérnio, descrito por (30).

$$
\begin{gathered}
\frac{d}{d t} q=\Omega(\overrightarrow{\boldsymbol{\omega}}) q \\
\Omega(\overrightarrow{\boldsymbol{\omega}})=\frac{1}{2}\left[\begin{array}{cc}
0 & -\overrightarrow{\boldsymbol{\omega}}^{T} \\
\overrightarrow{\boldsymbol{\omega}} & {[\overrightarrow{\boldsymbol{\omega}} \times]}
\end{array}\right] \quad[\overrightarrow{\boldsymbol{\omega}} \times]=\left[\begin{array}{ccc}
0 & -\omega_{z} & \omega_{y} \\
\omega_{z} & 0 & -\omega_{x} \\
-\omega_{y} & \omega_{x} & 0
\end{array}\right]
\end{gathered}
$$

Sendo o vetor $\overrightarrow{\boldsymbol{\omega}}(t)$ composto pela velocidade angular do corpo no sistema de coordenadas móvel no instante $t ; \overrightarrow{\boldsymbol{\omega}}=\left[\omega_{x} \omega_{y} \omega_{z}\right]^{T}$. Assim o novo estado é obtido pela integração temporal de (30) que é obtida, para o modelo em tempo discreto, pela expansão em série de Taylor, com intervalo de amostragem $T_{s}$, mostrado em (31).

$$
F=\exp \left(\Omega(\overrightarrow{\boldsymbol{\omega}}) T_{s}\right) \cong I+\Omega(\overrightarrow{\boldsymbol{\omega}}) T_{s}+\frac{\left(\Omega(\overrightarrow{\boldsymbol{\omega}}) T_{S}\right)^{2}}{2 !}+\cdots
$$

Para a aplicação desta expansão no sistema, considerando $T_{s}$ suficientemente pequeno para que a velocidade angular durante este intervalo possa ser considerada constante, é possível truncar a série no primeiro termo, $\left(I+\Omega(\overrightarrow{\boldsymbol{\omega}}) T_{s}\right)$ com um erro de discretização muito pequeno introduzido por essa simplificação.

Assim o filtro é construído com o vetor de estados contendo os elementos do quatérnio e a matriz de mudança de estado é obtida com as medidas de velocidade angular, de forma a atualizar a orientação, (32). 


$$
\vec{x}_{k+1}^{-}=\left[\begin{array}{c}
q_{0} \\
q_{1} \\
q_{2} \\
q_{3}
\end{array}\right]=F\left(\overrightarrow{\boldsymbol{\omega}}_{k}, T_{s}\right) \vec{x}_{k}+\vec{v}_{k}
$$

Sendo que $\vec{v}$ se refere ao ruído do processo, neste caso introduzido pelo ruído da medida do giroscópio, ${ }^{g} \vec{v}$, inserido no modelo de estados por uma transformação dependente do quatérnio, (33).

$$
\vec{v}_{k}=-\frac{T_{s}}{2} \boldsymbol{\Xi}_{k}{ }^{g} \vec{v}_{k} \quad \Xi_{k}=\left[\begin{array}{c}
-\overrightarrow{\boldsymbol{q}}_{k}^{T} \\
{\left[\overrightarrow{\boldsymbol{q}}_{k} \times\right]+q_{0 k} I}
\end{array}\right]
$$

- $q_{0 k}$ a parte escalar do quatérnio no instante $\mathrm{k}$.

- $\quad \overrightarrow{\boldsymbol{q}}_{k}$ a parte vetorial do quatérnio no instante $\mathrm{k}, \overrightarrow{\boldsymbol{q}}_{k}=\left[\begin{array}{lll}q_{1 k} & q_{2 k} & q_{3 k}\end{array}\right]$.

- I a matriz identidade.

A matriz de covariância do ruído do processo, $Q_{k}$, também depende desta transformação para relacionar o ruído da medida com o modelo de estado e é descrita em (34).

$$
Q_{k}=\left(\frac{T_{s}}{2}\right)^{2} \Xi_{k} \Sigma_{g} \boldsymbol{\Xi}_{k}^{T}
$$

Para a etapa de atualização da filtragem, o observador é elaborado de forma que os vetores gravidade e campo magnético reais conhecidos, rotacionados para o sistema de coordenadas móvel, possam ser comparados com as medidas de aceleração e campo magnético obtidas pelos sensores. A rotação entre os sistemas é obtida por meio dos elementos do quatérnio predito.

Assim o modelo de observação, obtido a partir do modelo proposto dos sensores, é demonstrado em (35).

$$
\vec{z}_{k+1}=\left[\begin{array}{l}
\overrightarrow{\boldsymbol{a}} \\
\overrightarrow{\boldsymbol{m}}
\end{array}\right]=h\left(\vec{x}_{k+1}\right)+\vec{v}_{k+1}=\left[\begin{array}{cc}
C_{F}^{M}\left(q_{k+1}\right) & \mathbf{0} \\
\mathbf{0} & C_{F}^{M}\left(q_{k+1}\right)
\end{array}\right]\left[\begin{array}{l}
\overrightarrow{\boldsymbol{g}} \\
\overrightarrow{\boldsymbol{h}}
\end{array}\right]+\left[\begin{array}{c}
{ }^{a} \vec{v}_{k+1} \\
{ }^{m} \vec{v}_{k+1}
\end{array}\right]
$$

Com matriz de covariância $R_{k+1}$.

$$
R_{k+1}=\left[\begin{array}{cc}
\Sigma_{a} & \mathbf{0} \\
\mathbf{0} & \Sigma_{m}
\end{array}\right]
$$

Como o modelo de observação é não linear, utiliza-se a Matriz Jacobiana da função, $H_{k+1}$, para a aplicação do filtro de Kalman estendido. A função $H_{k+1}$ é apresentada em (37).

$$
\begin{gathered}
H_{k+1}=\left.\frac{\partial}{\partial \vec{x}_{k+1}} \vec{z}_{k+1}\right|_{\vec{x}_{k+1}=\vec{x}_{k+1}^{-}} \\
H_{k+1}=\left[\begin{array}{c}
\frac{\partial}{\partial q_{k+1}^{-}} C_{F}^{M}\left(q_{k+1}^{-}\right) \overrightarrow{\boldsymbol{g}} \\
\frac{\partial}{\partial q_{k+1}^{-}} C_{F}^{M}\left(q_{k+1}^{-}\right) \overrightarrow{\boldsymbol{h}}
\end{array}\right]
\end{gathered}
$$


A DCM $C_{F}^{M}$ pode ser descrita em termos do quatérnio que a origina como demonstrado em (38), assim a derivada $\frac{\partial}{\partial q} C_{F}^{M}(q) \overrightarrow{\boldsymbol{g}}$ pode ser descrita como em (39) (Sabatini, 2011), seguindo o mesmo equacionamento para a derivada $\frac{\partial}{\partial q} C_{F}^{M}(q) \overrightarrow{\boldsymbol{h}}$.

$$
\begin{gathered}
C_{F}^{M}(q)=\boldsymbol{I}_{3}-2 q_{0}[\overrightarrow{\boldsymbol{q}} \times]+2[\overrightarrow{\boldsymbol{q}} \times]^{2} \\
\frac{\partial}{\partial q} C_{F}^{M}(q) \overrightarrow{\boldsymbol{g}}=\left[-2[\overrightarrow{\boldsymbol{q}} \times] \overrightarrow{\boldsymbol{g}} \quad 2 q_{0}[\overrightarrow{\boldsymbol{g}} \times]+2([\overrightarrow{\boldsymbol{g}} \times][\overrightarrow{\boldsymbol{q}} \times]-2[\overrightarrow{\boldsymbol{q}} \times][\overrightarrow{\boldsymbol{g}} \times])\right]
\end{gathered}
$$

O algoritmo do filtro segue da aplicação dos passos descritos do FKE na Seção 3.4.2, com os modelos obtidos para o problema, mostrado em (40)

$$
\begin{gathered}
F_{k}=I+\Omega\left(\overrightarrow{\boldsymbol{\omega}}_{\mathrm{k}}\right) T_{s} \\
\hat{x}_{k}^{-}=F_{k} \hat{x}_{k-1} \\
Q_{k}=\left(\frac{T_{s}}{2}\right)^{2} \boldsymbol{\Xi}_{k} \Sigma_{g} \boldsymbol{\Xi}_{k}^{T} \\
P_{k}^{-}=F_{k} P_{k-1} F_{k}^{T}+Q_{k-1} \\
H_{k}=\left[\begin{array}{l}
\frac{\partial}{\partial q_{k}^{-}} C_{F}^{M}\left(\hat{q}_{k}^{-}\right) \overrightarrow{\boldsymbol{g}} \\
\frac{\partial}{\partial q_{k}^{-}} C_{F}^{M}\left(\hat{q}_{k}^{-}\right) \overrightarrow{\boldsymbol{h}}
\end{array}\right] \\
K_{k}=P_{k}^{-} H_{k}^{T}\left(H_{k} P_{k}^{-} H_{k}^{T}+R_{k}\right)^{-1} \\
\hat{x}_{k}=\hat{x}_{k}^{-}+K_{k}\left(\left[\begin{array}{cc}
\overrightarrow{\boldsymbol{a}}_{\mathrm{k}} \\
\overrightarrow{\boldsymbol{m}}_{\mathrm{k}}
\end{array}\right]-\left[\begin{array}{cc}
C_{F}^{M}\left(q_{k}^{-}\right) & \mathbf{0} \\
\mathbf{0} & C_{F}^{M}\left(q_{k}^{-}\right)
\end{array}\right]\left[\begin{array}{l}
\overrightarrow{\boldsymbol{g}} \\
\overrightarrow{\boldsymbol{h}}
\end{array}\right]\right) \\
P_{k}=\left(I-K_{k} H_{k}\right) P_{k}^{-}
\end{gathered}
$$

Ao final de cada passo de filtragem o quatérnio é normalizado para garantir que este apresente norma unitária.

Os valores de desvio padrão do ruído dos sensores, $\sigma_{g}, \sigma_{a}$ e $\sigma_{m}$ e da matriz $P_{0}$ foram obtidos de forma interativa, minimizando o erro entre a estimativa filtrada e referências de orientação conhecidas, em um teste semelhante ao segundo experimento mostrado na seção 5.2.

\subsection{Considerações quanto à calibração dos sensores}

Para a obtenção de resultados coerentes, o processo de filtragem depende da calibração correta dos sensores, visto que estes apresentam desvios. As medidas fornecidas devem representar corretamente o estado real e serem coerentes com o resultado esperado, dado o modelo de observação implementado no filtro. 
Um dos principais problemas apresentados pelos sensores MEMS em geral é o offset. As medidas dos sensores que deveriam apresentar média zero têm este patamar deslocado.

Para o giroscópio, com o veículo em repouso, o offset de medida de velocidade angular implicaria na leitura de um movimento de rotação constante do veículo, o que não é coerente com a realidade. Este erro, porém, pode ser facilmente corrigido mantendo o sensor em repouso, nesta situação o valor apresentado é o offset em si. Assim, obtendo uma média de algumas amostras, basta subtrair este valor médio da medida.

Caso o acelerômetro apresente problema de offset, a inclinação medida do veículo é incoerente com a realidade. Mais uma vez, para a correção deste erro recorre-se ao repouso, garantindo-se que a única aceleração presente no sensor seja proveniente da gravidade. Alinhandose esta ao eixo $Z$ de medida do sensor, o valor esperado de medida é zero nos eixos $X$ e $Y$, e $1 \mathrm{~g}$ no eixo $Z$, portanto, basta adequar a medida para os valores esperados nesta situação. Na Figura 6 são mostrados dados reais obtidos do acelerômetro, sem e com calibração. É possível notar que a medida no eixo $Z$ possui um offset de aproximadamente $5 \mathrm{~g}\left(1 \mathrm{~g}=9,8 \mathrm{~m} / \mathrm{s}^{2}\right.$, a aceleração da gravidade).

\section{Figura 6 - Medidas obtidas do acelerômetro}

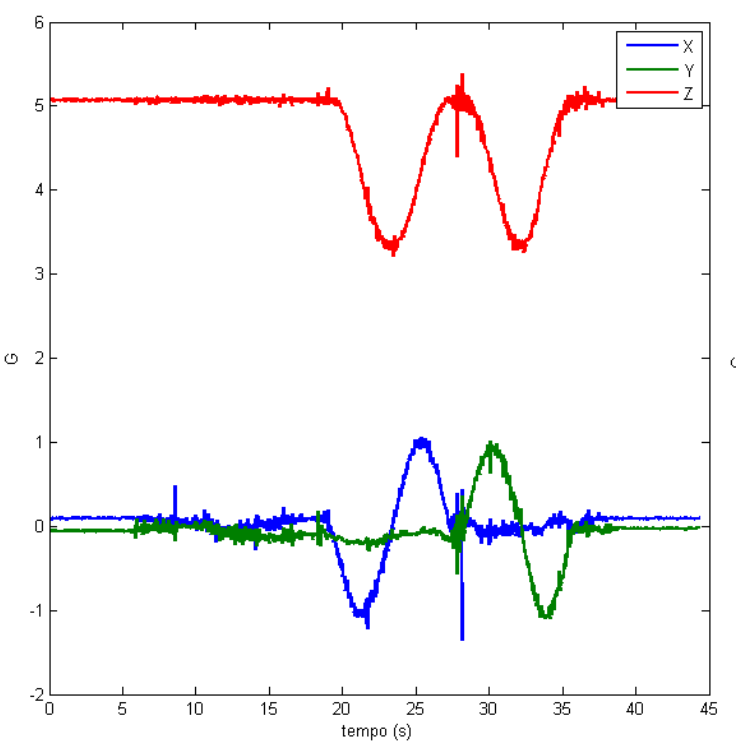

(a)

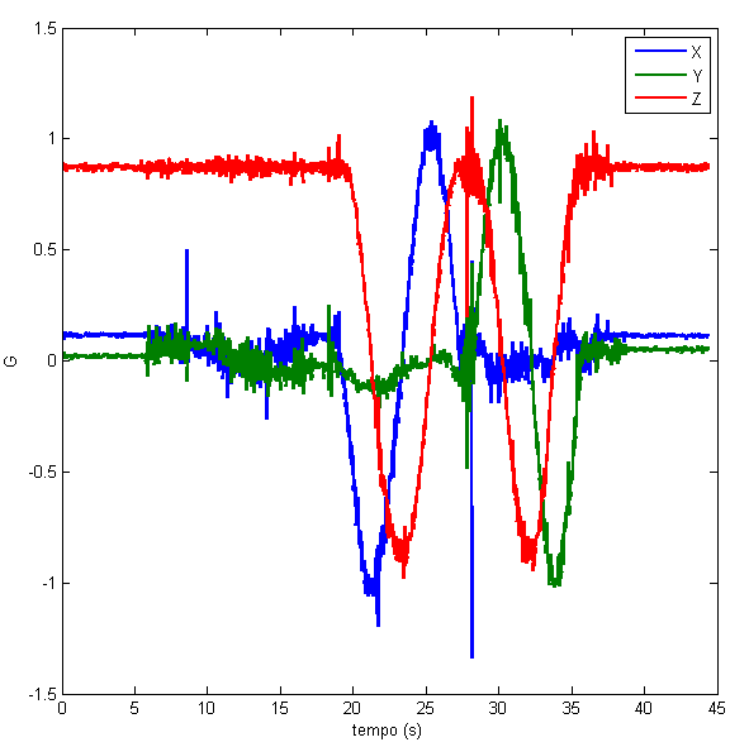

(b)

(a) sem correção do offset e (b) com correção do offset

Para o caso do magnetômetro, a medida com offset leva a distorções na estimação da direção para a qual aponta o veículo. A correção deste erro para o magnetômetro, no entanto, exige a amostragem da unidade em movimento, de forma que seja possível analisar os pontos de máximo e mínimo, para assim corrigir a média para zero. Na Figura 7 são mostrados os dados reais obtidos do magnetômetro, sem e com calibração 
Figura 7 - Medidas obtidas do magnetômetro

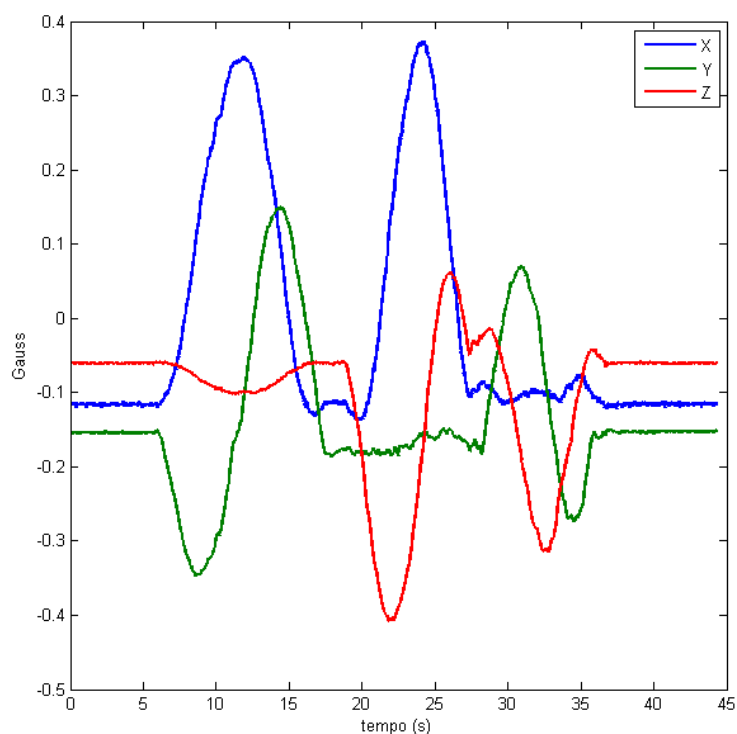

(a)

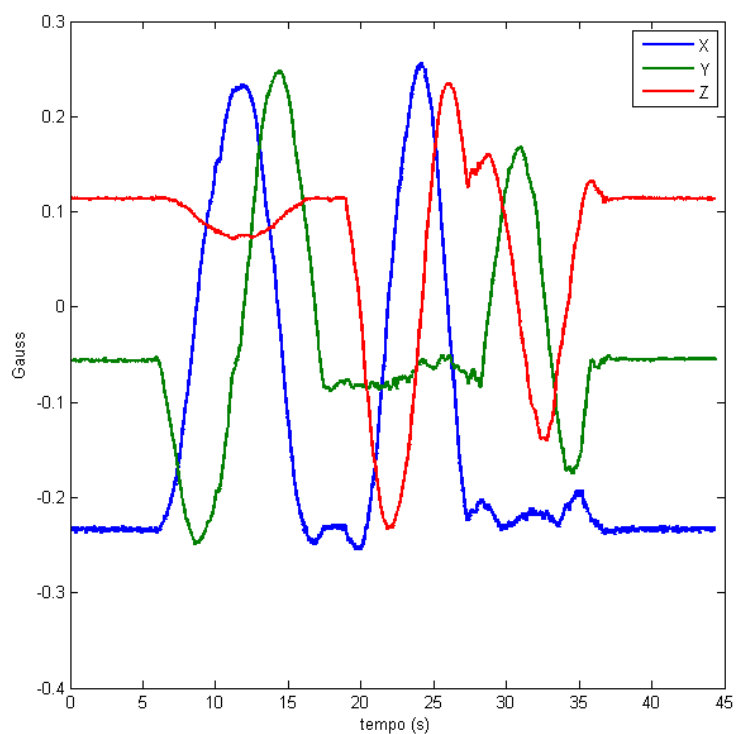

(b)

(a) sem correção do offset e (b) com correção do offset.

Outras técnicas mais avançadas analisam o perfil do elipsoide formado pela leitura dos três sensores, que deve idealmente representar uma esfera com centro em zero, e então corrigir esse elipsoide. Na Figura 8 é mostrado o elipsoide formado pelas medidas da Figura 7 (a) e sua vista superior.

O Magnetômetro pode também apresentar problemas nas medidas devido à presença de materiais ferromagnéticos ou de campos magnéticos próximos ao sensor. Estes não são problemas do sensor em sí, mas do campo a ser medido, porém devem ser corrigidos para o funcionamento adequado do filtro.

Campos magnéticos externos, que se movem junto ao sensor apenas geram offset, por exemplo motores na proximidade do sensor. Contudo, materiais ferromagnéticos podem distorcer 0 campo magnético da terra em intensidades diferentes para cada direção, gerando assim distorções que transformam a medida. Medida esta que deixa de estar contida em uma esfera (caso ideal) e passa a estar contida em um elipsoide e que, pode ainda ter seus eixos rotacionados em relação aos eixos do sistema de coordenadas solidário ao veículo (Renaudin, Afzal and Lachapelle, 2010). 
Figura 8 - Análise das medidas do magnetômetro

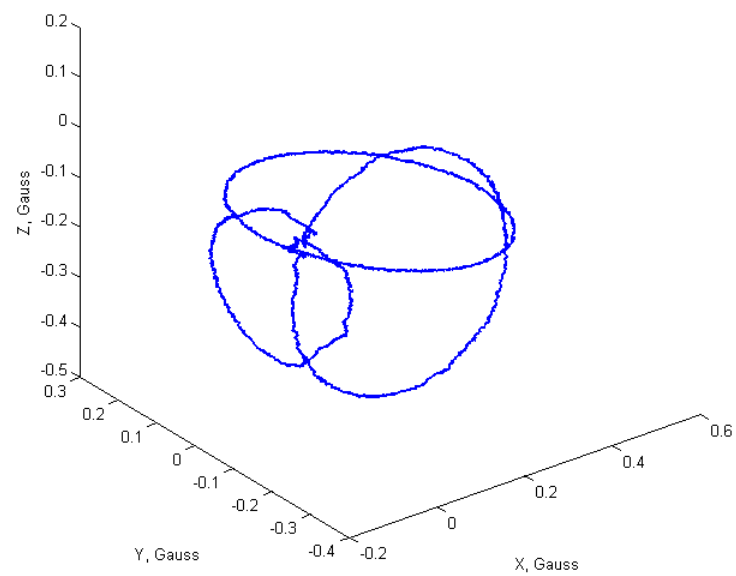

(a)

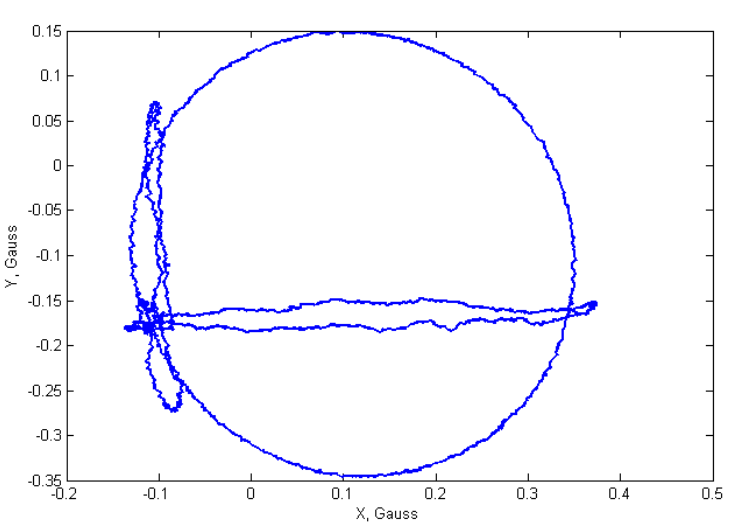

(b)

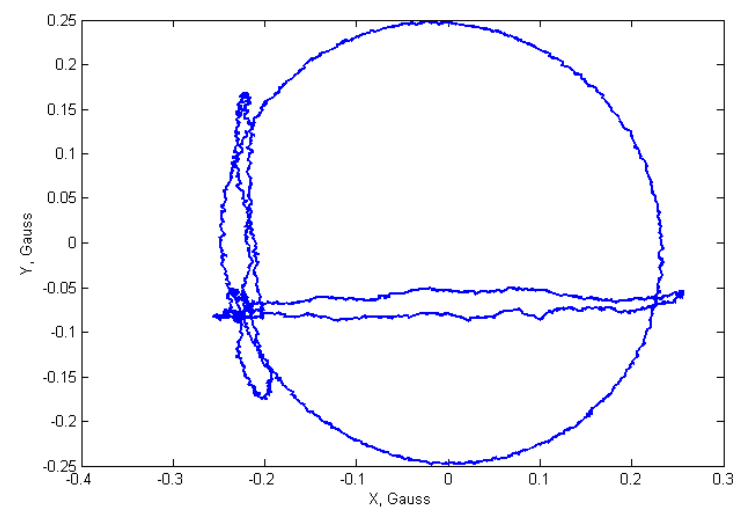

(c)

(a) Elipsoide formado pelas medidas do magnetômetro. (b) Vista superior do elipsoide.

(c) Vista superior após correção do offset.

Os magnetômetros de tecnologia MEMS sofrem também uma considerável variação na amplitude da medida conforme a variação da temperatura, assim este fator deve ser considerado para o ajuste da correção de offset ao longo do tempo. O sensor utilizado para o projeto possui uma função de auto-teste que mensura um campo, constante e conhecido, gerado internamente no sensor. Esta medida pode então ser comparada com a medida desse mesmo campo em outra condição de temperatura e ajustada para que se mantenha a amplitude desejada do sinal. Na Figura 9 é mostrada a curva de leitura em um eixo do campo gerado pela função de auto teste, com variação da temperatura ambiente. A medida de campo magnético apresenta uma variação de 0,2 Gauss para uma amplitude de $55^{\circ} \mathrm{C}$ de temperatura, para um campo aplicado de aproximadamente 1,1 Gauss. 
Figura 9 - Variação da amplitude na leitura do magnetômetro com mudança na temperatura ambiente.

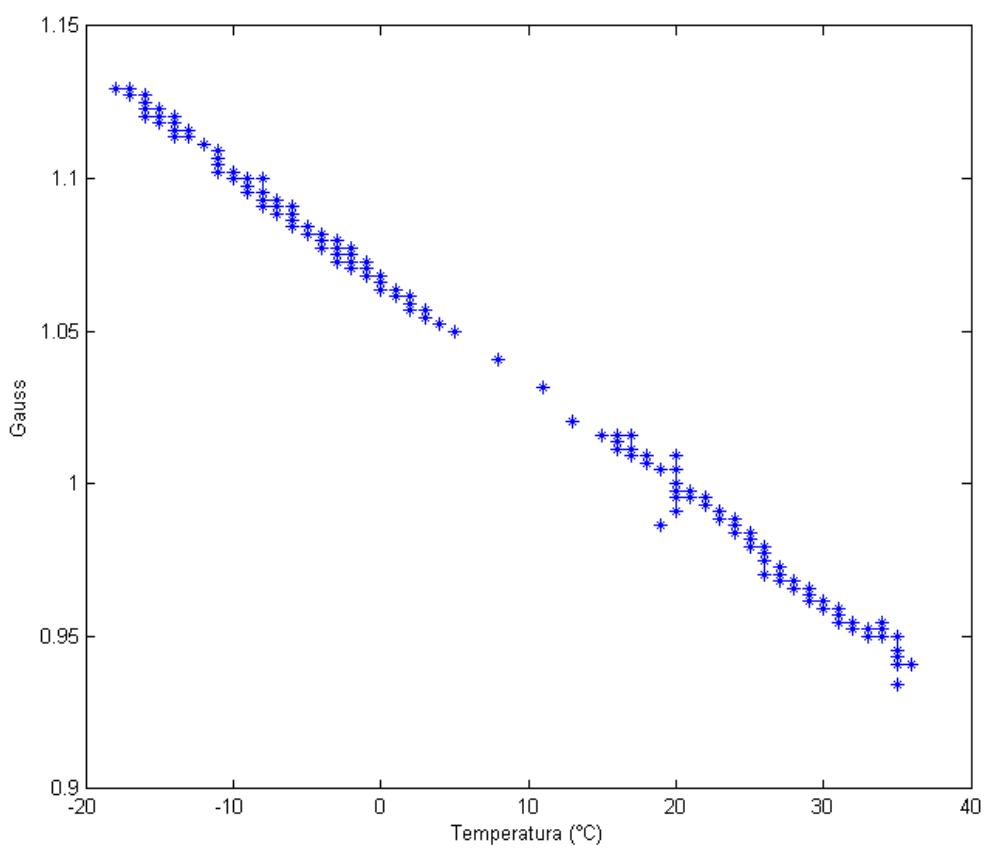




\section{Capítulo 5}

\section{Resultados}

\subsection{Metodologia dos Testes}

Para a verificação do funcionamento do algoritmo proposto são aplicadas duas fases: na fase inicial são realizados testes em bancada de forma offline, ou seja, com a analise das medidas após a coleta dos dados, nesta fase são verificados se os resultados são coerentes com a realidade e a capacidade do filtro de estimar a orientação mesmo com os sensores ruidosos; na segunda fase são realizados testes em campo, com o programa embarcado, realizando a análise das medidas em tempo de execução, de forma a fornecer a estimativa de orientação para ser utilizada pelo computador interno do veículo como referência para o controle de trajetória.

\subsection{Testes em bancada}

Para efeito de teste do filtro proposto, foram realizados dois procedimentos fundamentais com a unidade de medida: no primeiro são efetuados três giros completos, cada um ao redor de um eixo, de forma a testar o funcionamento em todas as direções; no segundo é realizado o giro ao redor do eixo $Z$ com pausas, a fim de se testar a acuracidade da medida no plano, visto que a aplicação a que se destina o sistema é a obtenção da orientação em um veículo aquático e este se movimenta apenas no plano da água, com pequenas ondulações.

Para cada teste são mostrados os ângulos de Euler calculados para o sistema com a estimativa filtrada, obtida da fusão dos sensores pelo filtro proposto. Também, para efeito de comparação, são mostrados os resultados com a estimativa obtida apenas pela integração da velocidade angular, aplicada ao modelo de integração do quatérnio. 
A taxa de amostragem utilizada para os testes e que também será fixada para o filtro embarcado é de $50 \mathrm{~Hz}$. Nos testes realizados em bancada a medida de guinada $(\Psi)$ tem o valor $0^{\circ}$ alinhado à direção inicial de cada experimento.

Na Figura 10 é apresentado o resultado do primeiro teste, sendo realizados consecutivamente um giro completo ao redor do eixo $\mathrm{Z}$, um giro completo ao redor do eixo $\mathrm{Y}$ e um giro completo ao redor do eixo Z, com a aplicação do filtro proposto.

Figura 10 - Ângulos de Euler no primeiro procedimento de teste offline aplicando o FKE.

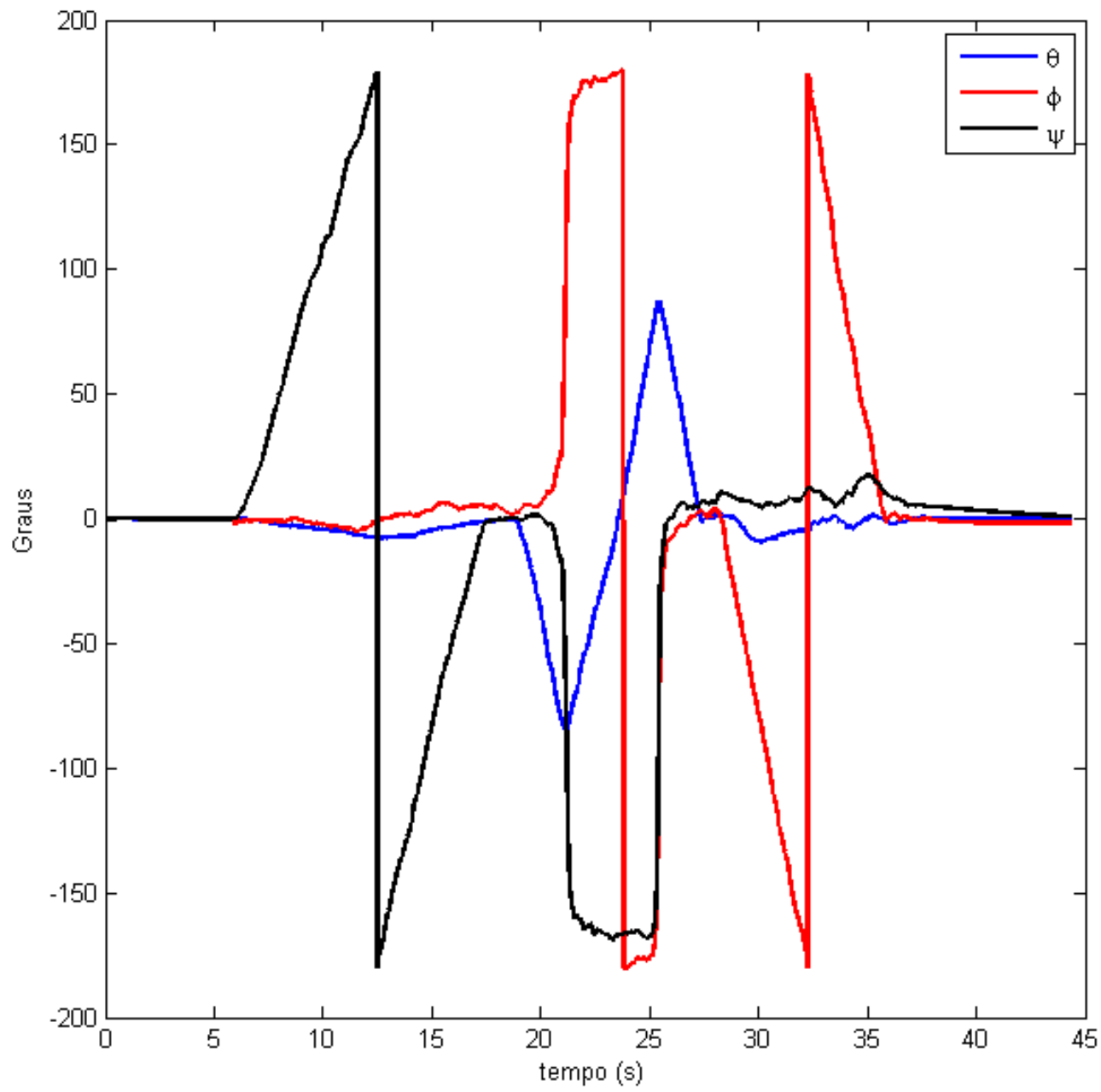


Na Figura 11 é apresentado o resultado obtido pelo mesmo teste com a integração apenas das velocidades angulares medidas.

Figura 11 - Ângulos de Euler no primeiro procedimento de teste offline, apenas com a integração da velocidade angular medida.

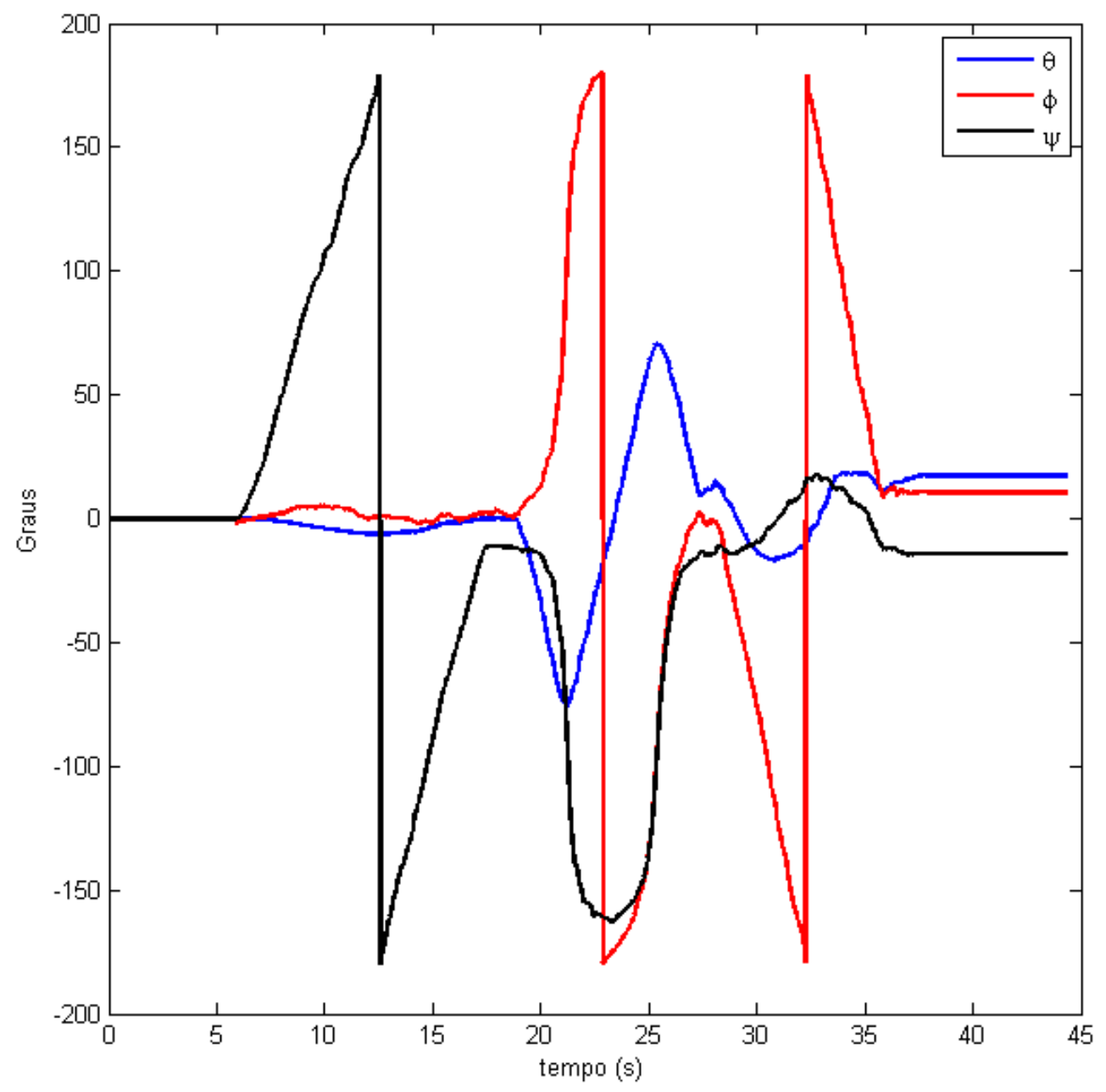

É notável que há um acumulo de erros de medida quando a orientação é calculada apenas com as medidas do giroscópio. Em 45 segundos, com a realização dos três giros, há um erro de $15^{\circ}$ na estimativa de guinada $(\Psi), 10^{\circ}$ na estimativa de rolagem $(\Phi)$ e $17^{\circ}$ na estimativa de arfagem $(\theta)$. Já na estimativa obtida com a aplicação do filtro, estes erros são reduzidos a menos de $2^{\circ}$ para as três medidas. Na Figura 12 são mostrados o trecho entre 36 e 45 segundos do teste para ambos os casos, a fim de se ilustrar a correção do erro obtida pelo filtro. 
Figura 12 - Intervalo de 36 a 45s do teste:

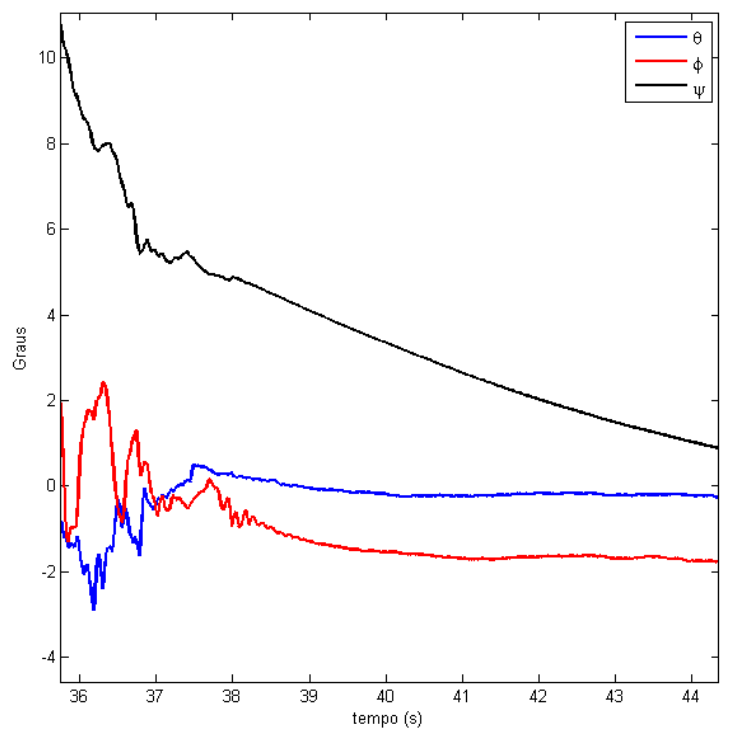

(a)

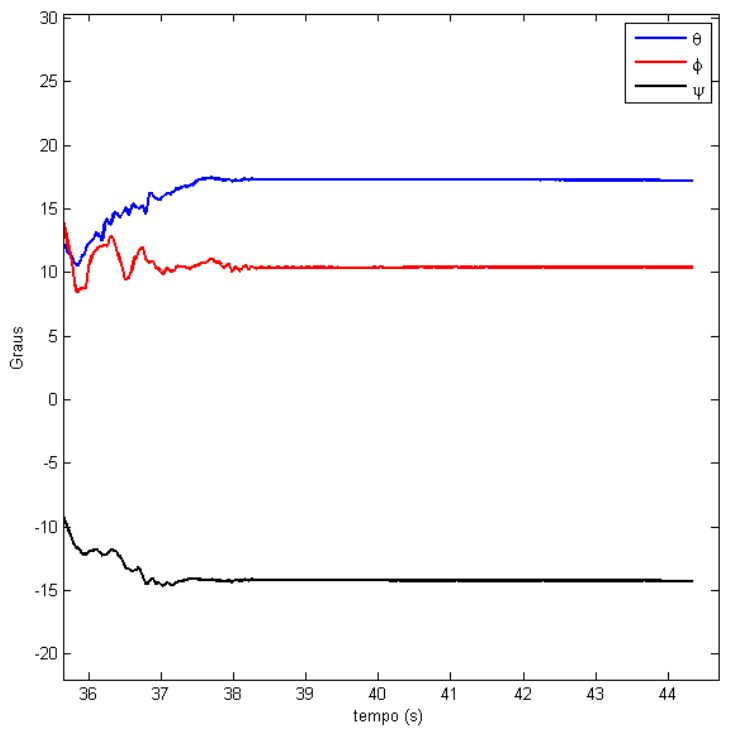

(b)

(a) aplicando o FKE e (b) com a integração apenas.

É possível notar também que com o filtro é obtido um comportamento mais coerente, como pode ser visto durante o giro ao redor do eixo $\mathrm{Y}$, no qual as estimativas de rolagem e arfagem permanecem constantes até a inversão, quando o sistema atinge $90^{\circ}$ de inclinação, para então mostrarem que o sistema passou a apontar para a direção oposta, de cabeça-para-baixo. Este trecho é mostrado na Figura 13.

Figura 13 - Giro sobre o eixo $Y$

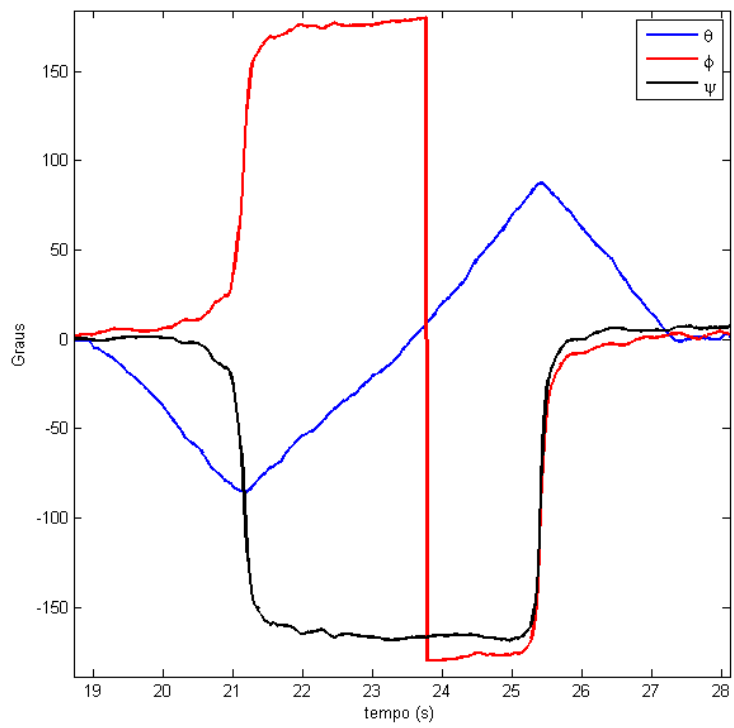

(a)

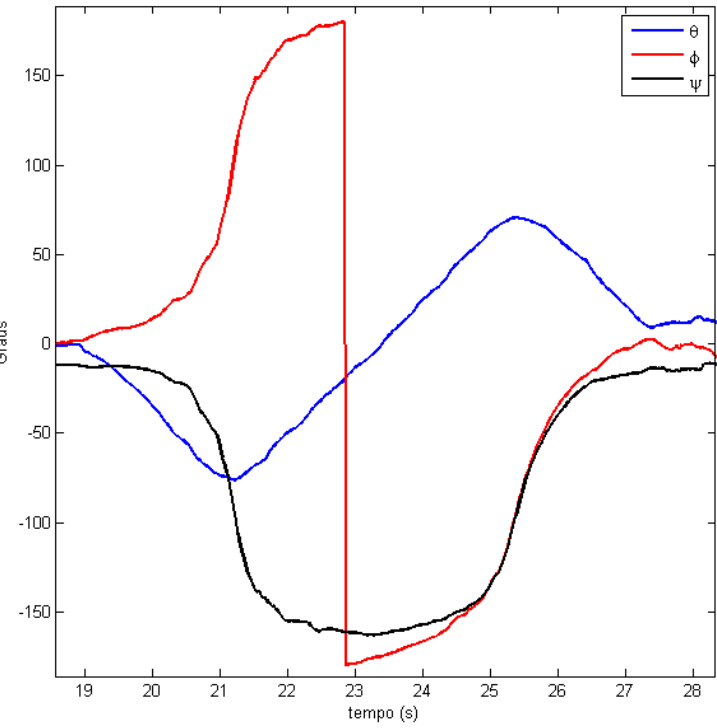

(b)

(a) aplicando o FKE e (b) com integração apenas. 
No segundo procedimento de teste, com o movimento de giro em torno do eixo Z, foram realizadas paradas em posições específicas para verificar a acuracidade da medida. Os pontos de teste foram $0^{\circ},-45^{\circ},-90^{\circ},-135^{\circ}, 180^{\circ}, 135^{\circ}, 90^{\circ}$ e $45^{\circ}$. O resultado obtido pela estimativa filtrada é mostrado na Figura 14.

Figura 14 - Ângulos de Euler no segundo procedimento de teste offline aplicando o FKE

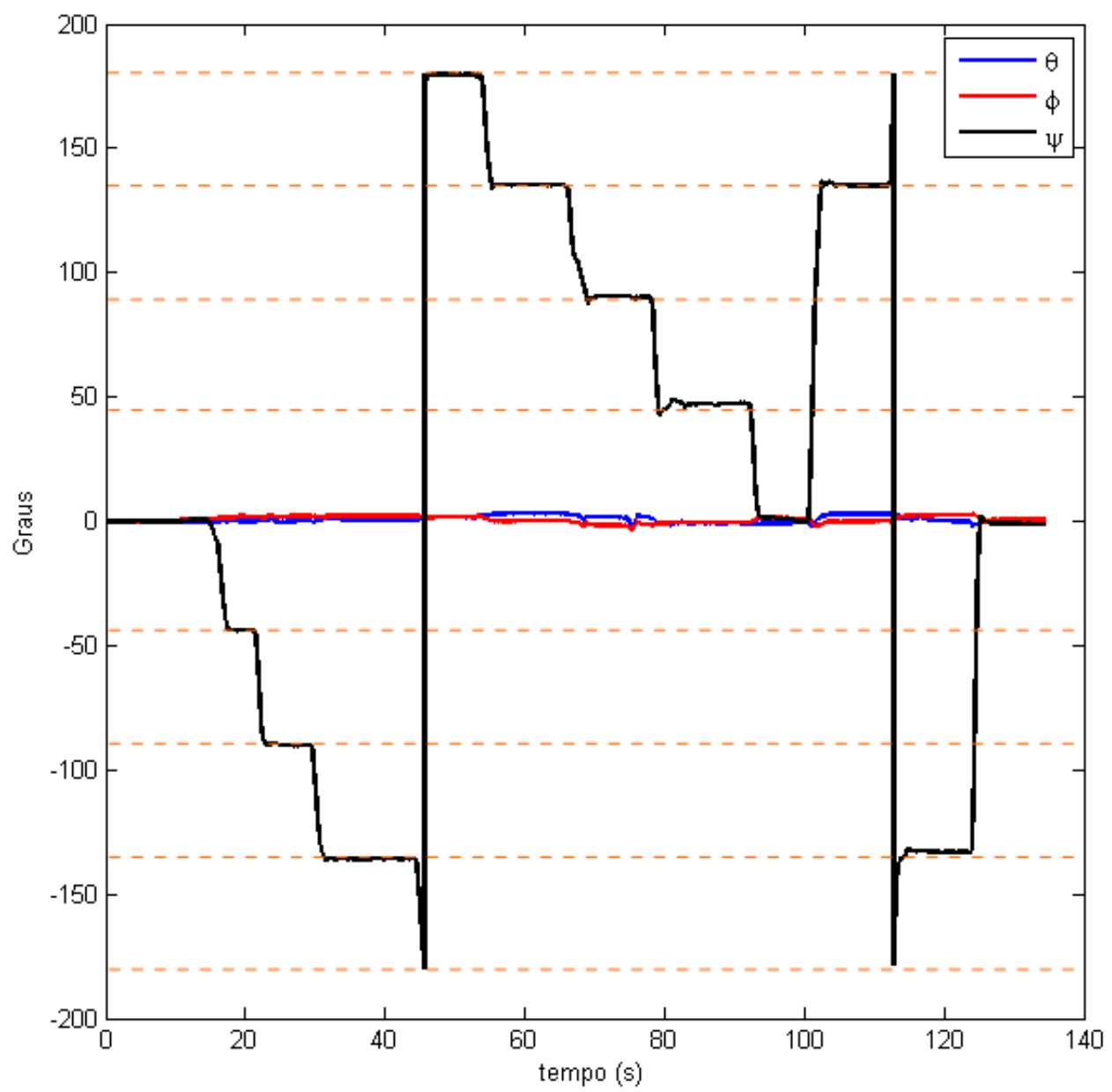

Na Figura 15 é apresentado o resultado obtido do mesmo teste apenas pela integração das velocidades angulares medidas.

Na Figura 16, Figura 17 e Figura 18 são mostrados intervalos do teste para efeito de comparação entre o resultado da estimativa filtrada e da integração apenas. Novamente é evidente que apenas com a integração da velocidade angular são acumulados erros de medida que levam a uma estimação errada da orientação. Já com a estimativa filtrada, para os valores esperados nas paradas o erro é menor que $2^{\circ}$, mostrando assim que os erros de medida são corrigidos com o processo de filtragem. 
Figura 15 - Ângulos de Euler no segundo procedimento de teste offline, apenas com a integração da velocidade angular medida

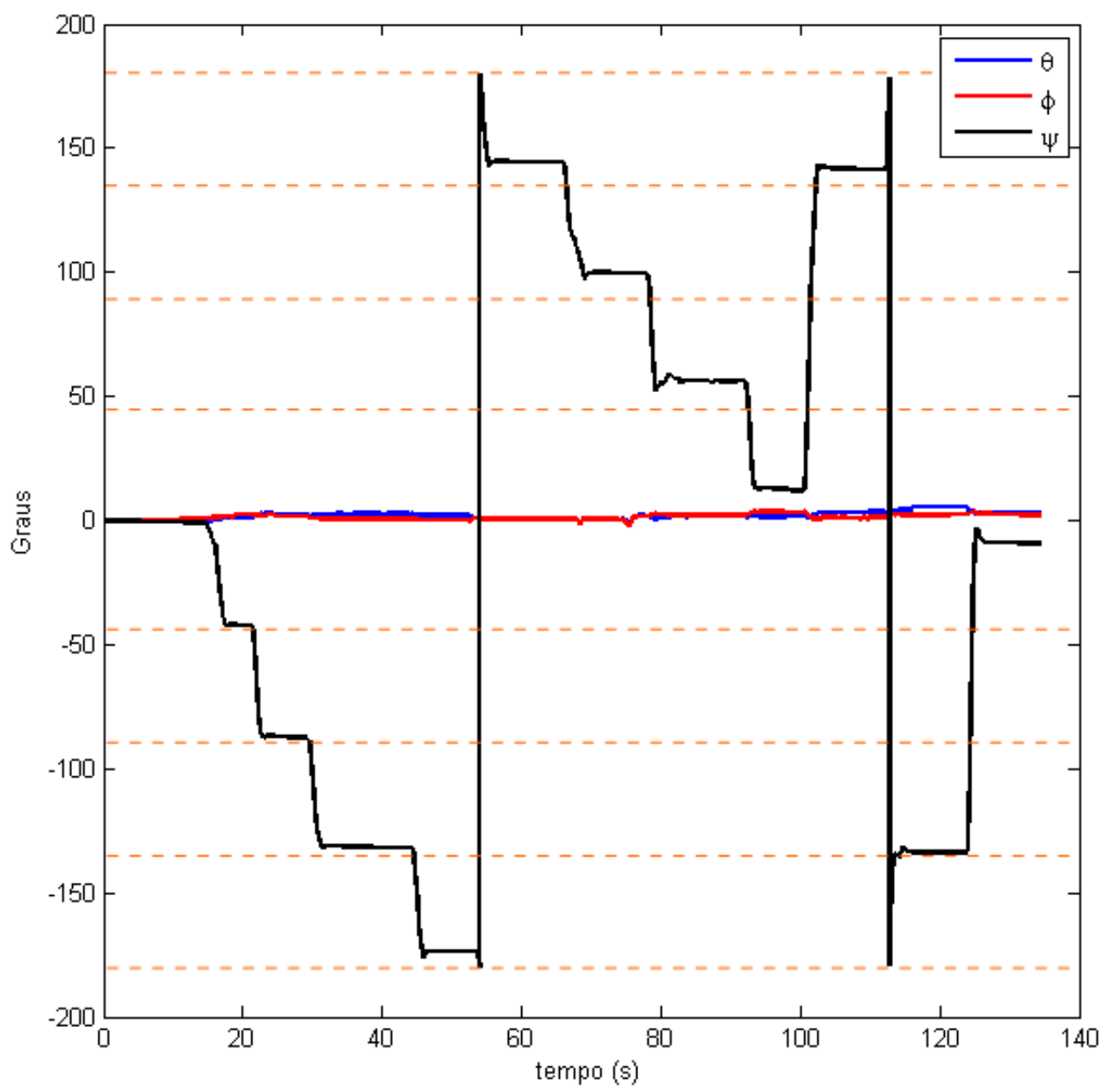

Figura 16 - Intervalo entre 19 e 37 s do segundo procedimento de teste

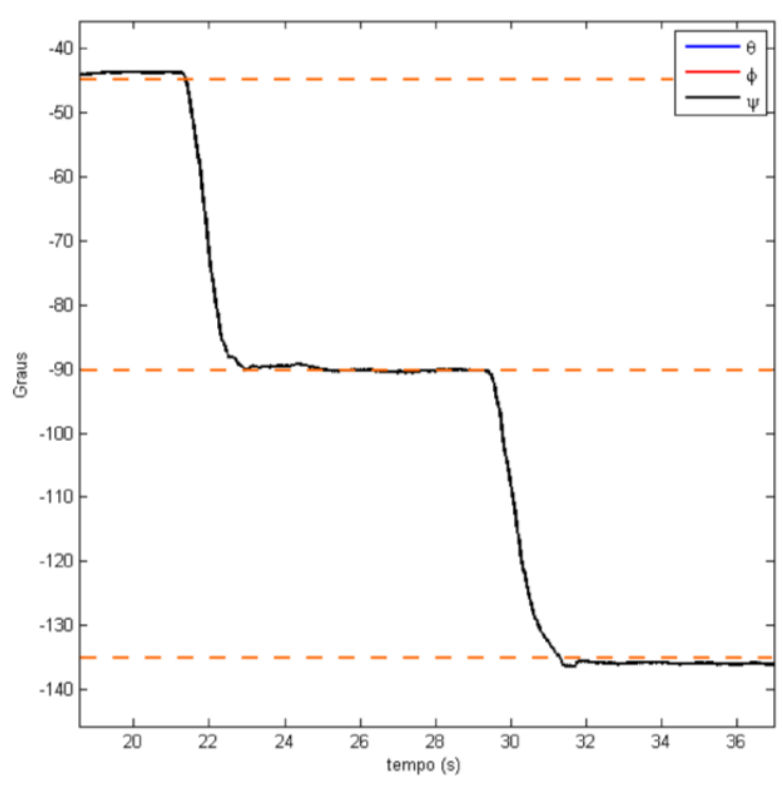

(a)

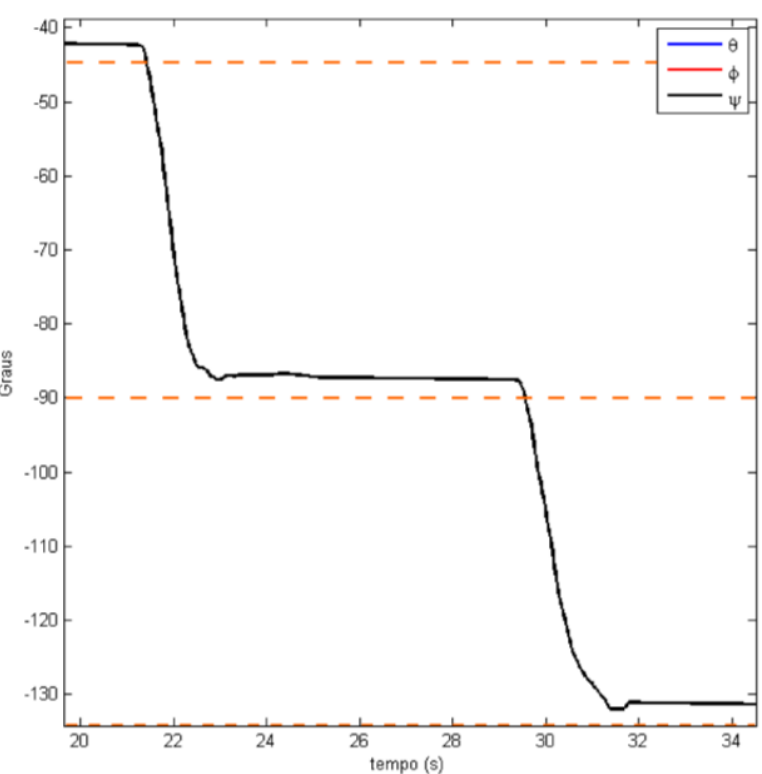

(b)

(a) aplicando o FKE e (b) com a integração apenas. 
Figura 17 - intervalo entre 60 e 90 s do segundo procedimento de teste

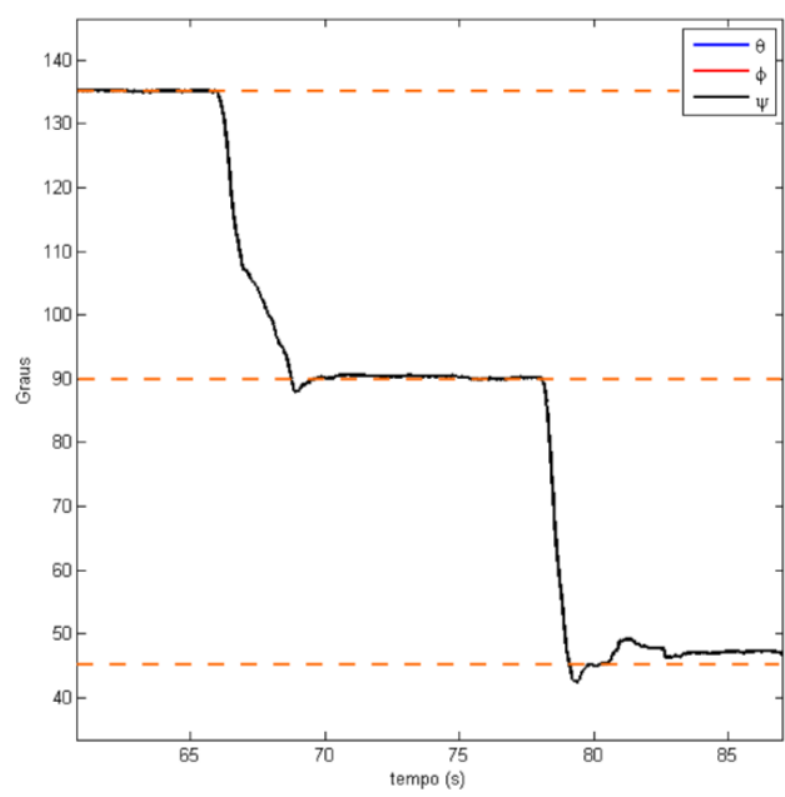

(a)

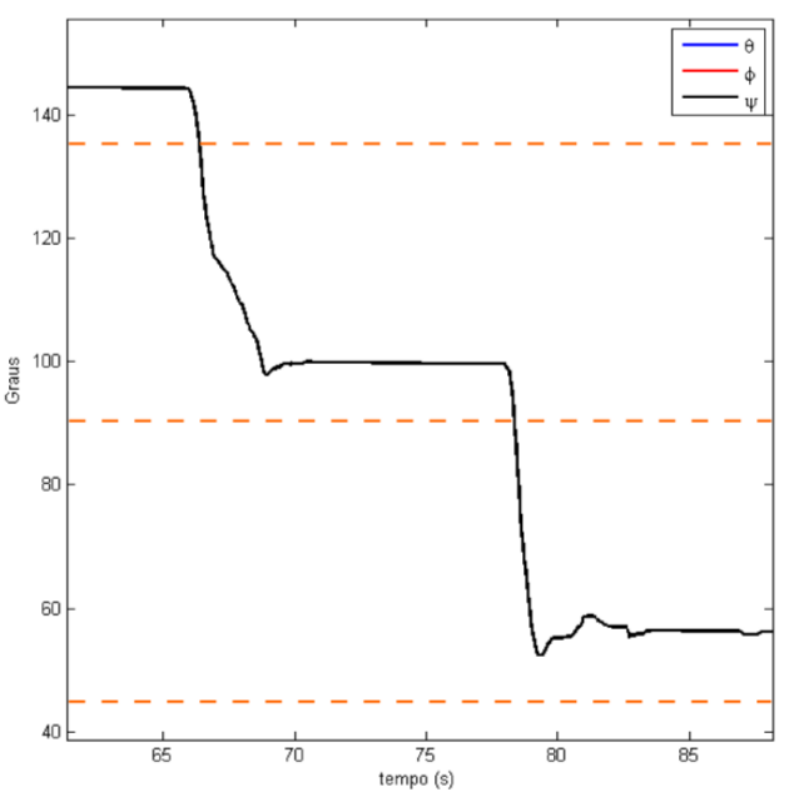

(b)

(a) aplicando o FKE e (b) com a integração apenas.

Figura 18 - intervalo entre 123 e 135 s do segundo procedimento de teste

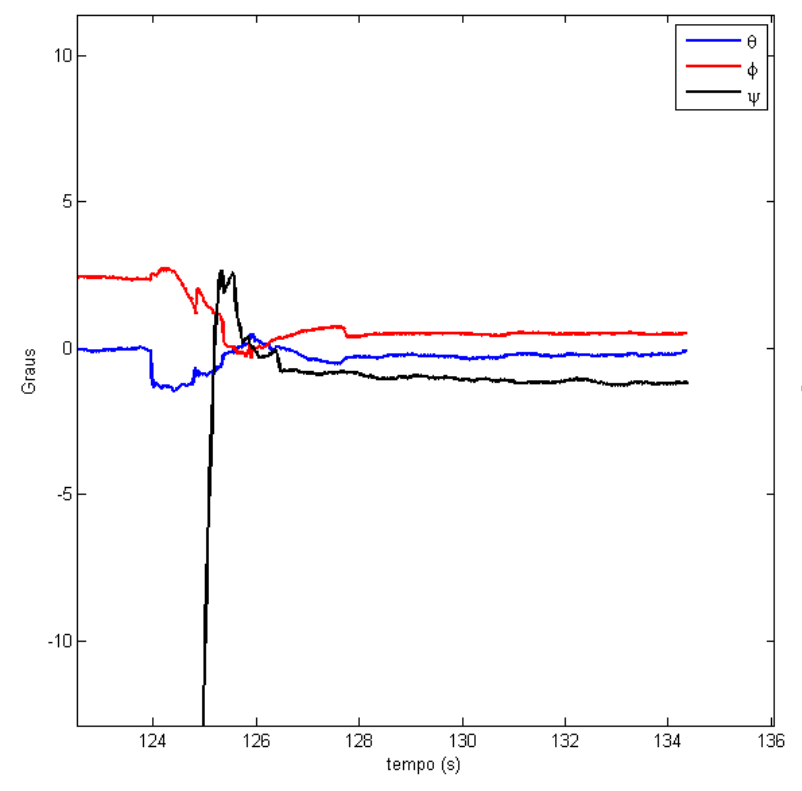

(a)

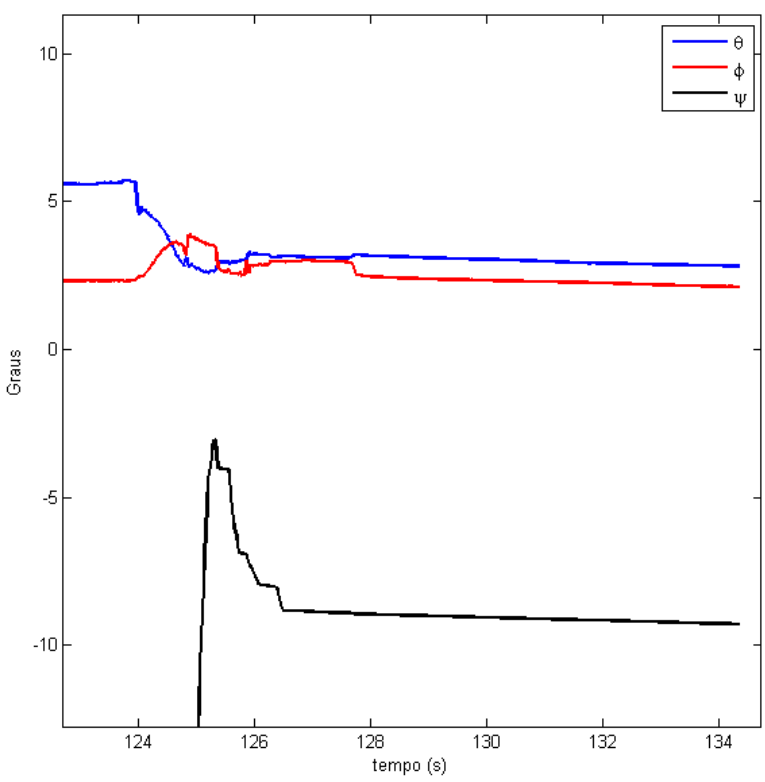

(b)

(a) aplicando o FKE e (b) com a integração apenas.

Na Figura 19 são mostradas as medidas de campo magnético obtidas pelo sensor e também, os valores esperados para essas medidas considerando a orientação estimada, obtidos pela equação 
do modelo do sensor, (29). Na Figura 20 é mostrado em detalhe um intervalo destes dados, evidenciando a natureza ruidosa das medidas obtidas pelo sensor.

Figura 19 - Medidas de campo magnético e valores esperados.

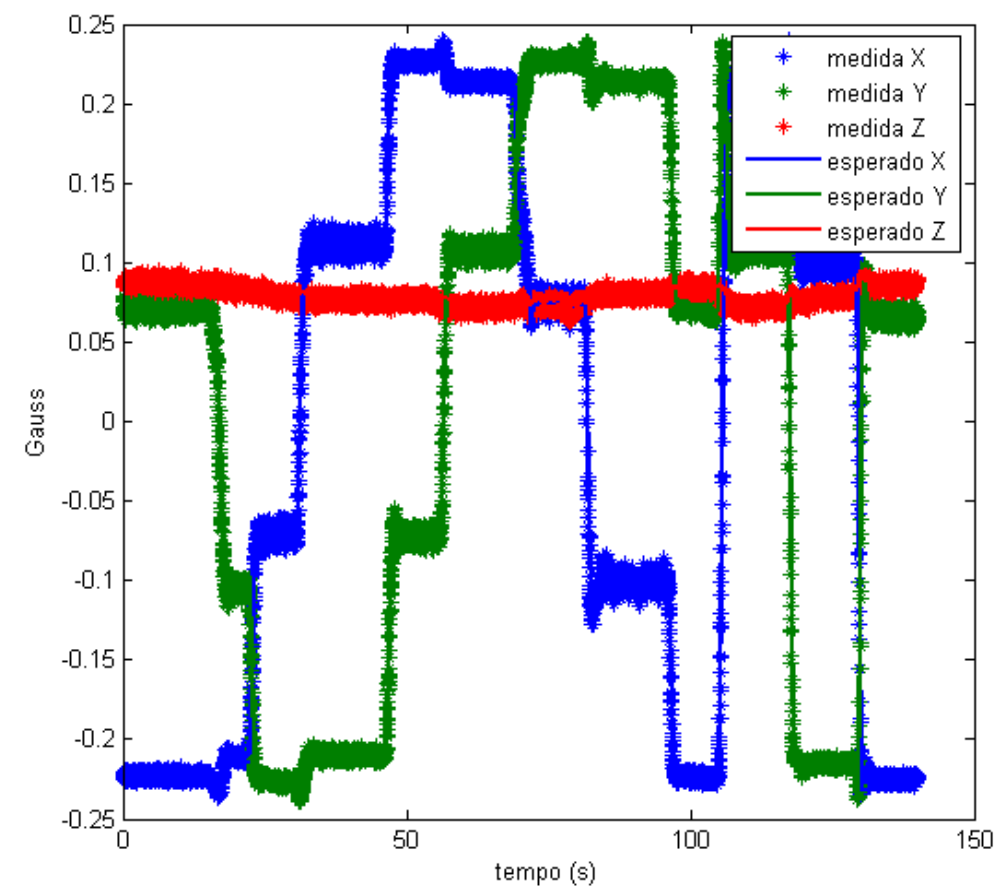

Figura 20 - Medidas de campo magnético e valores esperados

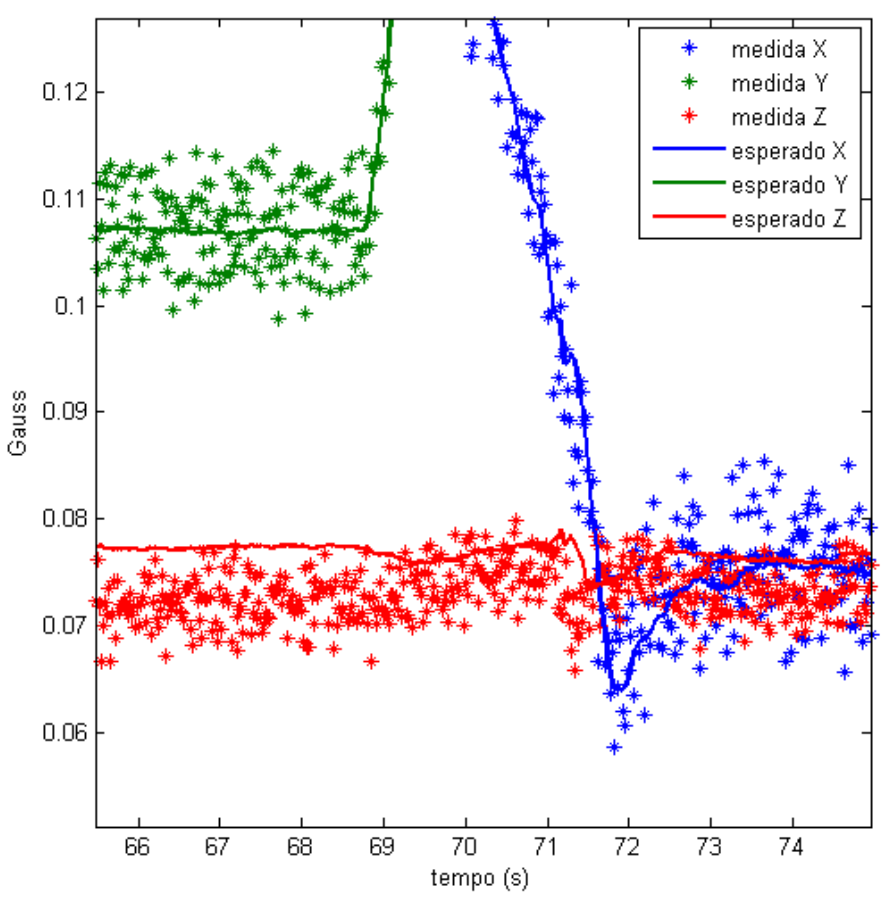

Por meio dos procedimentos experimentais executados na primeira etapa, é possível verificar que o filtro de Kalman Estendido proposto apresenta o comportamento esperado para a obtenção de uma estimativa confiável mesmo com a utilização de sensores ruidosos. 
O teste com as paradas nos ângulos definidos mostra que o filtro é capaz de estimar a orientação correta no plano, assim este cumpre seu propósito de fornecer uma referência confiável para o controle de trajetória.

\subsection{Testes embarcados}

Com o sistema de sensoriamento de orientação desenvolvido embarcado no veículo, foram realizadas diversas manobras na água. A estimativa de orientação calculada pelo próprio sistema foi armazenada em um arquivo de registro, armazenando também as medidas dos sensores para análise.

Assim, é possível comparar a estimativa obtida pelo sistema com a simples integração das medidas de velocidade angular, analisando a capacidade do sistema de corrigir o erro introduzido pelo acúmulo de imprecisões das medidas, fornecendo assim uma referência confiável para navegação.

Os testes embarcados foram realizados na Represa do Broa, Rio Lobo, em Itirapina, SP, no Centro de Recursos Hídricos e Ecologia Aplicada (CRHEA-USP) onde a represa pode ser acessada por um píer alinhado a $50^{\circ}$ com o Norte Geográfico.

\section{Figura 21 - Píer do Centro de Recursos Hídricos e Ecologia Aplicada (CRHEA-USP)}

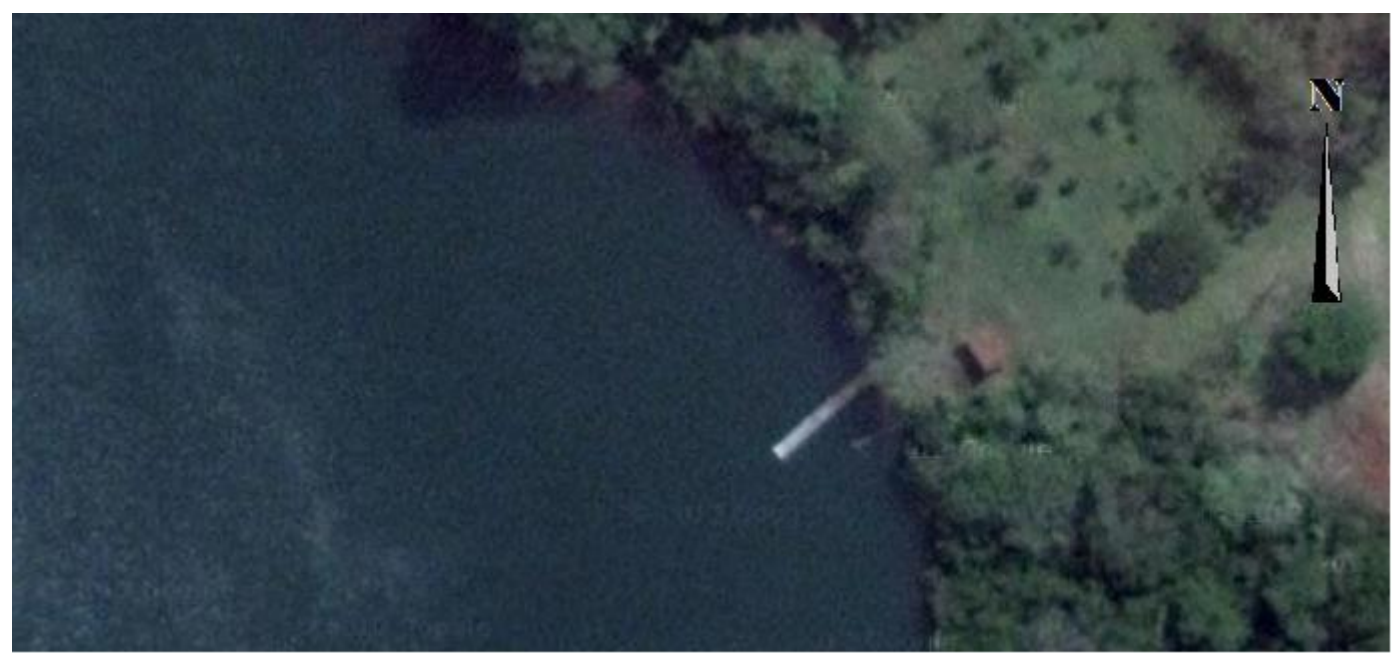

Nos testes realizados em campo a medida de guinada $(\Psi)$ tem o valor $0^{\circ}$ alinhado ao norte geográfico. Foram selecionado os resultados de dois experimentos para serem descritos. Para a movimentação do trimarã foi utilizado um veículo secundário, operado por controle remoto, pela indisponibilidade do sistema de propulsão próprio do trimarã no momento da execução dos testes. $\mathrm{Na}$ Figura 22 é mostrada uma fotografia do trimarã e da lancha utilizada para rebocá-lo durante as manobras. 

Figura 24 - Curva gerada com a integração apenas das medidas de velocidade angular no primeiro experimento

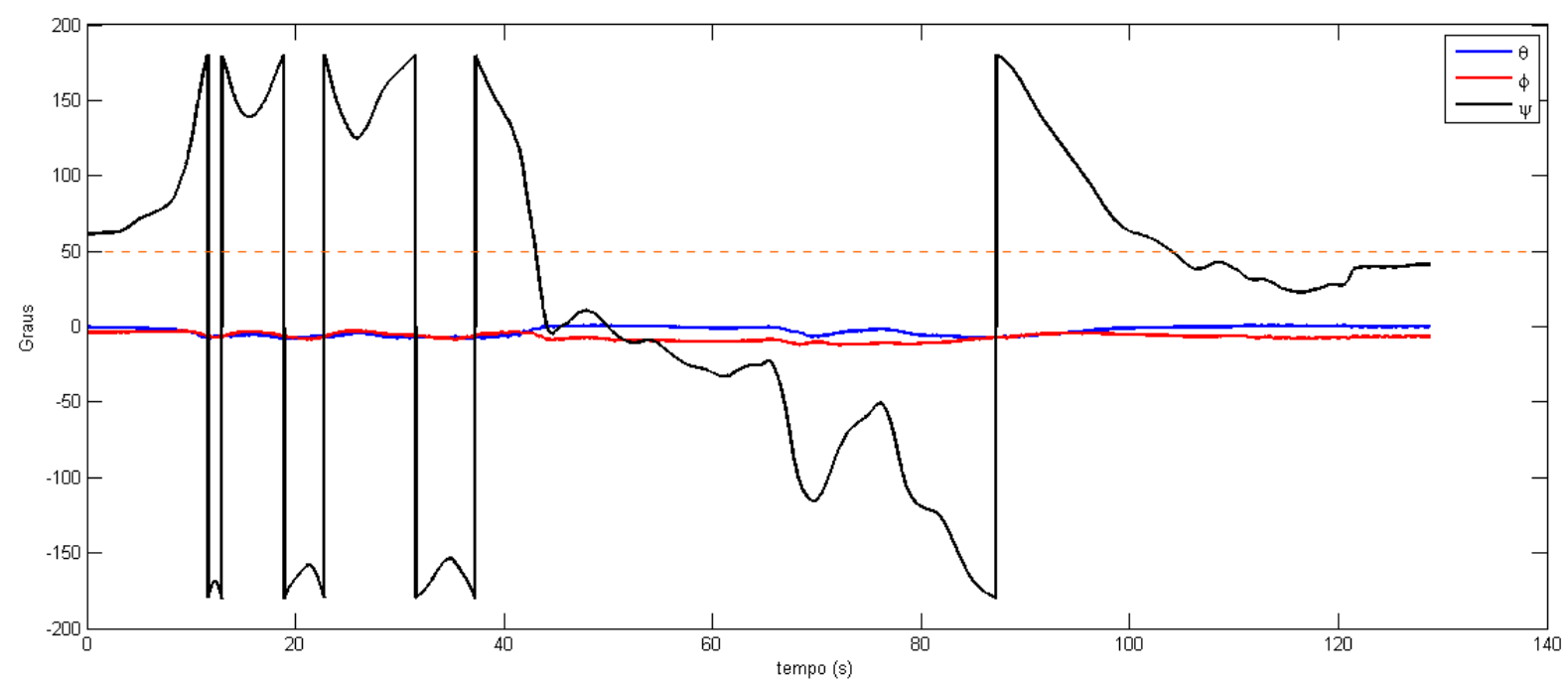

Apesar do perfil apresentado pelas duas curvas ser bastante parecido, a curva gerada pela integração da velocidade angular lentamente acumula erros, o que pode ser verificado pela análise do intervalo final do experimento, mostrado na Figura 25. É evidente que a estimativa com a aplicação do FKE manteve as estimativas de Arfagem e Rolagem próximas ao valor zero, a menos das ondulações da superfície da água, já a integração das velocidades angulares acumulou erros, apresentando um valor de $-7^{\circ}$ de rolagem, incoerente com o fato do veículo estar no plano.

Figura 25 - Intervalo final do primeiro experimento

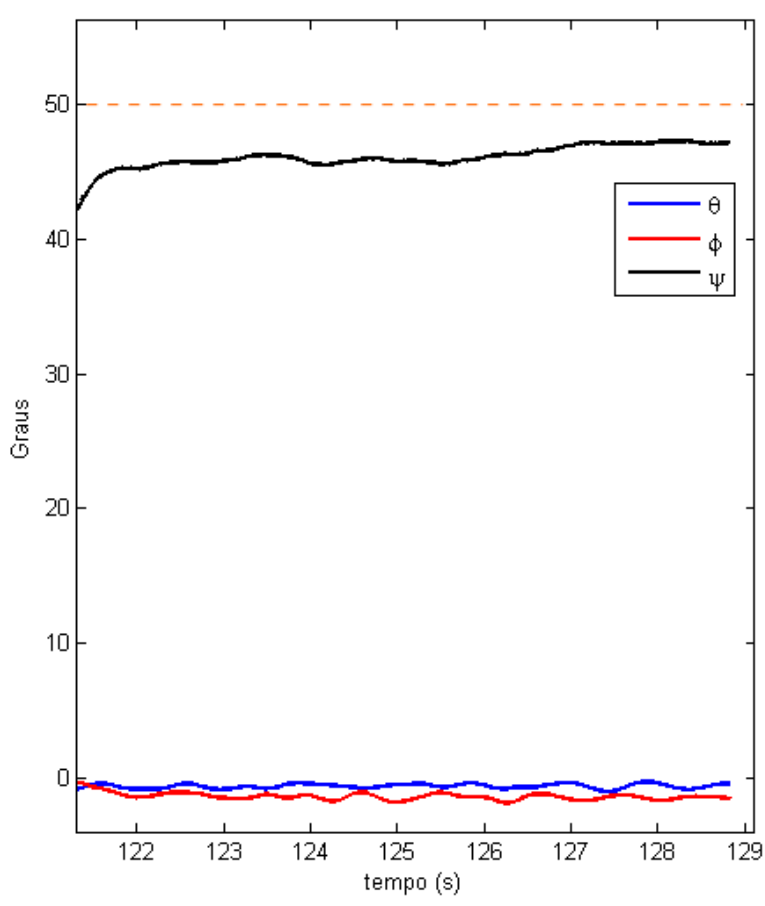

(a)

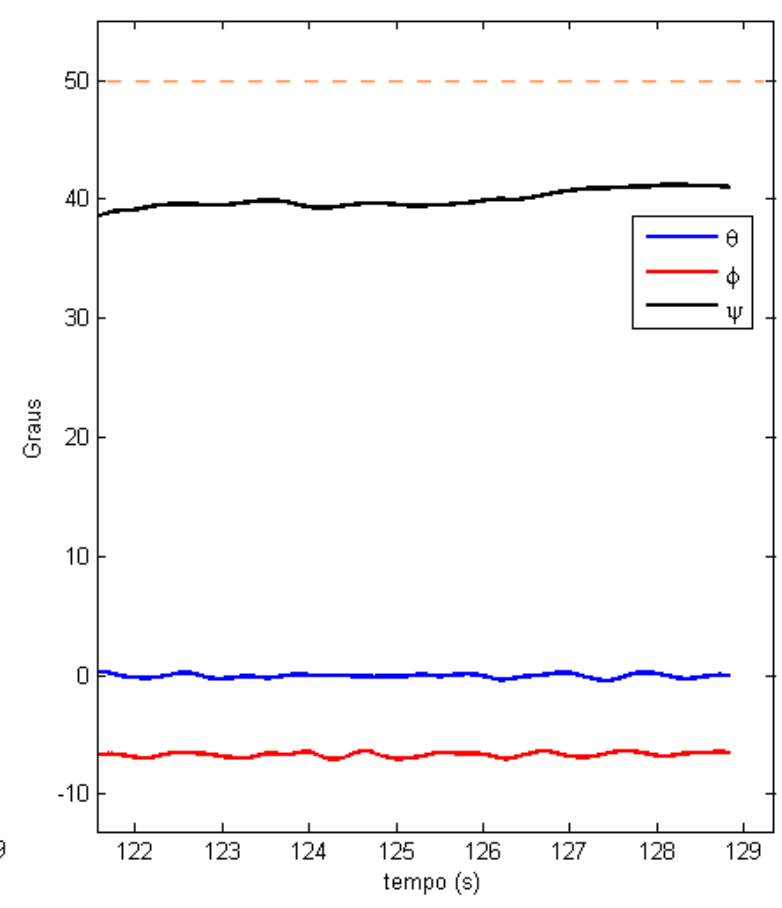

(b)

(a) aplicando o FKE. (b) Integração apenas das medidas de velocidade angular 
Durante o intervalo final do experimento, aproximando-se o veículo ao píer, traçou-se um trajeto que mais se aproximasse de sua orientação, porém não foi possível o alinhamento ideal, ainda assim o estimador aplicando o FKE evidencia esta aproximação, com um desvio em relação ao píer de 5ㅇ, enquanto que a integração apenas das velocidades angulares desviou a orientação ao longo do tempo, apresentando um desvio de $5^{\circ}$ em relação ao resultado obtido com a aplicação do FKE.

O mesmo procedimento foi adotado para o segundo experimento, porém este apresenta maior duração. Na Figura 26 são mostradas as estimativas calculadas pelo sistema embarcado aplicando o FKE e na Figura 27 a curva obtida pela integração das medidas de velocidade angular.

Figura 26 - Estimativas de orientação obtidas pelo sistema embarcado aplicando o FKE no segundo experimento

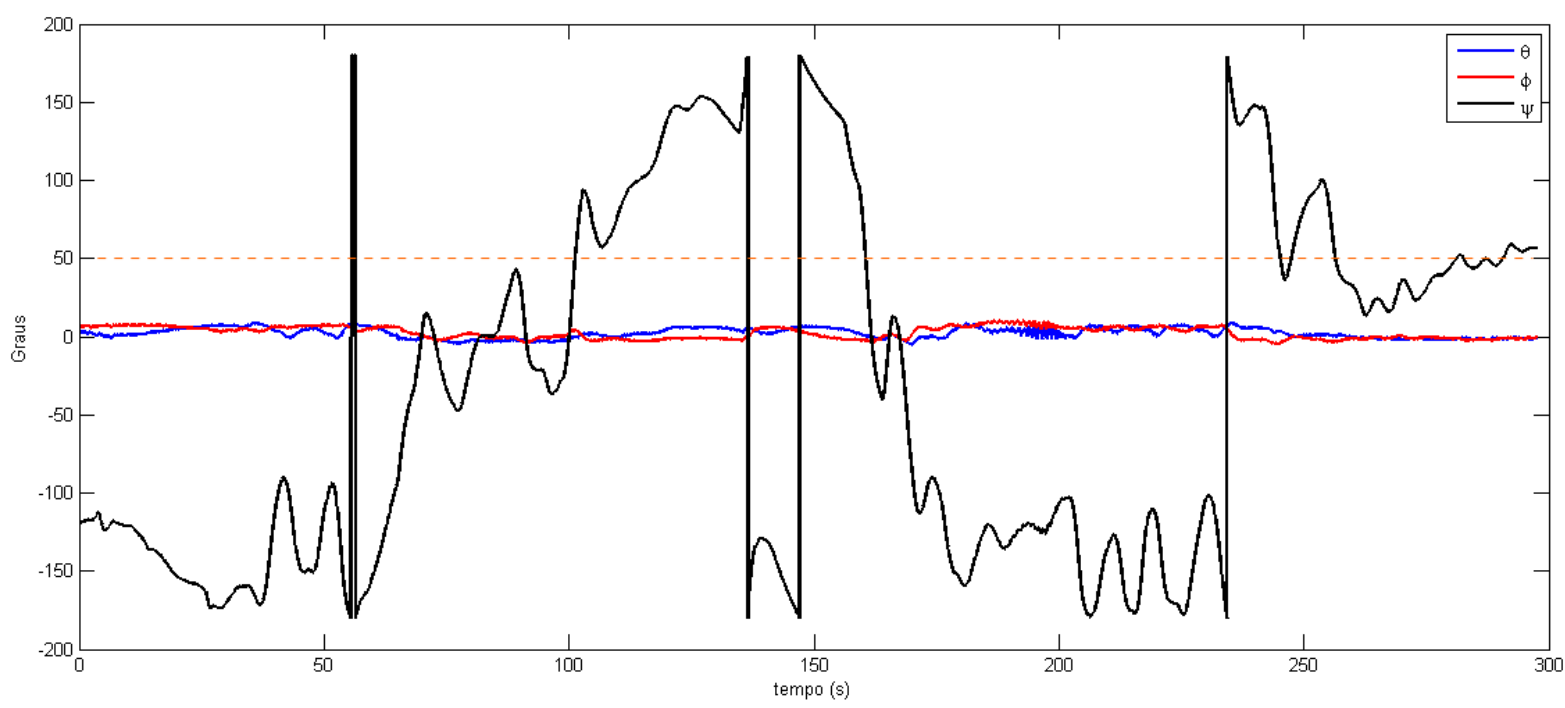

Figura 27 - Curva gerada com a integração apenas das medidas de velocidade angular no segundo experimento

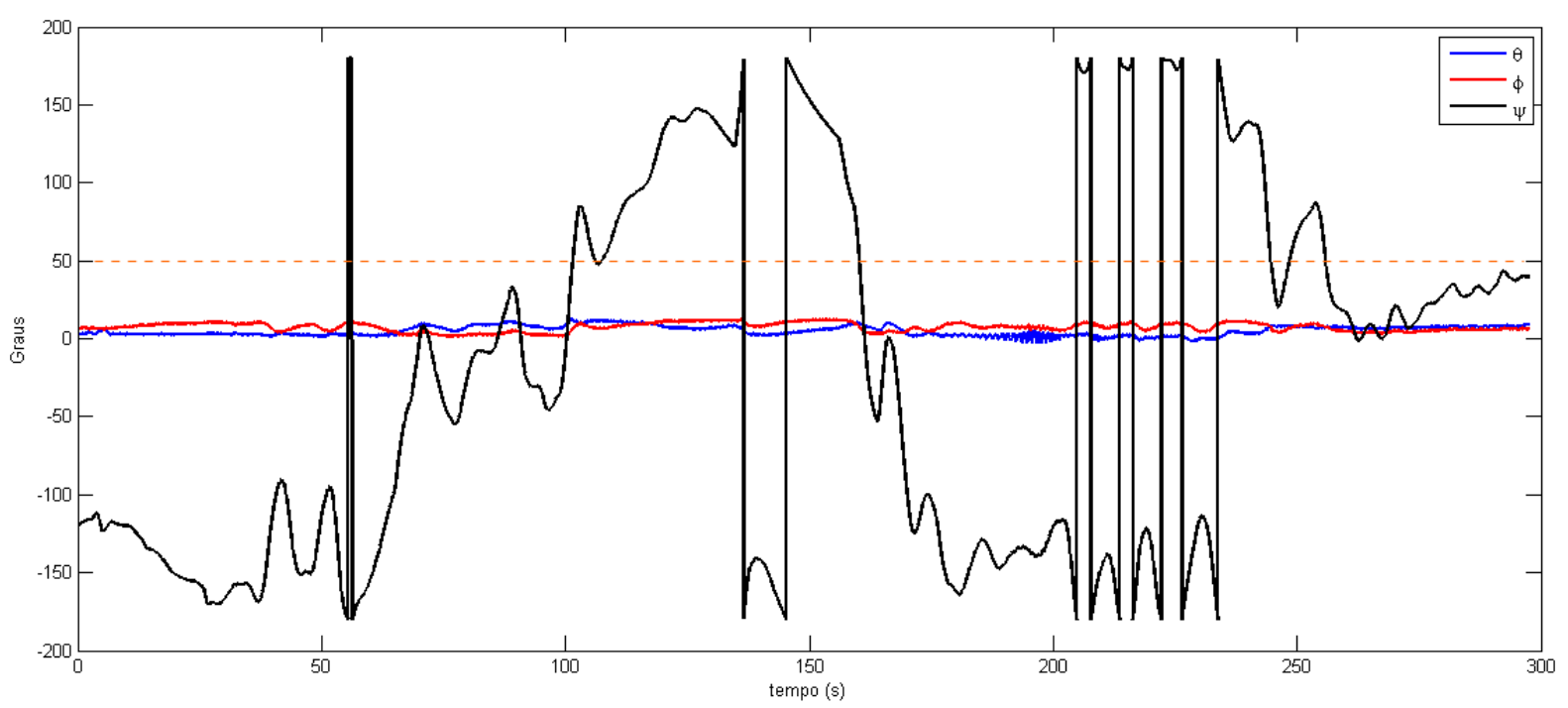

Novamente, a analise do intervalo final do experimento evidencia o acumulo de erros no sistema quando é utilizada apenas a integração das medidas de velocidade angular enquanto que o 
estimador aplicando o FKE mantém o resultado coerente com a orientação real do veículo. Na Figura 28 é mostrado esse intervalo. As medidas de arfagem e rolagem apresentam valores incoerentes quando calculadas apenas com as velocidades angulares, chegando a $10^{\circ}$ na arfagem e $7^{\circ}$ na rolagem, já a estimativa aplicando o FKE apresenta desvio menor que $2^{\circ}$ em relação ao zero nessas estimativas.

Figura 28 - Intervalo final do segundo experimento

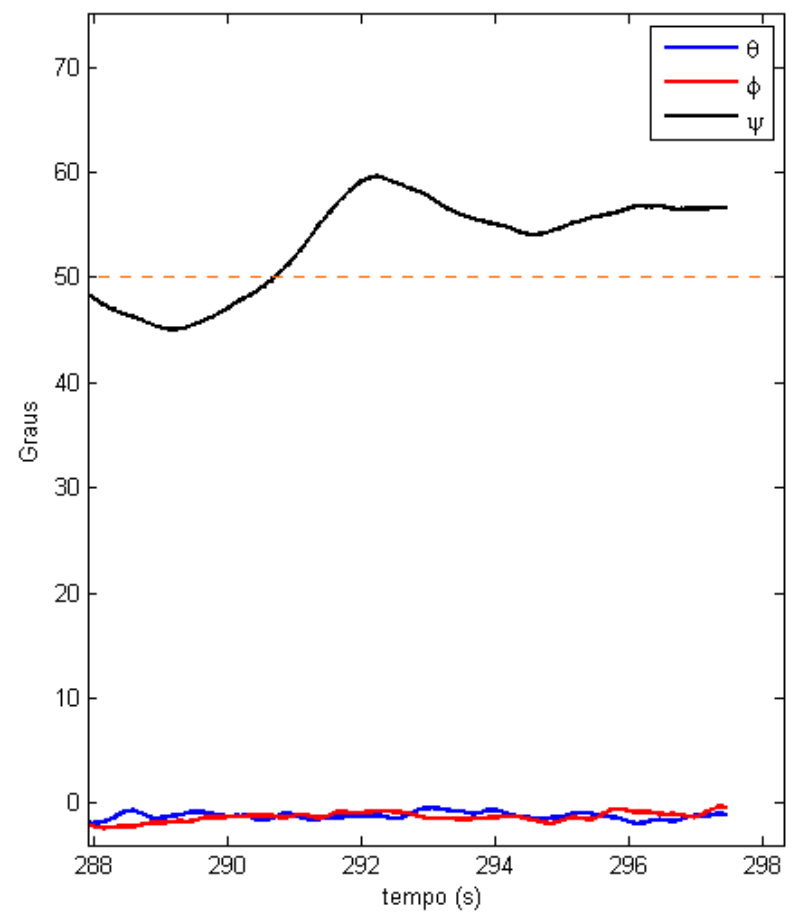

(a)

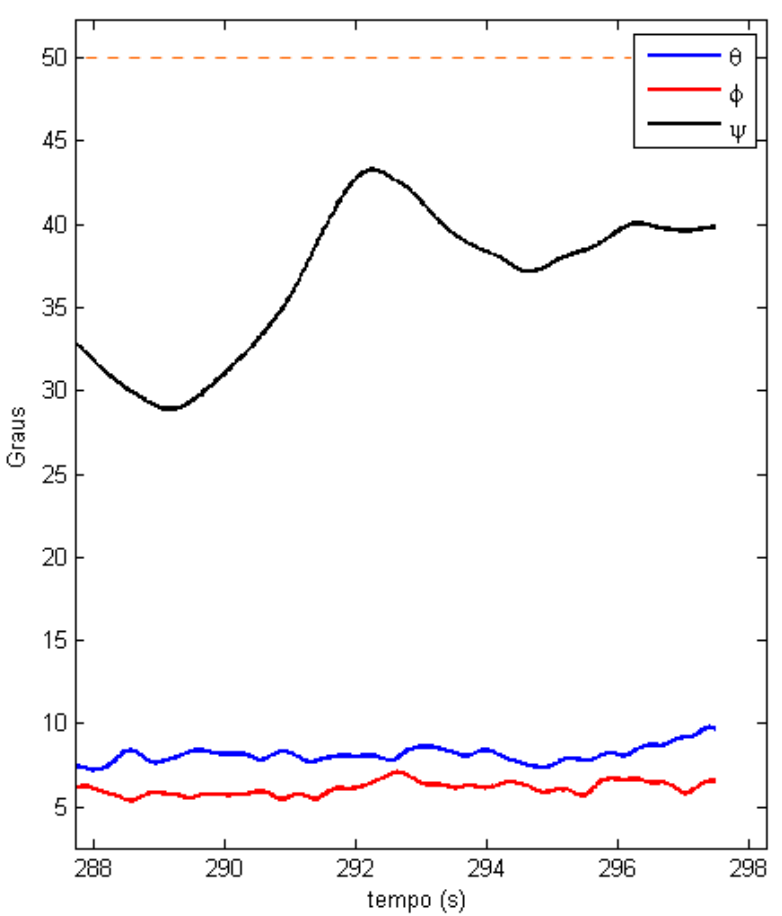

(b)

(a) Estimativa filtrada. (b) Integração das medidas

São mostrados também para este intervalo, as medidas obtidas pelos sensores. Na Figura 29 são apresentadas as medidas do acelerômetro, na Figura 30 são apresentadas as medidas do giroscópio, e finalmente na Figura 31 são apresentadas as medidas do magnetômetro, para ilustrar o natureza ruídos das medidas obtidas por esses sensores. 
Figura 29 - Medidas obtidas pelo acelerômetro

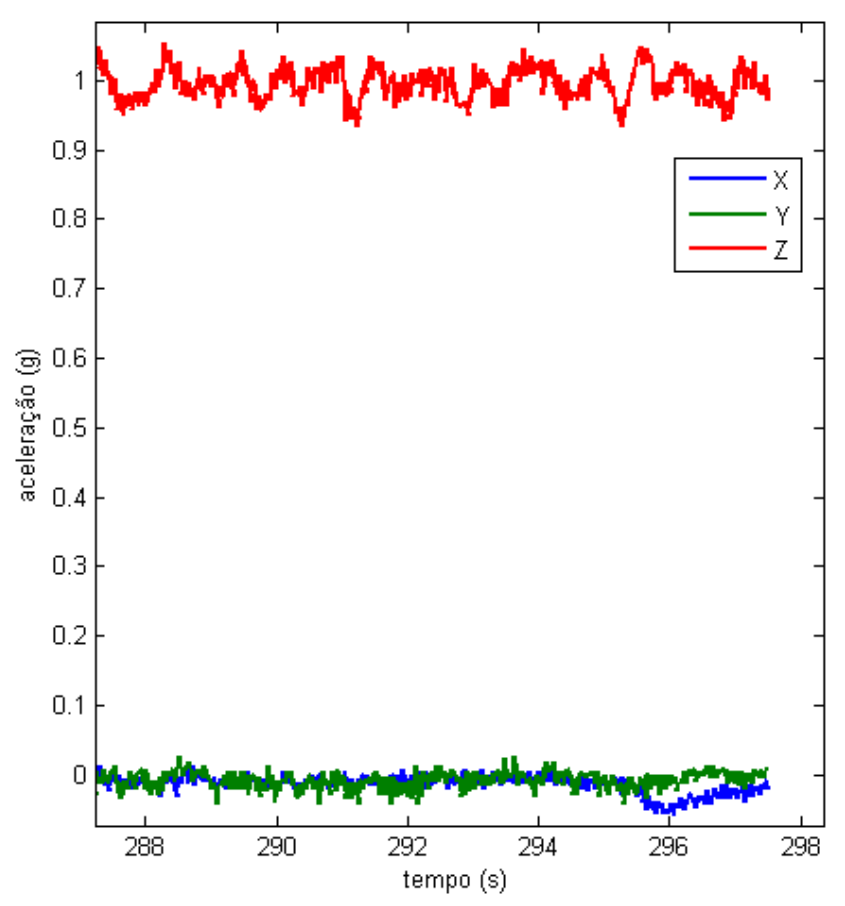

$\left(1 \mathrm{~g}=9,8 \mathrm{~m} / \mathrm{s}^{2}\right)$

Figura 30 - Medidas obtidas pelo giroscópio

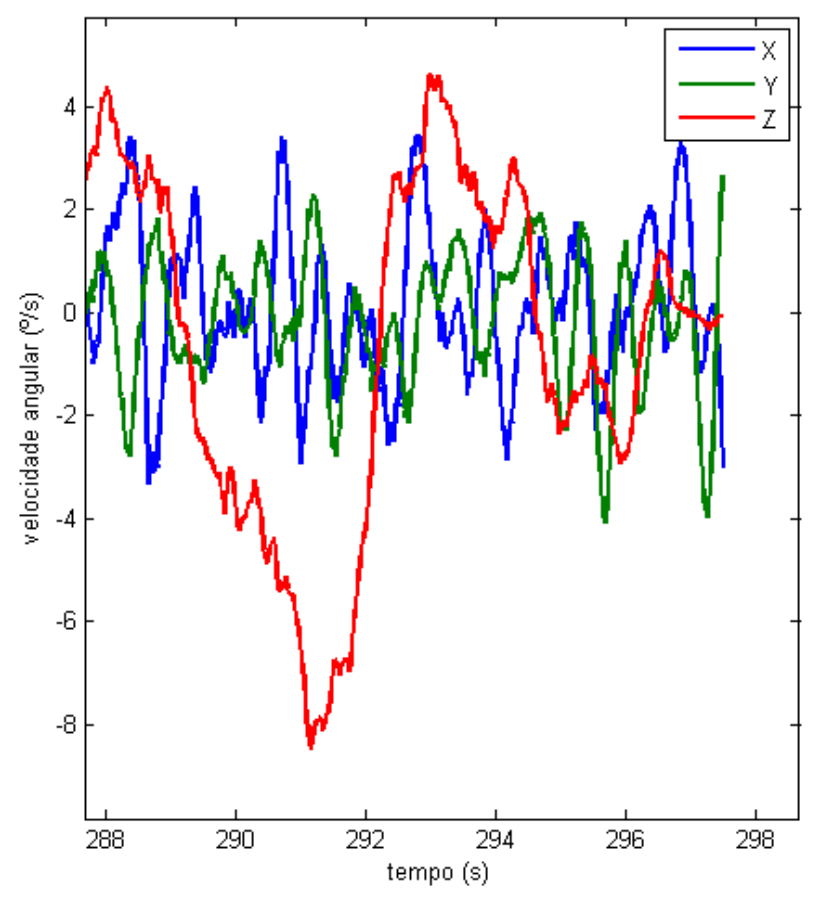


Figura 31 - Medidas obtidas pelo magnetômetro

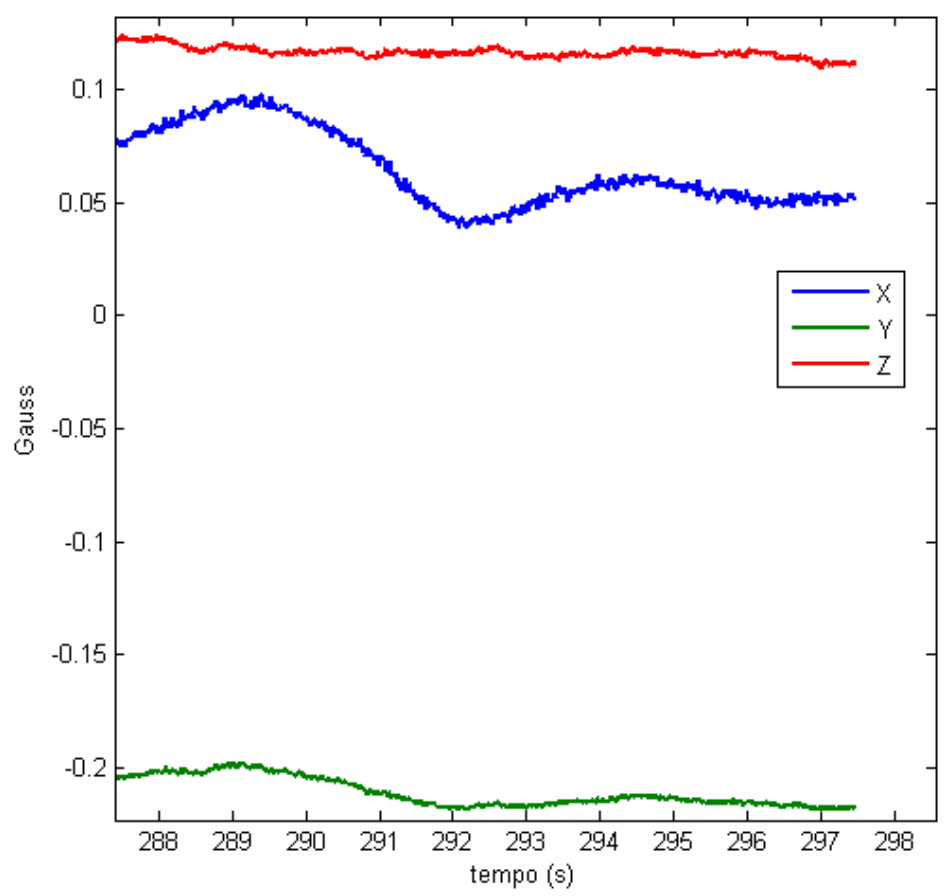





\section{Capítulo 6}

\section{Conclusão}

O trabalho apresenta o desenvolvimento e utilização de um sistema de sensoriamento de orientação aplicando sensores de baixo custo, através da utilização de FKE. O trabalho mostra que o filtro é viável para utilização em um veículo autônomo de superfície de pequeno porte, onde são abordadas as questões de navegação inercial, representação de orientação e filtragem,.

Com a análise da abordagem ao problema por diversos autores, entre eles (Sabatini, 2006) e (Phuong et al., 2009), optou-se por desenvolver um sistema com a representação da orientação via quatérnios, utilizando o filtro de Kalman estendido para realizar a fusão dos dados dos sensores. $O$ uso dos quatérnios ao invés da DCM reduz a dimensão do vetor de estados e das demais matrizes usadas no filtro, diminuindo a complexidade do problema para os cálculos no sistema embarcado.

Em relação ao filtro desenvolvido por Sabatini, o calculo dos desvios no acelerômetro e no giroscópio não foi implementado diretamente no processo de filtragem, diminuindo assim a complexidade do filtro para a aplicação embarcada, reduzindo a dimensão do vetor de estados e das matrizes do filtro. Porém se faz necessário verificar a calibração dos sensores periodicamente.

Os resultados obtidos em bancada e em campo demonstram que o filtro desenvolvido é capaz de estimar satisfatoriamente a orientação para a presente aplicação, sem ser afetado pelo acumulo de erros devido ao ruído presente nas medidas dos sensores. Nos testes em bancada foram apresentados desvios inferiores a $2^{\circ}$ na estimativa de orientação com a aplicação do filtro, enquanto 0 processo sem filtragem foi afetado pelos ruídos das medidas, chegando a um desvio de 15 na estimativa. Desta forma, comprova-se que o estimador aplicando o filtro desenvolvido pode ser aplicado como referência de orientação para um veículo de baixo custo.

O sistema foi testado em campo, embarcado no trimarã, de forma a avaliar seu funcionamento mesmo em um ambiente com ondulações constantes, para o qual o veículo foi projetado, fornecendo resultados satisfatórios. Para o teste em campo não foi possível obter uma medida de referência para calcular o erro absoluto apresentado pelo estimador, porém a análise dos 
resultados mostrou que a estimativa obtida foi condizente com os resultados esperados: os valores de arfagem e rolagem mantiveram-se próximas a zero a menos das ondulações da superfície da água e o valor de guinada foi coerente com as manobras realizadas.

Diante da solução apresentada para a obtenção da estimativa de orientação, são sugeridas para continuação do trabalho: desenvolver do filtro utilizando a representação via DCM, comparando os resultados e o tempo de processamento; desenvolver o sistema utilizando outra solução de filtragem, como o sliding mode observer (Hadri and Benallegue, 2009) ou o gradient descent algorithm (Madgwick, Harrison and Vaidyanathan, 2011), para comparação de resultados e do tempo de processamento; implementar o calculo dos desvios diretamente no filtro como em (Sabatini, 2006) para comparação de resultados e do tempo de processamento. 


\section{Referências Bibliográficas}

ALVES, J. et al. Vehicle and mission control of the delfim autonomous surface craft. 14th Mediterranean Conference on Control and Automation, 2006.

CARUSO, M. J. Applications of magnetic sensors for low cost compass systems. Position Location and Navigation Symposium, p. 177-184, 2000.

CIFUENTES, C.; BRAIDOT, A. Development of a wearable ZigBee sensor system for upper limb rehabilitation robotics. Biomedical Robotics and Biomechatronics, p. 1989-1994, 2012.

CRAIG, J. J. Introduction to Robotics Mechanics and Control. Third ed. New Jersey: Pearson, 2005.

DENTI, E.; GALATOLO, R.; SCHETTINI, F. An AHRS Based on a Kalman Filter for the Integration of Inertial, Magnetometric and GPS Data. 27th International Congress of the Aeronautical Sciences, 2010.

DIAS, N. et al. Manoeuvre based mission control system for Autonomous Surface Vehicle. Oceans 2009 Europe, p. 1-5, 2009.

DU, D.; LIU, L.; DU, X. A low-cost attitude estimation system for UAV application. Control and Decision Conference (CCDC), p. 4489-4492, 2010.

EDWAN, E. et al. Reduced DCM based attitude estimation using low-cost IMU and magnetometer triad. 2011 8th Workshop on Positioning Navigation and Communication, p. 1-6, 2011.

FERREIRA, HUGO et al. ROAZ Autonomous Surface Vehicle design and implementation. IEEE Robotica2006, p. 4994-4999, 2007.

FERREIRA, $\mathrm{H}$ et al. SWORDFISH: an Autonomous Surface Vehicle for Network Centric Operations. OCEANS 2007 Europe, v. 1-3, p. 1-6, 2007. 1994. p. 480

FOSSEN, T. I. Guidance and control of ocean vehicles. Baffins Lane, England: Wiley,

GOYAL, P. et al. Strap-down Pedestrian Dead-Reckoning system. 2011 International Conference on Indoor Positioning and Indoor Navigation, v. 27, n. September, p. 1-7, 2011.

GREWAL, M. S.; ANDREWS, A. P. Kalman filtering: theory and practice using MATLAB. Second ed. [s.I.] John Wiley \& Sons, Inc., 2001. v. 5p. 401 
HADRI, A. EL; BENALLEGUE, A. Sliding mode observer to estimate both the attitude and the gyro-bias by using low-cost sensors. International Conference on Intelligent Robots and Systems, p. 2867-2872, 2009.

INOUE, R. S. Controle robusto descentralizado de movimentos coordenados de robôs heterogêneos. [s.I.] Universidade de São Paulo, 2011.

JANG, J. S. J. J. S.; LICCARDO, D. Small UAV Automation Using MEMS. IEEE Aerospace And Electronic Systems Magazine, v. 22, n. 5, p. 30-34, 2007.

KUPIERS, J. B. Quaternions and rotation sequences. In: MLADENOV, I. M.; NABER, G. L. (Eds.). Geometry, Integrability and Quantization. Varna, Bulgaria: Coral Press, 1999. p. pp 127 143.

LEE, S.; KWON, K. A Fuzzy Logic for Autonomous Navigation of Marine Vehicles Satisfying COLREG Guidelines. International Journal of Control, Automation, and Systems, v. 2, n. 2, 2004.

LI, D.; LANDRY, R.; LAVOIE, P. Low-cost MEMS sensor-based attitude determination system by integration of magnetometers and GPS: A real-data test and performance evaluation. Position, Location and Navigation Symposium, p. 1190-1198, 2008.

LINDEN, D.; REDDY, T. Handbook of Batteries. [s.l: s.n.]. p. 1-1088

MADGWICK, S. O. H. An efficient orientation filter for inertial and inertial / magnetic sensor arrays. Report xio and University of Bristol UK, v. 2011, p. 1-32, 2010.

MADGWICK, S. O. H.; HARRISON, A. J. L.; VAIDYANATHAN, A. Estimation of IMU and MARG orientation using a gradient descent algorithm. IEEE International Conference on Rehabilitation Robotics proceedings, v. 2011, p. 5975346, 2011.

MARINA, H. G. DE et al. UAV attitude estimation using Unscented Kalman Filter and TRIAD. IEEE Transactions on Industrial Electronics, v. 59, n. c, p. 1-10, 2011.

MARINA, H. J. G. Sistema de fusión sensorial basado en UKF, para la estimación de actitud en vehículos aéreos no tripulados. [s.I.] Universidad de Alcalá, 2011. v. 1 p. $1-16$

MAYBECK, P. S. Stochastic models, estimation, and control. [s.I.] Academic Press, 1979.

NEBOT, E.; DURRANT-WHYTE, H. Initial calibration and alignment of low-cost inertial navigation units for land vehicle applications. [s.l: s.n.]. v. 16p. 81-92

PENG, Y.; HAN, J. Design and modeling of Unmanned Trimaran Surface Vehicles. 2009 International Conference on Information and Automation, p. 751-756, jun. 2009.

PENG, Y. P. Y.; ZHOU, B. Z. B.; HAN, J. H. J. Hardware design and UKF-based tracking control design of Unmanned Trimaran Surface Vehicle. 2007 IEEE International Conference on Robotics and Biomimetics ROBIO, p. 1618-1623, 2007.

PHUONG, N. et al. A DCM based orientation estimation algorithm with an inertial measurement unit and a magnetic compass. Journal of Universal Computer Science, v. 15, n. 4, p. 859-876, 2009.

RENAUDIN, V.; AFZAL, M. H.; LACHAPELLE, G. Complete Triaxis Magnetometer Calibration in the Magnetic Domain. Journal of Sensors, v. 2010, p. 1-10, 2010. 
RIBEIRO, M. I. Kalman and Extended Kalman Filters : Concept, Derivation and Properties. Institute for Systems and Robotics Lisboa Portugal, n. February, p. 42, 2004.

RUFINO, A. S. F. Modelização, Controlo e Planeamento de Trajectórias para Veículos Aquáticos. [s.I.] Faculdade de Engenharia do Porto, 2009.

SABATINI, A. M. Quaternion-based extended Kalman filter for determining orientation by inertial and magnetic sensing. IEEE Transactions on Biomedical Engineering, v. 53, n. 7, p. 13461356, 2006.

Estimating Three-Dimensional Orientation of Human Body Parts by Inertial/Magnetic Sensing. Sensors (2011), v. 11, n. 2, p. 1489-1525, jan. 2011.

Variable-State-Dimension Kalman-based Filter for orientation determination using inertial and magnetic sensors. Sensors (Basel, Switzerland), v. 12, n. 7, p. 8491-506, jan. 2012.

SU, S. W. et al. the Modelling and Control of an Unmanned Surface Vehicle for Environmental Monitoring. Conference Proceedings of the International Conference of IEEE Engineering in Medicine and Biology Society, v. 1, n. April, p. 4299-302, 2006.

TAN, C.-W.; PARK, S. Design of accelerometer-based inertial navigation systems. IEEE Transactions on Instrumentation and Measurement, v. 54, 2005.

WELCH, G.; BISHOP, G. An Introduction to the Kalman FilterChapel HillUniversity of North Carolina at Chapel Hill, , 2006.

YONGLIANG, W. et al. Attitude estimation for small helicopter using extended kalman filter. 2008 IEEE Conference on Robotics Automation and Mechatronics, p. 577-581, 2008. 



\section{Apêndice A}

\section{Modelagem dinâmica do veículo}

\section{A.1 Dinâmica de corpos rígidos}

A embarcação pode ser modelada como um corpo rígido com seis graus de liberdade, conforme mostrado na Figura 32. Definindo uma base ortogonal de três dimensões a partir de uma origem fixa no espaço, é possível definir a posição e a orientação do veículo, por meio de seis variáveis (Fossen, 1994).

Figura 32 - Sistema de coordenadas e variáveis

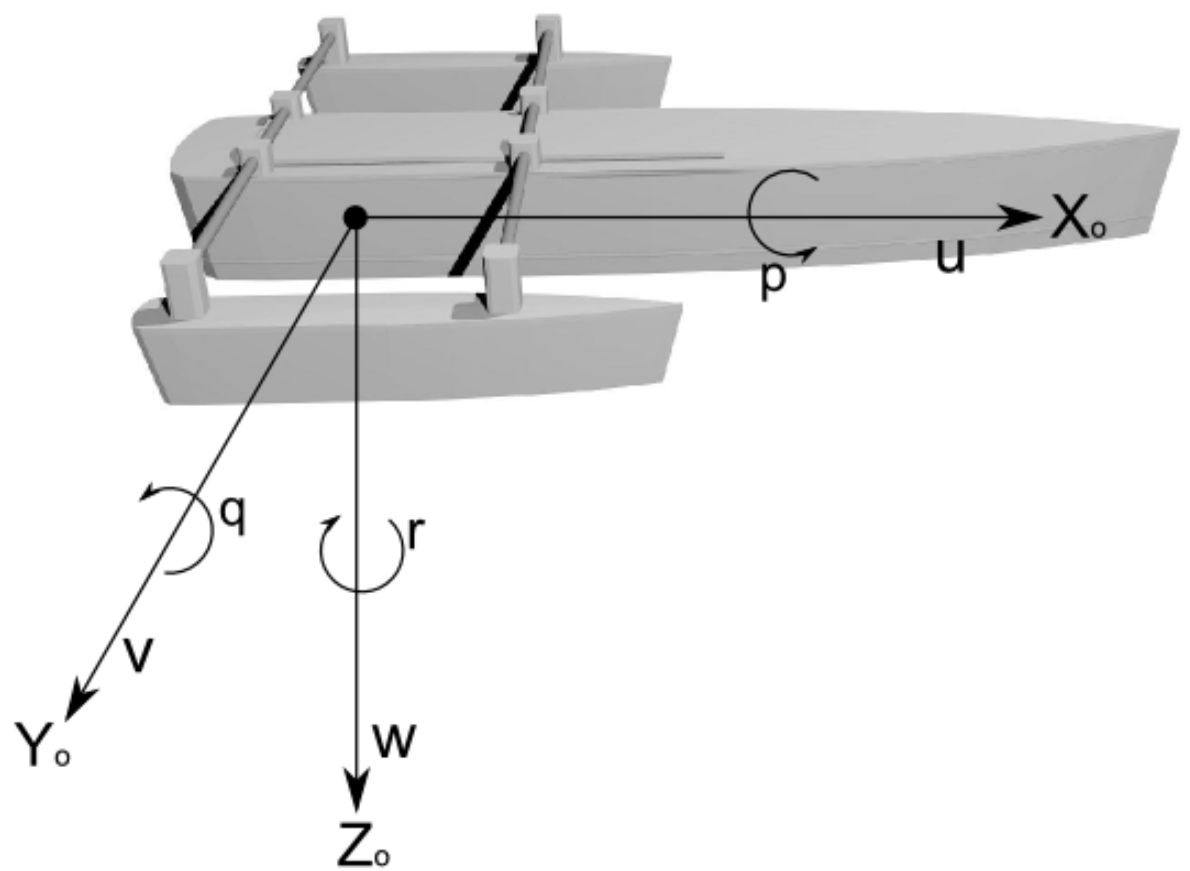


Dados os eixos do sistema de coordenadas como $X_{O}$ apontando para a frente, $Y_{O}$ para a direita e $Z_{O}$ para baixo, sistema também conhecido como NED, do inglês North East Down, são definidas as variáveis $\left(x_{0}, y_{0}, z_{0}\right)$ como variáveis de posição, por meio das quais se pode definir o posicionamento do veículo no espaço, com $(\mathrm{u}, \mathrm{v}, \mathrm{w})=\left(\dot{x}_{0}, \dot{y}_{0}, \dot{z}_{0}\right)$, as taxas de variação temporal do posicionamento, definindo assim as velocidades lineares no sentido de cada eixo.

São definidas, também, as variáveis $(\phi, \theta, \psi)$, como variáveis de orientação, sendo estas a rotação do veículo em relação a cada eixo, também conhecidas como ângulos de Euler. Com ( $p, q, r)$ $=(\dot{\phi}, \dot{\theta}, \dot{\psi})$, as taxas de variação temporal da orientação, definindo assim as velocidades angulares em torno de cada eixo.

Fixando a referência do sistema de coordenadas, acima descrito, ao centro de gravidade do veículo, é definido o sistema de coordenadas local, ou móvel. Considerando, também, um segundo sistema semelhante ao descrito, porém com sua origem fixa à terra, é definido o sistema de coordenadas fixo. Neste segundo sistema os eixos serão definidos como $\left(X_{T}, Y_{T}, Z_{T}\right)$.

Assim, mostra-se conveniente descrever a posição e orientação do veículo no sistema fixo, $\mathrm{X}_{\mathrm{T}} \mathrm{Y}_{\mathrm{T}} \mathrm{Z}_{\mathrm{T}}$, enquanto as velocidades linear e angular no sistema móvel, $\mathrm{X}_{\mathrm{O}} \mathrm{Y}_{\mathrm{O}} \mathrm{Z}_{\mathrm{O}}$.

As variáveis envolvidas são demonstradas na Tabela 2.

Tabela 2 - Variáveis do sistema dinâmico

\begin{tabular}{|c|c|c|c|}
\hline & Posição e Ângulo & Velocidade & Força / Momento \\
\hline Movimento na direção X & $\mathrm{X}$ & $\mathrm{u}$ & $\mathrm{X}$ \\
\hline Movimento na direção $\mathrm{Y}$ & $\mathrm{y}$ & $\mathrm{v}$ & $\mathrm{Y}$ \\
\hline Movimento na direção $\mathrm{Z}$ & $\mathrm{z}$ & $\mathrm{w}$ & $\mathrm{Z}$ \\
\hline Rotação em relação a X & $\phi$ & $\mathrm{p}$ & $\mathrm{K}$ \\
\hline Rotação em relação a Y & $\theta$ & $\mathrm{q}$ & $\mathrm{M}$ \\
\hline Rotação em relação a Z & $\Psi$ & $\mathrm{r}$ & $\mathrm{N}$ \\
\hline
\end{tabular}

Adaptado de (Fossen, 1994)

As equações de dinâmica de corpos rígidos com seis graus de liberdade, considerando que a origem coincide com o centro de gravidade e que os eixos de rotação do veículo coincidem com os eixos do sistema de coordenadas, podem ser expressas como nas equações (40). O Equacionamento completo é mostrado em (Fossen, 1994). 


$$
\begin{gathered}
m\left[\dot{u}-v r+w q-x_{G}\left(q^{2}+r^{2}\right)+y_{G}(p q-\dot{r})+z_{G}(p r+\dot{q})\right]=X \\
m\left[\dot{v}-w p+u r-y_{G}\left(r^{2}+p^{2}\right)+z_{G}(q r-\dot{p})+x_{G}(q p+\dot{r})\right]=Y \\
m\left[\dot{w}-u q+v p-z_{G}\left(p^{2}+q^{2}\right)+x_{G}(r p-\dot{q})+y_{G}(r q+\dot{p})\right]=Z \\
I_{x} \dot{p}+\left(I_{z}-I_{y}\right) q r+m\left[y_{G}(\dot{w}-u q+v p)-z_{G}(\dot{v}-w p+u r)\right]=K \\
I_{y} \dot{q}+\left(I_{x}-I_{z}\right) r p+m\left[z_{G}(\dot{u}-v r+w q)-z_{G}(\dot{v}-u q+v p)\right]=M \\
I_{z} \dot{r}+\left(I_{y}-I_{x}\right) p q+m\left[x_{G}(\dot{v}-w p+u r)-y_{G}(\dot{u}-v r+w q)\right]=N
\end{gathered}
$$

Onde $I_{x}, I_{y}$ e $I_{z}$ são os momentos de inércia em torno aos eixos $X_{O}, Y_{O}$ e $Z_{O}$.

$$
\begin{aligned}
& I_{x}=\int_{V}\left(y^{2}+z^{2}\right) \rho_{A} d V \\
& I_{y}=\int_{V}\left(x^{2}+z^{2}\right) \rho_{A} d V \\
& I_{z}=\int_{V}\left(x^{2}+y^{2}\right) \rho_{A} d V
\end{aligned}
$$

Sendo $\rho_{A}$ a densidade de massa do corpo,

$$
m=\int_{V} \rho_{A} d V
$$

Tratando-se de um veículo aquático, sua movimentação ocorre essencialmente no plano da água, de forma que alguns graus de liberdade podem ser desconsiderados para simplificar as equações de dinâmica do veículo, de forma que $w=p=q=\dot{w}=\dot{p}=\dot{q}=0$.

Além disso, é possível considerar que a distribuição de massa do veiculo é homogênea e simétrica em relação ao plano $x z$, assim o sistema de equações fica reduzido a (44).

$$
\begin{gathered}
m\left(\dot{u}-v r-x_{G} r^{2}\right)=X \\
m\left(\dot{v}+u r+x_{G} \dot{r}\right)=Y \\
I_{z} \dot{r}+m x_{G}(v+u r)=N
\end{gathered}
$$

\section{A.2 Dinâmica do veículo}

Baseado no sistema de equações simplificado (44) foi desenvolvido o conjunto de equações para representar a dinâmica do veículo, considerando o formato de trimarã e o posicionamento dos propulsores fora da linha central. Na Figura 33 está representado um esboço da vista superior do veículo, para facilitar a análise. 
Figura 33 - Visão superior do veículo, com variáveis do equacionamento

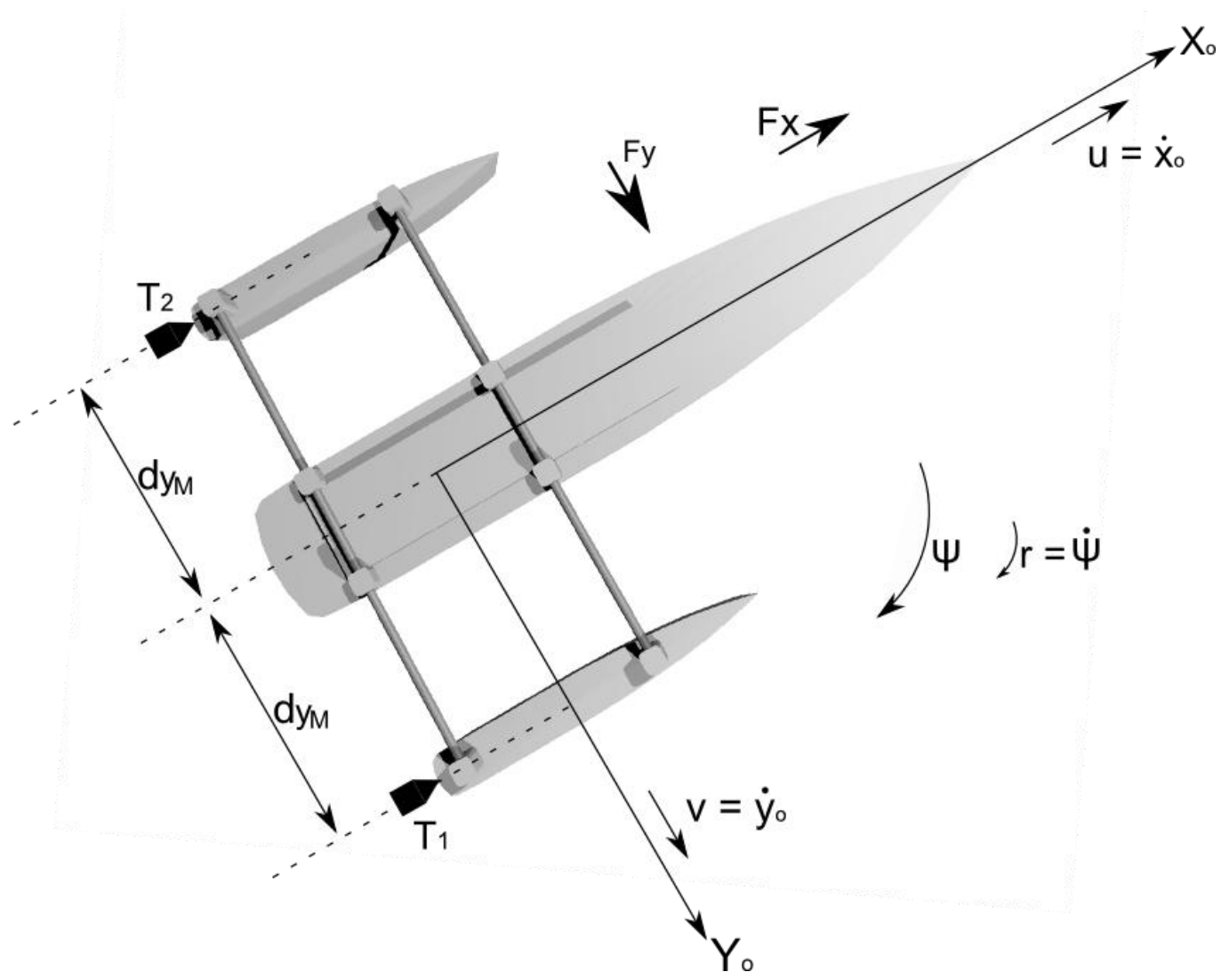

A posição dos motores, $M_{1}$ e $M_{2}$, é simétrica em relação à linha central, assim quando o empuxo gerado pelos dois motores for igual, a força resultante gerará movimento apenas para a frente, caso os empuxos sejam diferentes existirá, um torque, forçando o veículo a girar. A força aplicada por cada motor é representada por $T_{1}$ para $M_{1}$ e $T_{2}$ para $M_{2}$.

Para simplificar a modelagem foi considerado que quaisquer forças externas aplicadas ao veículo, seja pelo vento ou por ação das correntes marinhas, estão embutidas nas variáveis $F_{x}$ e $F_{y}$, sendo estas a decomposição no eixo $X_{0}$ e no eixo $Y_{O}$, respectivamente, das forças aplicadas. As equações desenvolvidas estão mostradas em (45), e os demais símbolos em (46). Por simplicidade foi desconsiderada a rotação que poderia ocorrer devido a $F_{y}$.

Movimento

em X

$m . \dot{u}=T_{1}+T_{2}+F_{x}+m v r-D_{H} u-2 D_{M} u$

Movimento

em $Y$

$$
m \dot{v}=-L_{H T} v-2 L_{A T} v+F_{y}-2 L_{M} v-m u r
$$

Rotação

$$
I_{Z} \dot{r}=-T_{1} d_{Y M}+T_{2} d_{Y M}-B_{r} r-B_{H v} v-B_{A v} v-B_{M} v
$$

$D_{H}$ e $D_{M}$ são os arrastos no sentido do eixo $X_{O}$ devido ao corpo principal do veículo e aos motores, respectivamente, que contribuem negativamente à aceleração. Da mesma forma, $L_{H T}$ é a composição do arrasto no sentido do eixo $Y_{O}$ devido ao corpo principal do veículo, $L_{A T}$ a composição do arrasto no sentido do eixo $Y_{O}$ devido às amas e $L_{M v}$ arrasto no sentido do eixo $Y_{O}$ de cada motor. 
$O$ arrasto no sentido $Y_{O}$ devido ao corpo principal e às amas pode ser dividido nas porções que estão à frente e atrás do centro de massa, assim é possível modelar a rotação do veículo devido à diferença de arrasto quando o veículo é acometido por uma velocidade no sentido $Y_{\mathrm{O}}$. Sendo $\mathrm{L}_{\mathrm{H} 1} \mathrm{e}$ $\mathrm{L}_{\mathrm{H} 2}$ as porções do arrasto do corpo principal à frente e atrás do centro de massa, respectivamente, com $d_{L H 1}$ a distância do centro da porção $L_{H 1}$ ao centro de massa do veículo e $d_{L H 2}$ a distância do centro da porção $L_{H 2}$ ao centro de massa do veículo. Da mesma forma $L_{A 1}$ e $L_{A 2}$ as porções do arrasto das amas, com $d_{L A 1}$ e $d_{L A 2}$.

$$
\begin{gathered}
B_{H v}=L_{H 1} d_{L H 1}-L_{H 2} d_{L H 2} \\
B_{A v}=2\left(L_{A 1} d_{L A 1}-L_{A 2} d_{L A 2}\right) \\
B_{M}=2 L_{M} d_{x M} \\
B_{r}=L_{H 1} d_{L H 1}{ }^{2}+L_{H 2} d_{L H 2}{ }^{2}+2\left(L_{A 1} d_{L A 1}{ }^{2}+L_{A 2} d_{L A 2}{ }^{2}\right) \\
L_{H T}=L_{H 1}+L_{H 2} \\
L_{A T}=L_{A 1}+L_{A 2}
\end{gathered}
$$

Por meio do sistema de equações desenvolvido, é possível representar o movimento do veículo no plano da água, possibilitando o estudo do comportamento do veículo e o desenvolvimento de estratégias de controle. 